\title{
DEVELOPMENT, CHARACTERIZATION AND IN VIVO EVALUATION OF POLYELECTROLYTE COMPLEX MEMBRANE GEL MICROCAPSULES CONTAINING MELATONIN-RESIN COMPLEX FOR ORAL USE
}

Ibrahim El-Gibaly and Mamdouh M. Anwar*

Department of Pharmaceutics, Faculty of Pharmacy, Assiut University, Assiut, Egypt 'Department of Physiology, Faculty of Medicine, Assiut University, Assiut, Egypt

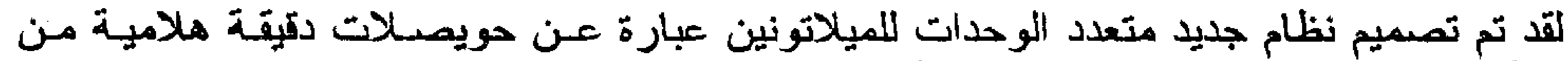

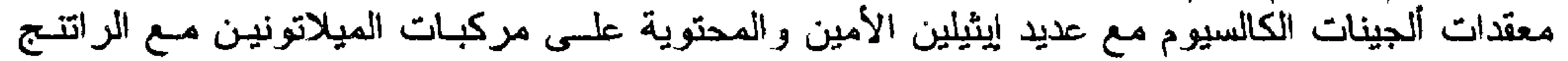

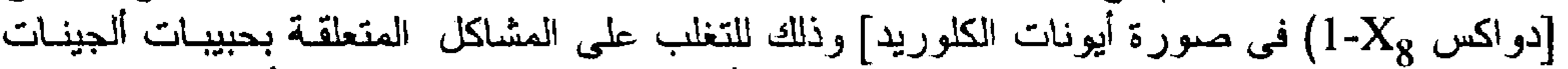

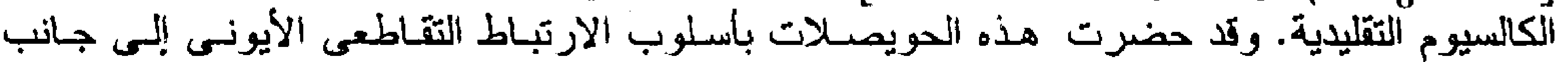

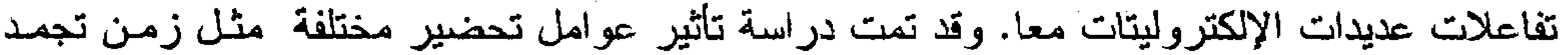

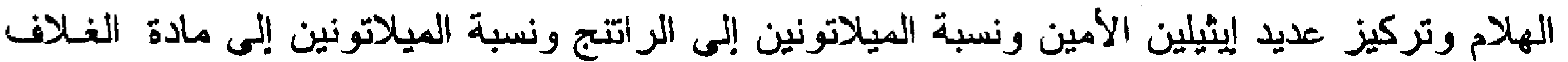

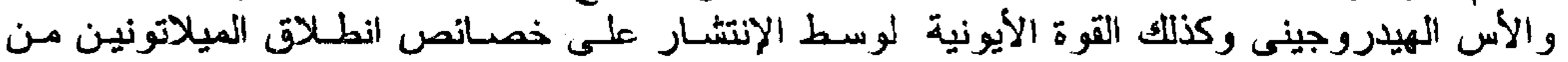

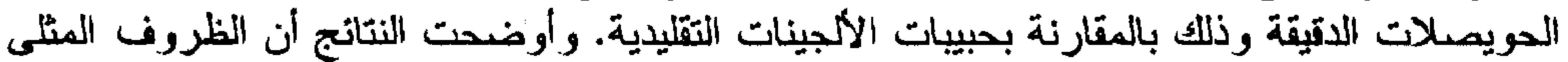

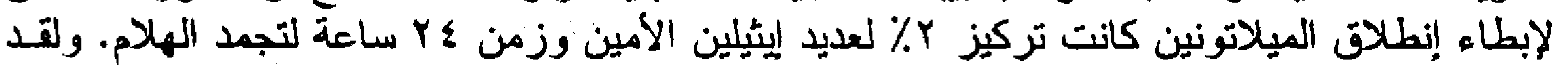

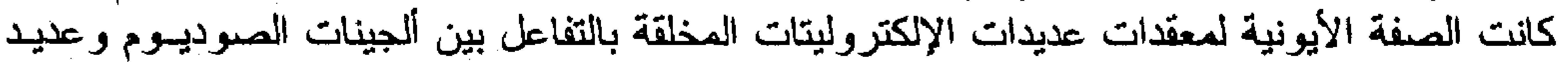

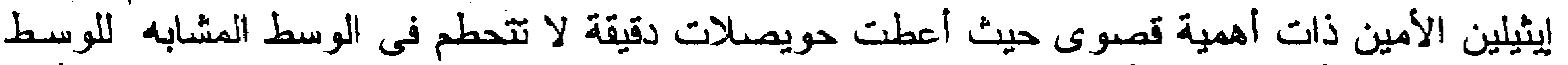

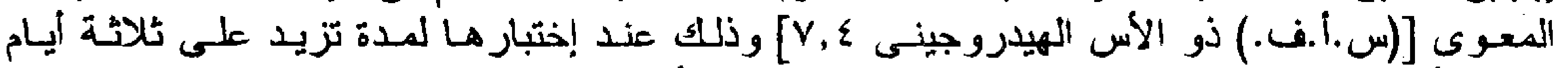

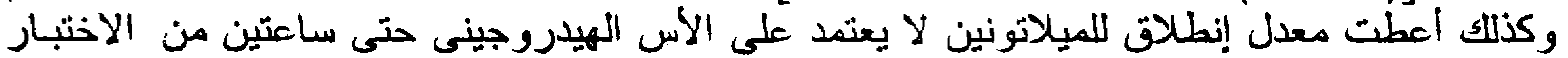

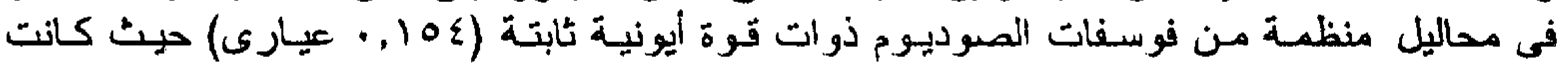

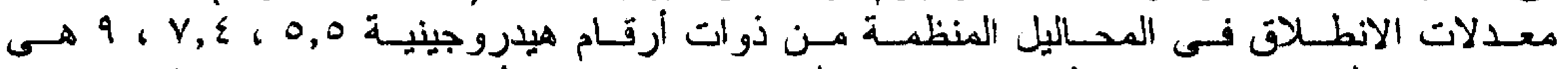

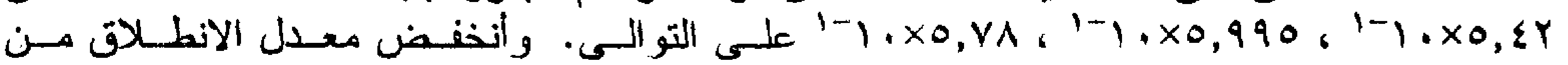

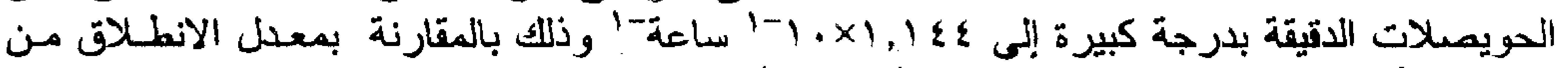

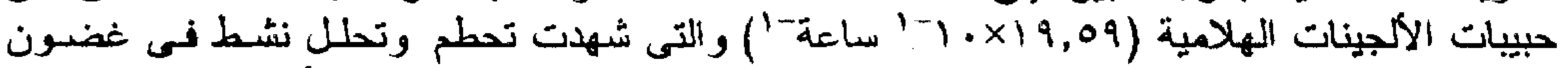

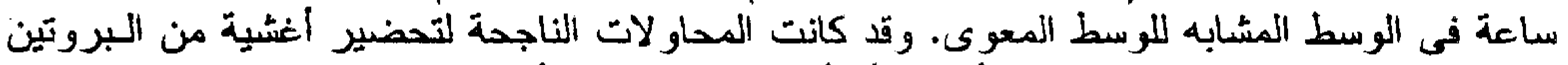

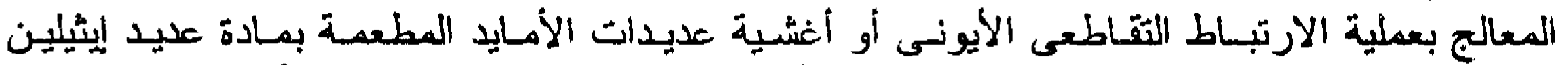

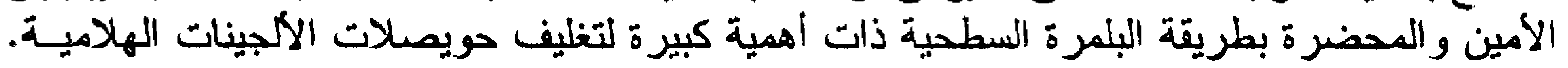

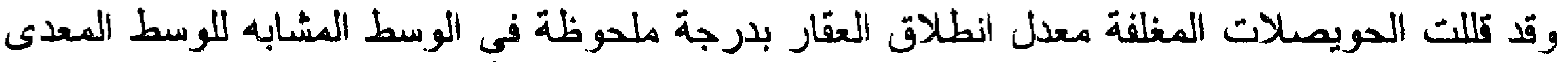

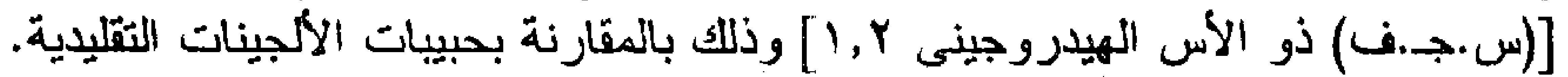

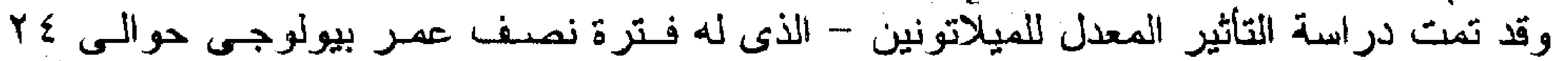

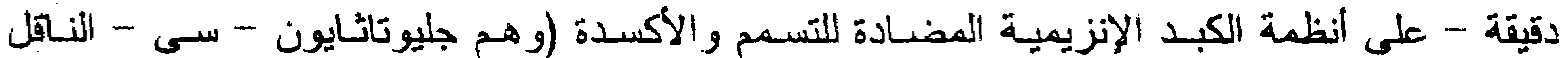

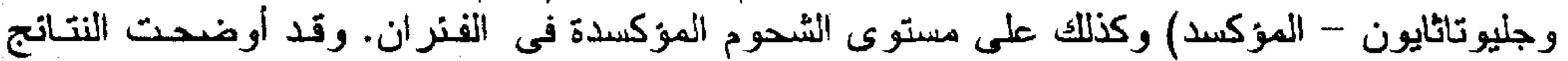

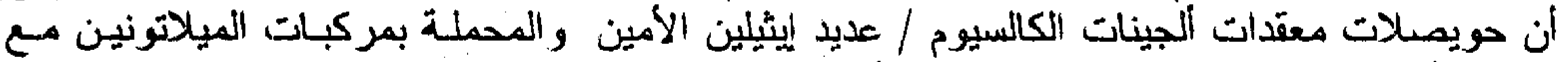

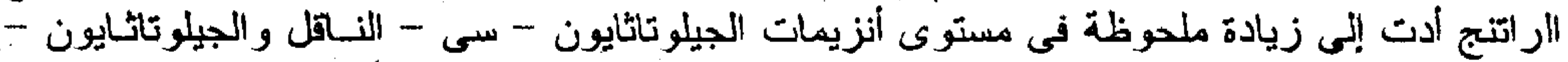

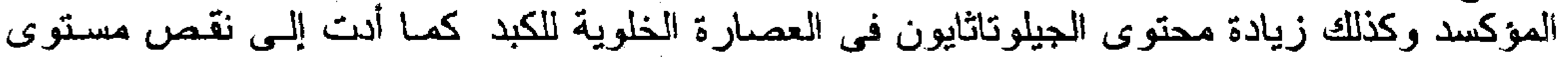

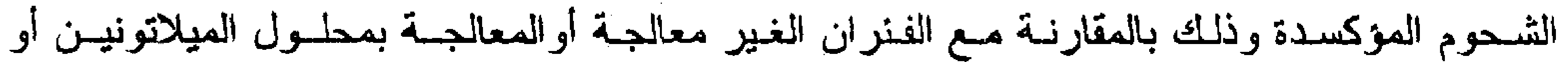

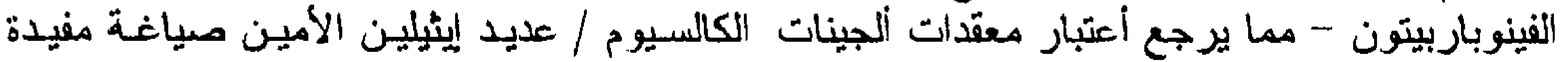
للتحكم في أنطلاق الميلاتونين. 


\begin{abstract}
A novel oral multiple-unit delivery system for melatonin, (Ca) alginate/polyethyleneimine (PEI) gel microcapsules containing melatonin-resin (Dowex $1-X_{8} C l$ ) complex, which overcame many of the problems encountered with the conventional dosage forms, Ca-alginate gel beads was designed through an ionic crosslinking/interpolyelectrolyte complexation technique. The effect of different processing variables viz., gelation time, PEI concentration, melatonin/resin ratio, core/coat ratio and $\mathrm{pH}$ and ionic strength of the dissolution mediurn on the release characteristics of microcapsules in comparison with alginate beads was investigated. The results obtained indicated that a PEI concentration of $2 \%$ and gelation time of $24 . h$. were the optimal conditions for a marked release retardation. Of ultimate importance is the ionic character of the synthetic polyelectrolyte complex (PEC) membrane (alginate/PEI) that produced microcapsules which did not disintegrate in simulated intestinal fluid (S. I.F., pH 7.4) over a period of 3 days of testing and allowed a $p H$-independent release rate of melatonin up to $2 \mathrm{~h}$. in phosphate buffer $\left(0.154 \mathrm{M} \mathrm{Na}^{+}\right.$ions $)\left(K_{1}=5.42 \times 10^{-1}, 5.995 \times 10^{-1}\right.$ and $5.78 \times 10^{-1} \mathrm{hr}^{-1}$ for $p H s$ of 5.5, 7.4 and 9.0, respectively). The melatonin release rate of microcapsules $\left(K_{1}=\right.$ $\left.1.144 \times 10^{-1} h^{-1}\right)$ in S.I.F. (pH 7.4) was significantly reduced when compared to that of the original alginate beads $\left(K_{1}=19.59 \times 10^{-1} \mathrm{hr}^{-1}\right)$ which showed a dramatic disintegration and dissolution in S.I.F. (pH 7.4) within 1 h. Most importantly, successful attempts to prepare crosslinked protein or polyamide/PEI-graft co-polymer membranes-coated alginate microcapsules were achieved by making use of a modified interfacial polymerization process. The coated microcapsules offered a remarkable reduction of the release rate in simulated gastric fluid (S.G.F., pH 1.2) as compared to alginate beads. The modulatory influence of melatonin (biological half-life $=24 \mathrm{~min}$ ) on liver detoxifying and antioxidant enzyme systems (glutathione-S-transferases (GSTs) and glutathione peroxidase (GSH-Px), as well as lipid peroxides (LPER) levels was studied in rats. The obtained results revealed that melatonin resinates-loaded $(\mathrm{Ca})$ alginate/PEI gel microcapsules $\left(T_{50 \%}=6.06 \mathrm{~h}\right)$ produced a significant marked elevation in hepatic cytosolic activities levels of GSTs and GSH-PX as well as glutathione (GSH) content with a reduction in (LPER) levels, when compared with the corresponding controls, suggesting that alginate/PEI gel microcapsules could be a useful reservoir system for controlled-release melatonin delivery.
\end{abstract}

\section{INTRODUCTION}

Melatonin(N-acetyl-5-methoxy-tryptamine) is an indole neurohormone secreted by the pineal gland in a circadian rhythm. ${ }^{1}$ Because endogenous melatonin secretion is generally high during night time in normal subjects, exogenous melatonin administration has been used as a circadian rhythm synchronizer in humans to treat a variety of circadian rhythm disorders including delay of sleep, Jet lag and seasonal depression. ${ }^{1-3}$ Melatonin is a potent antioxidant due to its direct effects as an antioxidant and as scavengers for hydroxyl free radicals. ${ }^{4}$ This results in reduction of lipid peroxides levels, thereby protecting body from the highly damaging free radicals.s Melchiorri et al. ${ }^{6}$ reported that melatonin in conjunction with paraquat overcame the rise in lipid peroxidation products, increased the levels of Glutathione (GSH) and its oxidized form and prevented oxidative damage. Most importantly, the antioxidant effects of melatonin may be through the induction of the most potent antioxidant and detoxifying enzyme systems, glutathione s-transferases (GSTs) and glutathione peroxidase (GSH-Px) and elevation of glutathione (GSH) content in liver cells. ${ }^{7}$ Daniel. ${ }^{8}$ reported that GSTs can inhibit microsomal lipid peroxidation and lower the incidence of experimental cancer in rodents. Moreover, Ketterer. ${ }^{5}$ postulated that GSTs and its dependent GSH-Px were part of a system for the repair of free radical damage to membrane phospholipids and protection against chemical stress and carcinogenesis. Unfortunately, the very short half-life of melatonin (up to 24 minutes) produced rapid elimination of melatonin from the body and build a problem in use of melatonin in a large doses to exert its effects. ${ }^{9}$ Thus, it may be desirable to develop 
controlled-release dosage forms that deliver melatonin over several hours in patients with below normal melatonin blood concentrations. Lee $e t a l .{ }^{3}$ prepared sugar spheres loaded with melatonin and coated with $20 \%$ aquacoat to control the release of melaonin over 8 hours from 8-10 mesh beads.

The use of strong anion and sulfonic acid exchange resins for the development of controlled-release systems has received particular attention with practical systems relying upon the influx of ions into the resin to release the drug together with a coating membrane to provide control of release rate. ${ }^{10-13}$ However, there is no available informations on the application of this technology to the sustained delivery of melatonin.

Sodium alginate (anionic block co-polymer of $\beta$-D-mannuronic and $\alpha$-L-guluronic acid) which forms gels with divalent and multivalent cations is a readily available, non-toxic and biodegradable polysaccharide and also has been found to have a protective effect on the mucous membranes of the upper gastrointestinal tract. ${ }^{14,15}$ Therefore, alginate is used as an immobilization matrix for cells, enzymes, hybrids, artificial organs and oral delivery of transforming growth factor - $\beta_{1}\left(\text { TGF- } \beta_{1}\right)^{16-19}$

Recently, the use of Ca-alginate gel beads as a vehicle for controlled drug delivery has attracted considerable attention because of their property of reswelling which is susceptible to environmental $\mathrm{pH}$, consequently, acid-sensitive drugs incoporated into the beads would be protected from gastric juice. ${ }^{20}$ Alginate gel beads loaded with different drugs such as propranolol, ${ }^{21}$ theophylline, ${ }^{22}$ imipramine, ${ }^{23}$ and nifedipine,$^{24}$ have been prepared and various factors which affect the drug release rate from beads have been intensively investigated. However, major disadvantages of alginate beads are their fast disintegration in simulated intestinal fluid and high porosity which result in rapid drug release and a very low efficiency of drug incorporation. ${ }^{25}$

Interpolyelectrolyte complex membranes (PECM) obtained by mixing aqueous solutions of two oppositely charged polyelectrolytes have received increasing importance because of the diversity of their structures and formation of durable and water-insoluble semipermeable membranes. ${ }^{26-29}$ Thus, the electrostatic interaction of carboxyl groups of alginate with the amine groups of chitosan forms microcapsule membranes for use as a polymeric delayed-release protein delivery system. ${ }^{30}$

Tomida et al.$^{31}$ reported a novel method for the preparation of theophylline-loaded Kcarrageenan/chitosan polyelectrolyte complex membrane capsules whose release rates were independent of $\mathrm{pH}$ of the dissolution medium.

Poly-L-lysine stabilized calcium alginate gel system was used to encapsulate living cells and enzymes..$^{32,33}$ Moreover, Lee et al. ${ }^{34}$ prepared immobilized aminoacylase by entrapment in calcium alginate beads coated with chitosan, polyethyleneimine and polyethyleneimineglutaraldehyde to prevent enzyme leakage from the beads.

Synthetic microcapsule membranes can also be formed by the interfacial polymerization process (which involves the reaction of monomers at the interface of droplets dispersed in an immiscible liquid phase) between protein and/or aqueous monomers dissolved in a buffered aqueous solution at an initial $\mathrm{pH}$ of 9.8 and diacid halide (terephthaloyl chloride) dissolved in the organic solvent (chloroform:cyclohexane, 1:4 v/v)..$^{35,36}$

However, studies on the preparation of alginate gel microcapsuels as a controlled-release system were scarcely performed. Moreover, drug encapsulation in $(\mathrm{Ca})$ alginate/ polyethyleneimine gel microcapsules have hitherto not been reported.

The objective of the present study was primarily to prepare melatonin resinates and then develop a method of microencapsulation for the drug-resin complex. Thus, (Ca) alginate/ polyethyleneimine (polyelectrolyte complex membranes (PECM)) gel microcapsules containing melatonin resinates were prepared through an ionic-crosslinking/interpolyelectrolyte complexation technique and their release characteristics in comparison with the conventional $\mathrm{Ca}$-alginate gel beads were investigated. The effect of several preparative variables viz., gelation time, polyethyleneimine concentration, melatonin/resin ratio and core/coat ratio as well as the $\mathrm{pH}$ and ionic 
strength of the release medium on melatonin release rate was studied. For further modification of the release rate, crosslinked protein membranes or polyamide/polyethyleneimine-graft co-polymer membranes-coated (Ca) alginate/ polyethyleneimine gel microcapsules were obtained by a modified interfacial polymerization process. In vivo tests were also performed in order to evaluate the effect of microencapsulated melatonin resinates on induction of one of the most important detoxifying enzyme systems in liver, glutathione s-transferases (GSTs) and glutathione peroxidase (GSH-Px) enzymes as well as, on elevation of glutathione (GSH) content. Lipid peroxides (LPER) levels of animals serum were also estimated.

\section{MATERIAL AND METHODS}

The following chemicals were obtained from commercial suppliers and used without further purification: melatonin, sodium alginate, bovine serum albumin (Sigma Chemical Co., St. Louis, Mo.), Chitosan (Proton Laboratories, Redmond, Wash), polyethyleneimine (molecular weight, 40,000-50,000), tetraethylenepentamine (Tokyo Kasei Kogyo, Co.), Terephthaloyl chloride (Aldrich Chemical Co.), Amberlite IRP-69, Amberlite CG-120, Amberlite IRC-50 (Rohm \& Haas Co., Philadelphia, PA 19105), Dowex-50 $\mathrm{W} \mathrm{H}^{+}$and Dowex $1-\mathrm{X}_{8}\left(\mathrm{Cl}^{-}\right)$(The Dow Cheimcal Co. Midland, MI, U.S.A.), Span 85 (Nihon Surfactant, Ind. Inc. Tokyo). All other chemicals were of reagent grade and were used as received.

\section{Preparation of resins}

The resins $(5 \mathrm{gm})$ were purified by washing consecutively with deionized distilled water ( 150 $\mathrm{ml})$ and methanol $(150 \mathrm{ml})$ to remove organic and coloured impurities. The resins were then activated by three treatments (each treatment takes $24 \mathrm{~h}$ by a batch process) with alternate aliquots of $1 \mathrm{M} \mathrm{NaOH}$ and $1 \mathrm{M} \mathrm{HCl}$ and tinally the resin in the acid form (cationic exchange resins) or in the chloride form (anionic exchange resins) was washed with deionized distilled water until the eluate was neutral. Resins were then dried at $50^{\circ} \mathrm{C}$ to a constant weight prior to use.

\section{Equilibrium studies}

A series of solutions were prepared to contain $15 \mathrm{mg}$ of melatonin dissolved in $1 \mathrm{ml}$ methanol and then completed to $10 \mathrm{ml}$ with deionized water and were put into a $15 \mathrm{ml}$ plastic tubes together with $90 \mathrm{mg}$ resin and mixed using a rotator at 50 r.p.m. At specified time intervals, the contents of each tube were filtered, diluted and the melatonin concentration in the filtrate was determined spectrophotometrically (Shimadzu, Double-Beam Spectrophotometer 150-02, Japan) at $278 \mathrm{~nm}^{3}$ The time required for a constant amount of melatonin to react with the resin was taken as the equilibrium time.

\section{Preparation of melatonin-resin complex}

Different melatonin/resin ratios, for example 1:6, 1:3, 1:2, 1:1 and $2: 1$ were prepared by a batch process as follows: an accurately weighed amount of the resin $(90 \mathrm{mg})$ was added into solution $(10 \mathrm{ml})$ of melatonin in methanol/deionized water. After stirring for 24 $\mathrm{h}$, the dispersion was filtered and washed with deionized water to remove any unreacted melatonin and other ions. The amount of free melatonin in the filtrate as well as the washing water was determined spectrophotometrically at $278 \mathrm{~nm}$.

The amount of melatonin loaded in the complex (M-R) was calculated as: $\mathbf{M}-\mathbf{R}=\mathbf{M}_{\mathbf{i}}-$ $M_{f}$, where $M_{i}$ is the initial amount of melatonin added and $M_{r}$, the amount of free melatonin.

\section{Microencapsulation of melatonin-resin complex}

Preparation of (Ca) alginate/polyethyleneimine gel microcapsules

A variation of the technique used by Polk et al. ${ }^{\text {30 }}$ for chitosan-alginate microcapsules was einployed to form alginate/polyethyleneimine gel microcapsules through an ionic crosslinking/ interpolyelectrolyte complexation process as follows: The resinate microparticles were dispersed into aqueous solution of sodium 
alginate $(1.7 \% \mathrm{w} / \mathrm{v}$ in deionized water). Three milliliters of the dispersion was loaded into a 5cc disposable syringe, to which a micropippette tip (1-cc) was then attached to the syringe opening. The gel microcapsules were formed by dropping the bubble free dispersions at an average rate of $1 \mathrm{ml} / \mathrm{min}$ onto gently agitated crosslinking solution of the counter ion $(5 \mathrm{ml}$ of $2 \%$ calcium chloride solution containing polyethyleneimine at $2 \% \mathrm{w} / \mathrm{v}$ concentration). The gelation solution also contained a concentration of melatonin equivalent to that of the resinates, thereby eliminating leaching effects during longer gelation times. The agglomeration occurred instantaneously and every drop turned into a gel sphere. The gelled microcapsules were separated, unless otherwise noted, after a reaction time of $30 \mathrm{~min}$., rinsed with deionized water and air-dried for $24 \mathrm{~h}$. In this manner, 900-1000 $\mu \mathrm{m}$ diameter microcapsules (measured by using calibrimeter) were formed. Melatonin resinates-loaded calcium alginate gel beads (no polyethyleneimine membrane) were used as a control; these were also made at alginate concentration of $1.7 \%$ and $2 \%$ calcium chloride solution.

The following preparative variables were investigated in this study: gelation time $(0.5,24$, 48, 72 and $96 \mathrm{~h}$ ), polyethyleneimine concentration $(0.5,1$ and $2 \% \quad w / v)$, melatonin/resin ratio $(1: 6,1: 2$ and $1: 1)$ and core/coat ratio $(1: 2,1: 1$ and $2: 1)$.

In another set of experiments, performed calcium alginate gel beads (prepared as described above) were treated by using each of the following treatment agents separately: (1) polyethyleneimine $(0.5,2$ and $4 \% \mathrm{w} / \mathrm{v}),(2)$ chitosan $(0.05,0.1$ and $0.15 \% \mathrm{w} / \mathrm{v})$ in $1 \%$ acetic acid solution, (3) chitosan:polyethyleneimine at varying ratios $(0.05: 1,0.075: 1,0.1: 1,0.125: 1$ and 0.2:1), (4) acetic acid (1.96, 4.76 and $9.0 \%$ $\mathrm{v} / \mathrm{v})$ or (5) acetic acid:polyethyleneimine at ratios of $1.96: 2$ and $4.76: 2$. The beads were suspended in $5 \mathrm{ml}$ of the treatment agents or their combinations containing $2 \%$ calcium chloride for $72 \mathrm{~h}$ with gentle stirring at room temperature. The beads were then filtered, washed with distilled water and air-dried for $24 \mathrm{~h}$.
Preparation of crosslinked protein membrane-coated (Ca) alginate/polyethyleneimine gel microcapsules

The cured microcapsules were washed several times on sieve by $10 \mathrm{ml}$ of the aqueous phase (1\% bovine serum albumin solution adjusted to pH 9.0 with $0.45 \mathrm{M} \mathrm{Na}_{2} \mathrm{CO}_{3}$ and containing melatonin concentration equivalent to that of microcapsules). The microcapsules were then magnetically stirred for $3 \mathrm{~min}$ in an organic phase of cyclohexane containing $0.5 \mathrm{M}$ terephthaloyl chloride as the organic monomer and span $85(5 \% \mathrm{v} / \mathrm{v})$ as an emulsifier. The filtered microcapsules were washed with cyclohexane and air-dried for $24 \mathrm{~h}$.

Preparation of polyamide/polyethyleneimine (PEI)-graft co-polymer membrane-coated (Ca) alginate/polyethyleneimine gel microcapsules

Coating the microcapsules with graft copolymer membranes of polyamide/PEI via interfacial polymerization process could be summarized as follows: the aqueous phase $(\mathrm{pH}$ 10.5) contained $0.1 \mathrm{M}$ tetraethylenepentamine (aqueous monomer), 4\% PEI (aqueous polymer), bovine serum albumin $(0.5 \% \mathrm{w} / \mathrm{v})$, and melatonin concentration equivalent to that of microcapsules. The cured microcapsules were dipped for $3 \mathrm{~min}$ in the aqueous phase then filtered off. The synthetic membrane on the microcapsule surface was instantaneously formed by adding the obtained microcapsules coated with the aqueous phase in the organic phase $(0.5$ $M$ terephthaloyl chloride in cyclohexane containing span $85(5 \% \mathrm{v} / \mathrm{v}))$, then stirring magnetically for 3-5 min. The microcapsules were then filtered, washed with cyclohexane and air-dried for $24 \mathrm{~h}$.

\section{Disintegration studies}

Disintegration tests were performed in simulated intestinal fluid $(\mathrm{pH} 7.4)$ using the rotating paddle apparatus (USP XXII) $(250 \mathrm{ml}$, $\left.37^{\circ} \mathrm{C}, 50 \mathrm{rpm}\right)$. The measured disintegration time was the time necessary for the microcapsules, beads and treated beads to disintegrate completely into fragments and release resinate microparticles (Table 4). 


\section{Gelling rate determination}

The gelling rate of alginate gel microcapsules, alginate beads or treated beads was determined from the weight changes as described by Yotsuyanagi et al. ${ }^{37}$ as follows: Ten curing microcapsules or beads were taken out from the crosslinking solution at appropriate time intervals and weighed immediately after the removal of surface moisture on a filter paper. The weight fraction of curing microcapsules or beads was expressed as the ratio between the weight (Wt) after the curing period and the weight of 10 original droplets of alginate solution (Wo) assumed at $\mathrm{t}=0$.

\section{Melatonin content determination}

An accurately weighed amount of resinates $(30 \mathrm{mg}$ ) or the coated resinate particles $(75 \mathrm{mg}$ ) were powdered in mortar using a pestle. Melatonin was extracted with $100 \mathrm{ml}$ of simulated intestinal tluid ( $\mathrm{pH} \mathrm{7.4).} \mathrm{The} \mathrm{solution}$ was filtered and melatonin was assayed spectrophotometrically at $278 \mathrm{~nm}$.

\section{In-vitro release studies}

The release experiments were performed using the USP XXII rotating paddle dissolution apparatus at $50 \mathrm{rpm}$. The release media included simulated gastric fluid $(\mathrm{HCl} / \mathrm{NaCl}$ solution, $\mathrm{pH}$ 1.2), simulated intestinal fluid $\left(\mathrm{KH}_{2} \mathrm{PO}_{4} / \mathrm{NaOH}\right.$ buffer, $\mathrm{pH}$ 7.4), and phosphate buffer solution $\left(\mathrm{Na}_{2} \mathrm{HPO}_{4} / \mathrm{NaH}_{2} \mathrm{PO}_{4}\right)$ with various $\mathrm{pH}$ values $(5$, 7.4 and 9$)$ and ionic strengths $(0.05,0.1$ and $0.154)$. An amount of resinate particles $(30 \mathrm{mg}$ ) or microencapsulated resinate particles $(75 \mathrm{mg}$ ) was added to $250 \mathrm{ml}$ of the release medium at $37^{\circ} \mathrm{C}$. At appropriate intervals, $5 \mathrm{ml}$ samples were withdrawn and replaced by an equivalent volume of fresh medium. The concentration of melatonin was determined spectrophotometrically at $278 \mathrm{~nm}$.

\section{In-vivo studies}

Sixty adult male albino rats, spragueDawley strain (150-200 g) were fed a normal diet. The animals were divided into four groups, 15 rats each. The first group (control) treated with saline $(1 \mathrm{ml})$, orally for 15 days. The second group treated orally with melatonin solution (200 $\mu \mathrm{g} / \mathrm{ml}$ saline) for 15 days. The third group injected with $75 \mathrm{mg} / \mathrm{kg}$ phenobarbitone $(\mathrm{pB})$ intraperitoneally for 15 days. The fourth group were given melatonin resinates-loaded $(\mathrm{Ca})$ alginate/polyethyleneimine gel microcapsules (equivalent to $200 \mu \mathrm{g}$ of melatonin) orally together with saline $(1 \mathrm{ml})$ for 15 days. All treatments were administered into rats before sunset by two hours, where the melatonin receptors were active.

After the treatment period, blood samples were collected from each rat (by puncture of the retro-orbital sinus) in sterile centrifuge tube without anticoagulant for obtaining sera, which were stored at $-20^{\circ} \mathrm{C}$ until lipid peroxides assay.

\section{Tissue preparation}

Liver was perfused with saline and excised immediately in each rat. The livers were homogenized individually in cold $0.1 \mathrm{M}$ potassium phosphate buffer $(\mathrm{pH}$ 7.4). Homogenates were centrifuged at $11.000 \times$ xg for 20 minutes and the resulting supernatant was further centrifuged at $105.000 \times g$ for $1 \mathrm{~h}$. to obtain cytosolic fraction. The centrifugations were carried out at $4^{\circ} \mathrm{C}$. The total protein in liver homogenates was determined by using commercial protein kit, based on biuret-tartarate chemical method (Sclavo diagnostics, Italy).

\section{Enzymes activity determination}

Glutathione-S-transferases (GST) activity was measured in the cytosolic fractions by the method of Habig et al.$^{38}$ with glutathione (GSH) and the substrate 1-chloro-2,4-dinitrobenzene. Glutathione peroxidase (GSH-Px) enzyme activity was determined according to Goodwin $e t$ al. ${ }^{39}$ Glutathione (GSH) content was determined in homogenates according to the method of Ellman. ${ }^{40}$

Lipid peroxides (LPER) were determined in sera of animals in all groups by the method of Beuge and Aust. ${ }^{41}$

\section{Statistical analysis}

Data were expressed as the mean \pm S.E. for all groups then analyzed according to students ' $t$ - 
test. Multiple correlation analysis was tested between parameters.

All tests were done by using PC-stat computer programme. Results were considered significant at $p<0.05$ or less.

\section{RESULTS AND DISCUSSION}

\section{In-vitro characterization of beads and microcapsules}

In an attempt to prepare controlled-release system for melatonin, five ion exchange resins were used to prepare melatonin-resin complexes (Table 1). The maximum melatonin loading of the resins was in the following order: Dowex 50-w $\left(\mathrm{H}^{+}\right), 79.8 \%>$ Amberlite IRP-69 $\left(\mathrm{H}^{+}\right)$, 78.62\% > Dowex 1- $\mathrm{X}_{8} \mathrm{Cl}^{-}, 40 \%>$ Amberlite IRC-50 $\left(\mathrm{H}^{+}\right), 19.13 \%$. It was also found that strong cation exchange resins in the $\mathrm{H}^{+}$form $(\mathrm{pH}<2)$ showed a greater loading capacity than the resins in the $\mathrm{Na}^{+}$form (neutral $\mathrm{pH}$ ) (Tables 1 and 2). This is mainly due to the effect of resin $\mathrm{pH}$ on the ionization of the drug. ${ }^{13}$ Melatonin, pKa $\left(\mathrm{NH}_{2}\right)$ of 8.2 is expected to be highly ionized at a low $\mathrm{pH}$. Therefore, resin in the $\mathrm{H}^{+}$form allows a high degree of ion exchange, resulting in high melatonin loading. Unfortunately, resins in the $\mathrm{H}^{+}$form caused melatonin degradation as indicated by UV absorption of the release eluant at higher wavelength $(292 \mathrm{~nm})$, darkening of the dried resinates and disappearance of the characteristic IR peaks of melatonin (carbonyl peak around $1620 \mathrm{~cm}^{-1}$ ) and appearance of a broad amine peak at $3475 \mathrm{~cm}^{-1}$ as a result of acetamide hydrolysis (Fig. 1). These findings may be related to acid hydrolysis of melatonin due to the strong acidic nature of the resin in the $\mathrm{H}^{+}$form. A similar finding has been previously reported on doxorubicin loading onto cation exchange resins. ${ }^{13}$

Table 3 reveals that the amount loaded of melatonin was increased by increasing the initial melatonin concentration (melatonin/resin ratio).

Figure 2 shows the influence of melatonin/resin (Dowex 1- $\mathrm{X}_{8} \mathrm{Cl}^{-}$) ratio on melatonin release in simulated gastric fluid (S.G.F., pH 1.2) and simulated intestinal fluid (S.I.F., pH 7.4). The melatonin/resin ratio of 1:6 and 1:1 exhibited the slowest release profiles during the first hour of testing. The release of melatonin was found to be generally higher in S.G.F. than in S.I.F.

As shown in Fig. 3, increasing ionic strengths of the phosphate buffer ( $\mathrm{pH}$ 7.4) from 0.05 to 0.154 enhanced the liberation of melatonin from resinates prepared using Dowex $1-\mathrm{X}_{8} \mathrm{Cl}^{-}$.

Thus, Dowex 1- $\mathrm{X}_{8}\left(\mathrm{Cl}^{-}\right)$, although having lower melatonin loadings and displayed lower sustained-release profiles, but still maintains all melatonin properties. Meanwhile, the inadequate sustained action properties of resins necessitates an additional diffusion barrier to modify the release profiles.

In the present study, a novel oral multipleunit delivery system, melatonin resinates-loaded (Ca) alginate/polyethyleneimine (PEI) gel microcapsules, is described and their characteristics as compared with the traditional calcium alginate beads were investigated.

Microcapsules were prepared through ionic crosslinking/ interpolyelectrolyte complexation technique. A single-step process under very mild conditions was adopted by dropping dispersions of resinate microparticles in sodium alginate solutions onto the gelation medium (calcium chloride/polyethyleneimine solution). In fact, the formed microcapsules probably resulted from ionic interactions between negatively charged polyelectrolytes (alginate) and the counter ions $\left(\mathrm{Ca}^{2+}\right)$ and at the same time, between positively and negatively charged polyelectrolytes (polyethyleneimine and alginate, respectively), thus yielding a semipermeable synthetic polyelectrolyte complex (PEC) membranes around the alginate gel solution. In addition, calcium ions may diffuse through the formed membranes for completion of alginate gelification by ionotropic gelation, thus, microcapsule membrane formation can be obtained according to the following scheme:

$$
\begin{aligned}
& \mathrm{Na} \text { alginate } \\
& \text { Ca-alginate-Polyethyleneimine }(\mathrm{PEC})+\mathrm{Ca}^{2+}+\mathrm{Na}^{+}
\end{aligned}
$$

To develop a melatonin delivery system with controlled-release properties, the disintegration time of the microcapsules, beads or treated beads in simulated gastric fluid (S.G.F., pH 1.2) and simulated intestial fluid 
Table 1: Characteristics of the tested synthetic ion-exchangc resins.

\begin{tabular}{|l|c|c|c|c|c|}
\hline Resin type & Character & Form & $\begin{array}{c}\text { Active } \\
\text { group }\end{array}$ & $\begin{array}{c}\text { Mean size } \\
(\mu \mathrm{m})\end{array}$ & $\begin{array}{c}\text { Melatonin } \\
\text { loading (\%) }\end{array}$ \\
\hline Dowex - 50W $\left(\mathrm{X}_{8}\right)$ & Strong acid & Sodium & $-\mathrm{SO}_{3}^{-}$ & 13.68 & 14.81 \\
Dowex - 50W $\left(\mathrm{X}_{8}\right)$ & Strong acid & Hydrogen & $-\mathrm{SO}_{3}^{-}$ & 20.37 & 70.10 \\
Dowex 1-X & Strong base & Chloride & $\left.-\mathrm{N}_{8}-\mathrm{CH}_{3}\right)_{3}$ & 11.11 & 33.40 \\
Amberlite IRP-69 & Strong acid & Sodium & $-\mathrm{SO}_{3}^{-}$ & 19.70 & 10.31 \\
Amberlite IRP-69 & Strong acid & Hydrogen & $-\mathrm{SO}_{3}^{-}$ & - & 67.40 \\
Amberlite CG-120 & Strong acid & Sodium & $-\mathrm{SO}_{3}^{-}$ & - & 13.03 \\
Amberlite IRC-50 & Weak acid & Hydrogen & $-\mathrm{COO}^{-}$ & - & 19.13 \\
\hline
\end{tabular}

- Equilibrium time : 2 hours ;-Melatonin/Resin ratio : 1:6

Table 2: Effect of equilibrium time on the loading of mclatonin on ion-exchange resins.

\begin{tabular}{|c|c|c|c|c|c|}
\hline Resin type & $\begin{array}{c}\text { Equili- } \\
\text { brium } \\
\text { time (h.) }\end{array}$ & $\begin{array}{c}\text { Amount } \\
\text { loaded } \\
(\mathrm{mg} / 0.09 \mathrm{gm})\end{array}$ & $\begin{array}{c}\text { Loading } \\
\text { capacity } \\
(\mathrm{mg} / \mathrm{gm})\end{array}$ & $\begin{array}{c}\text { Loading } \\
\vdots \\
(\%)\end{array}$ & $\begin{array}{c}\text { Theoretical } \\
\text { melatonin content } \\
(\%)\end{array}$ \\
\hline & 1 & 9.54 & 106.00 & 63.35 & 9.58 \\
Dowex-50 W (H') & 2 & 10.43 & 115.90 & 69.25 & 10.38 \\
& 8 & 10.60 & 117.73 & 64.55 & 10.53 \\
& 12 & 12.58 & 139.73 & 76.61 & 12.26 \\
& 24 & 13.10 & 145.55 & 79.80 & 12.71 \\
& 48 & 10.70 & 119.00 & 65.24 & 10.63 \\
\hline & 1 & 5.09 & 56.53 & 33.70 & 5.35 \\
& 2 & 5.05 & 56.10 & 33.40 & 5.30 \\
& 4 & 4.47 & 49.60 & 27.19 & 4.73 \\
& 8 & 5.50 & 61.11 & 33.50 & 5.76 \\
& 24 & 6.50 & 72.13 & 39.60 & 6.74 \\
& 48 & 6.40 & 71.11 & 38.98 & 6.64 \\
\hline
\end{tabular}

Melatonin $/$ Resin ratio $=1: 6$ 


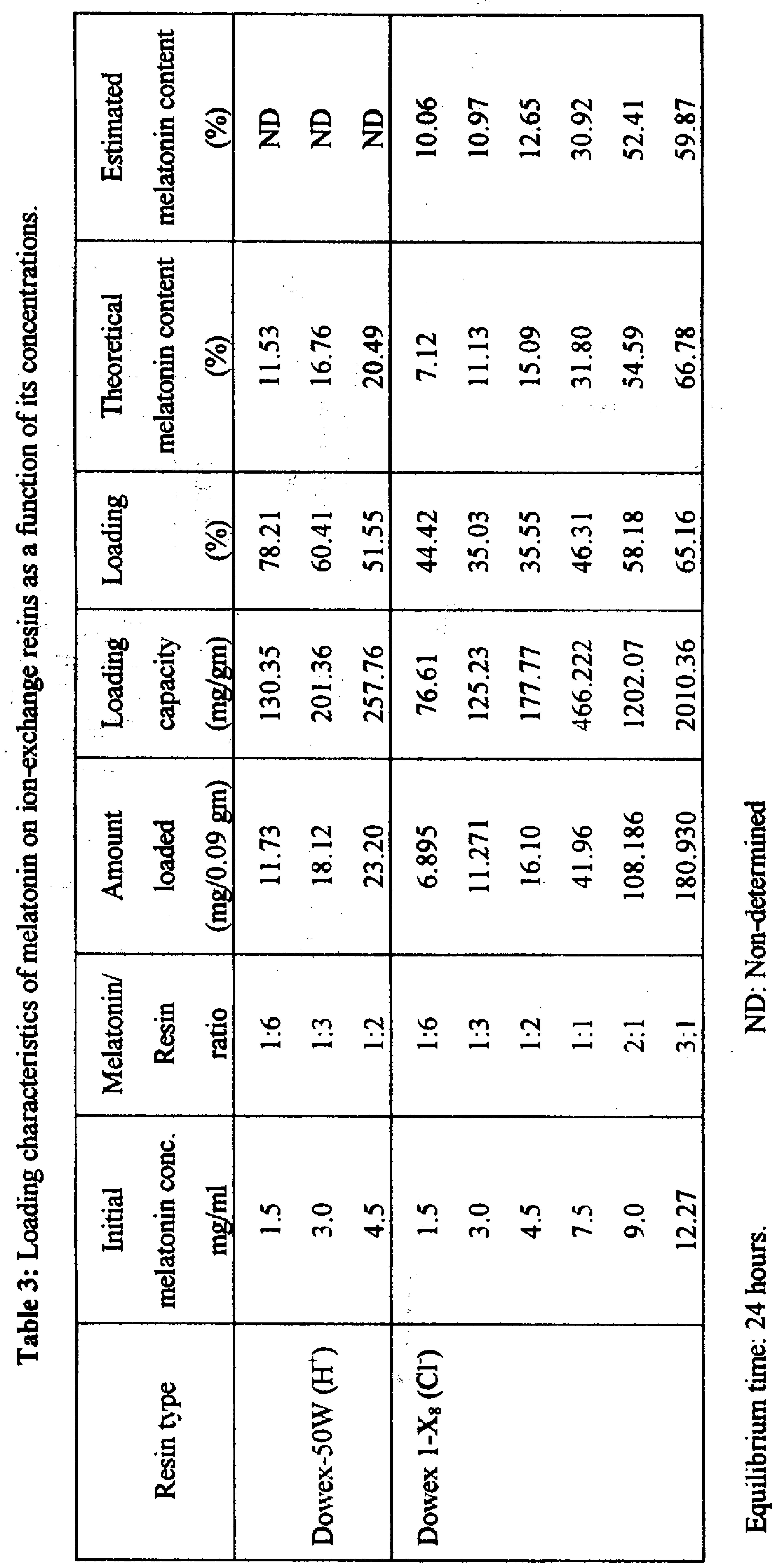


Amount releosed, \%
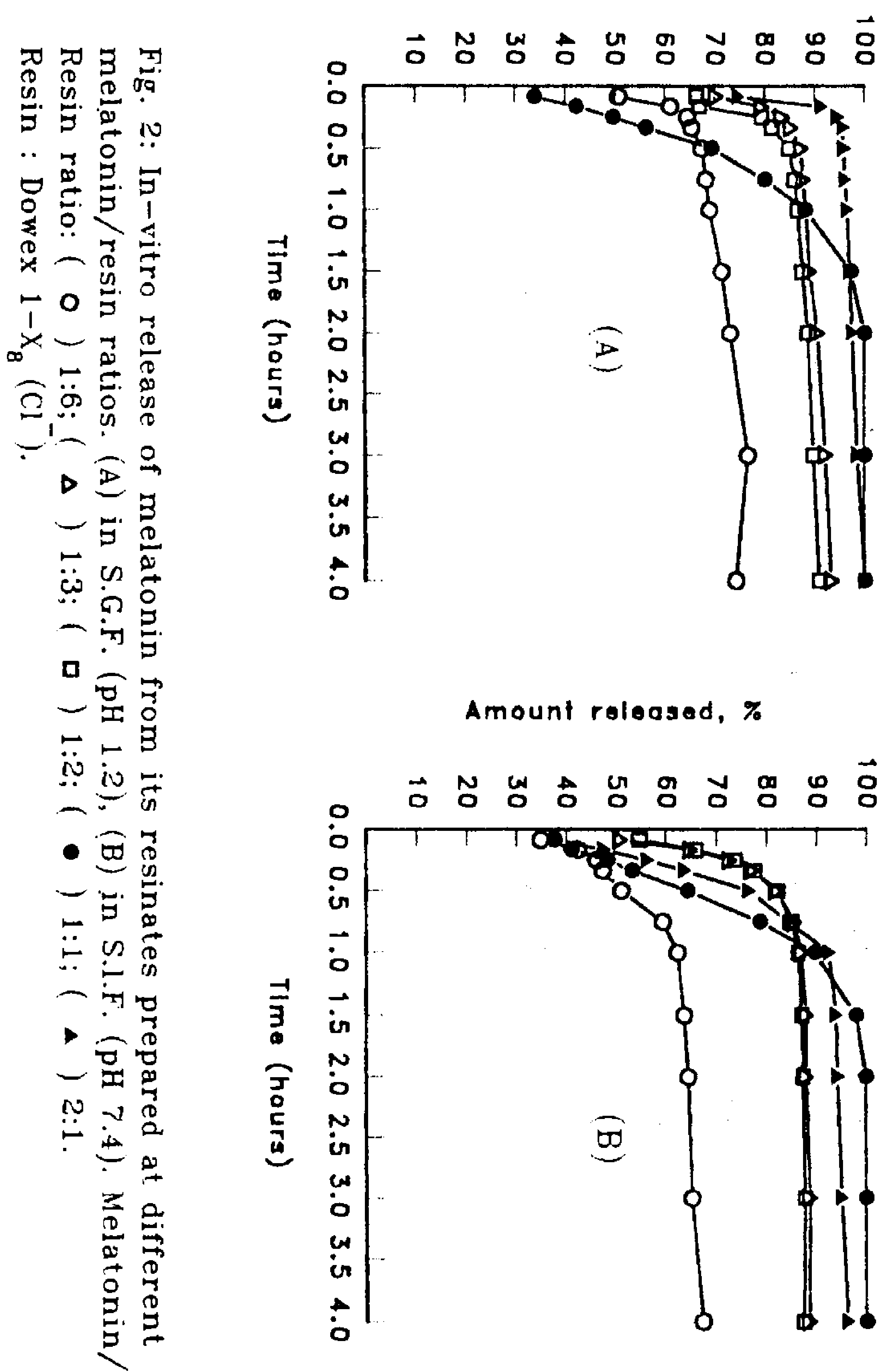

Ibrahim El-Gibaly, et 으.

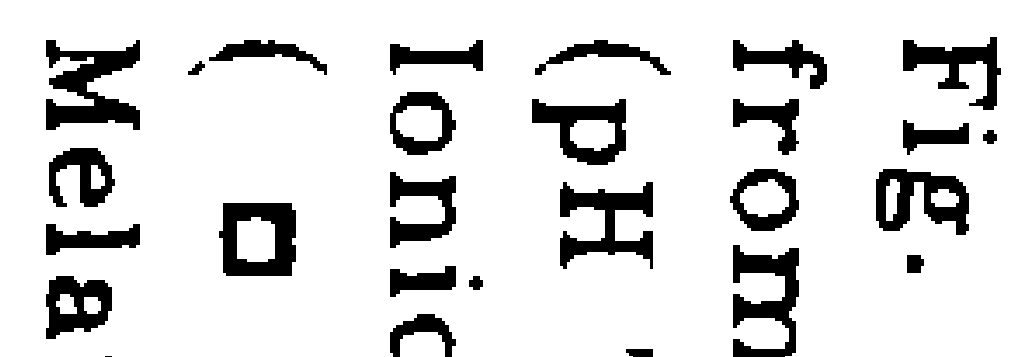

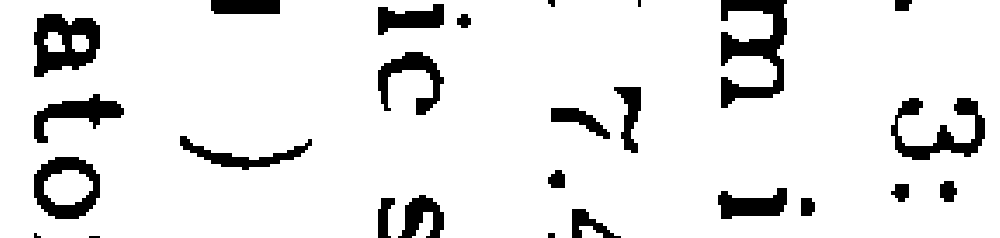

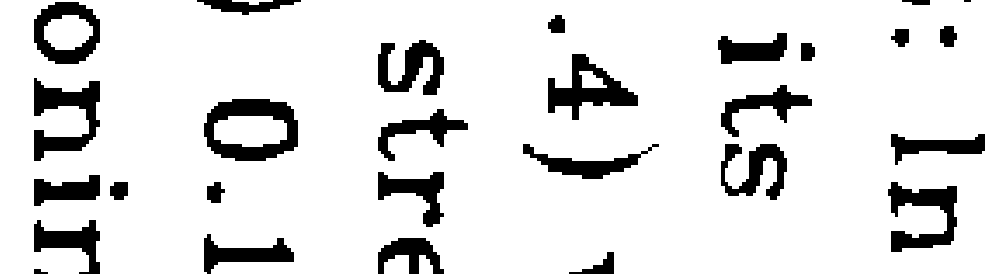

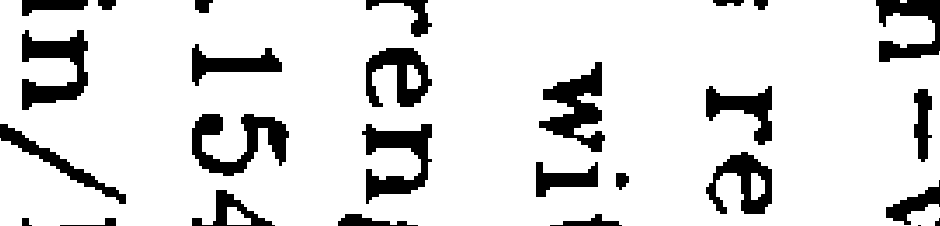

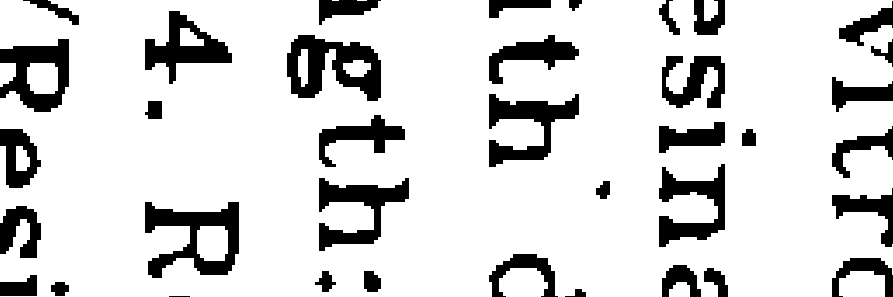

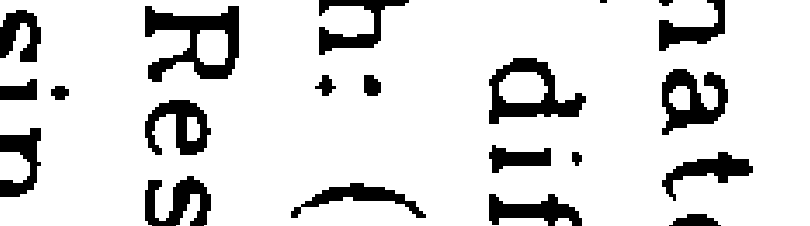

450 怘

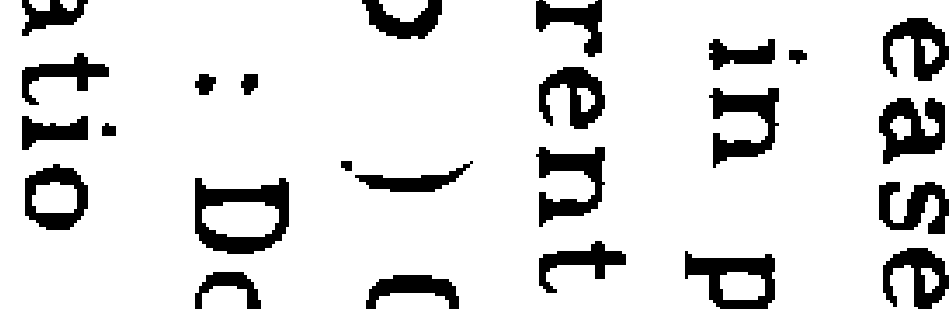

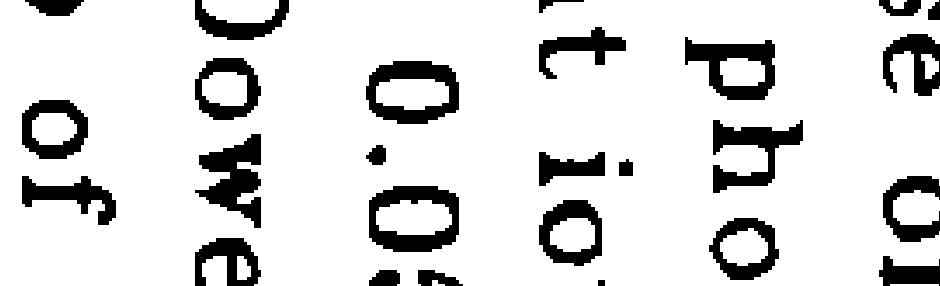

- 导马 品

- $-\frac{1}{5}$

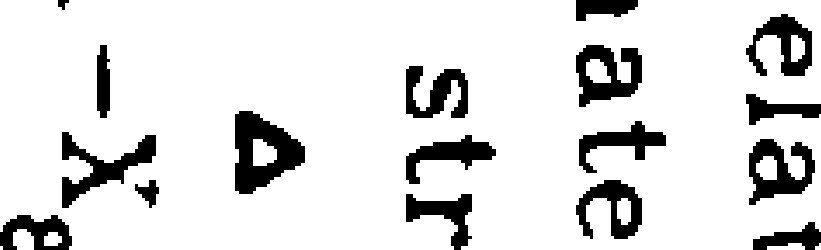

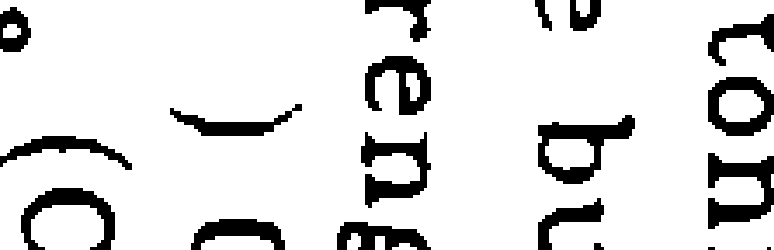

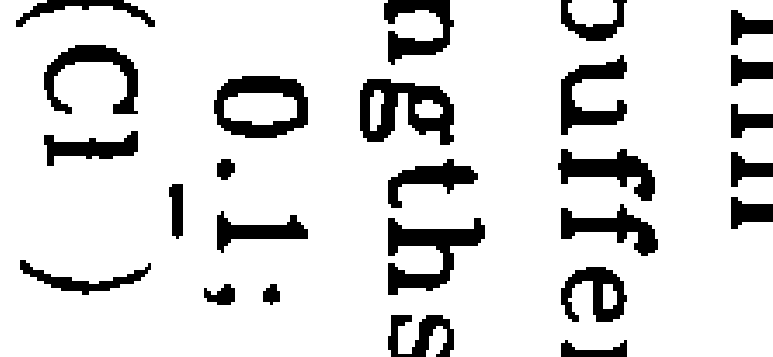
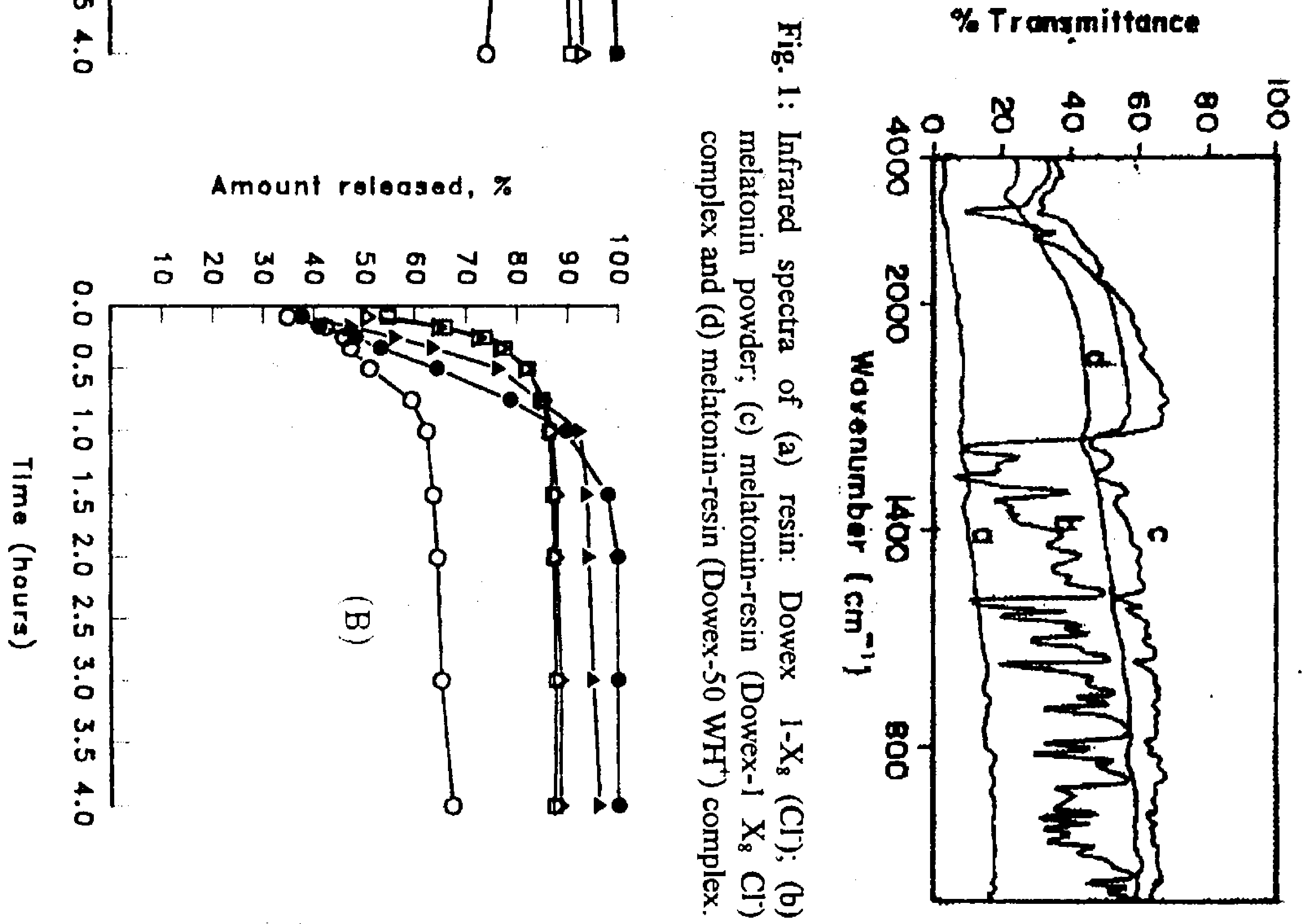

Amount reloased, \%

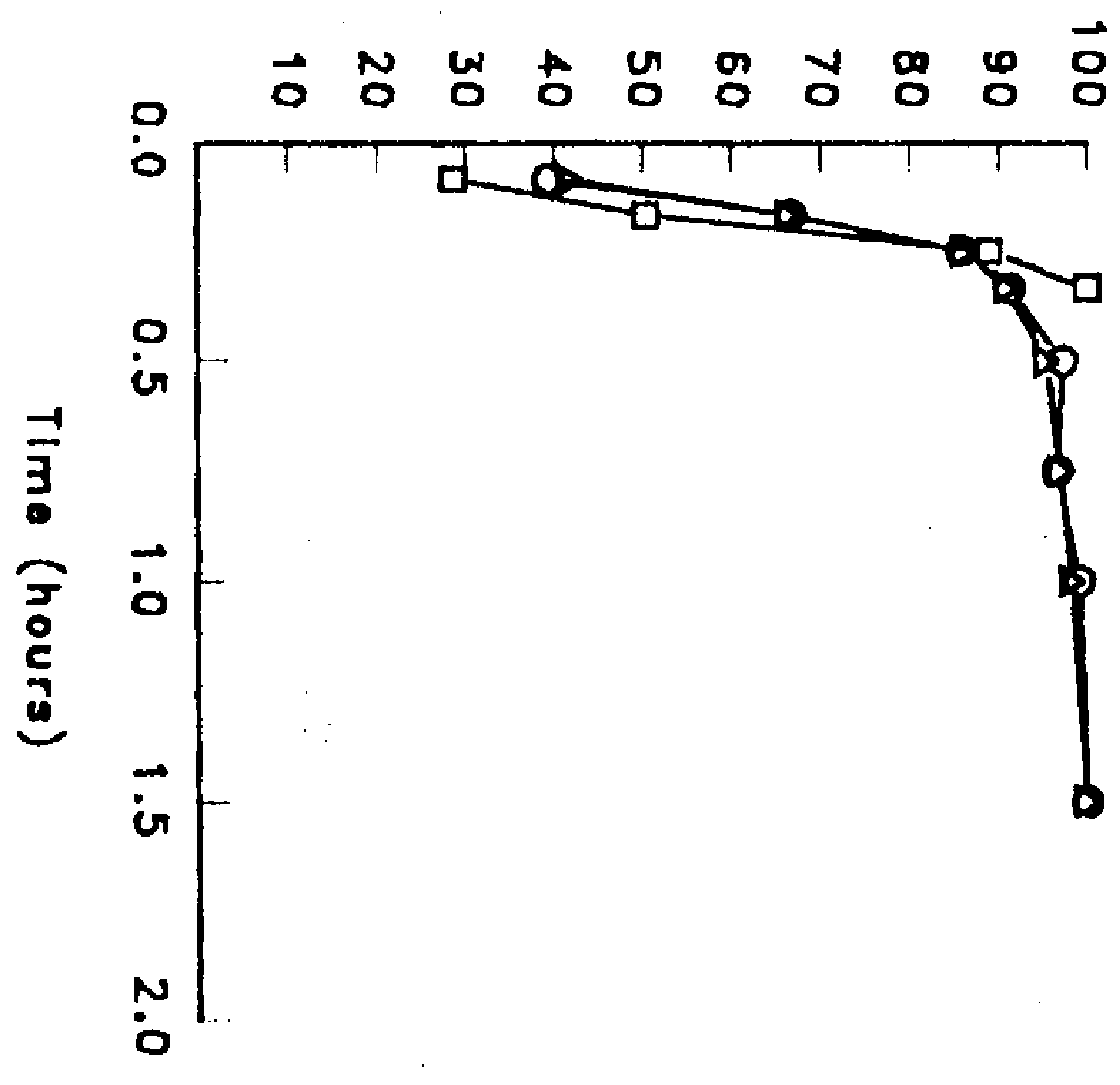


(S.I.F., pH 7.4) was studied as a function of concentration and type of treatment agents and their combinations thereof (Table 4). The ionic character of the polysaccharide resulted in $\mathrm{pH}$ dependent disintegration of calcium alginate beads which stayed intact in S.G.F. (pH 1.2) but rapidly disintegrated and dissolved in S.I.F. (pH 7.4) within $1 \mathrm{~h}$. Thus, the gel structure was destroyed, probably by dissociation of carboxyl acid residue and an ion exchange between the gel forming $\mathrm{Ca}^{2+}$ ions and the $\mathrm{Na}^{+}$ions, and the subsequent hydration and dissolution of the polysaccharide matrix. ${ }^{14,23}$

Polyethyleneimine-stabilized calcium alginate beads exhibited slower disintegration times (3- > 48 h., in S.I.F., pH 7.4) depending on polyethyleneimine concentration. However, the disintegration time of chitosan or acetic acidtreated calcium alginate beads varied between 1 and $3 \mathrm{~h}$. The disintegration times of beads treated with a mixture of chitosan/ polyethyleneimine was prolonged for $72 \mathrm{~h}$. with increasing polyethyleneimine concentration (up to $2 \% \mathrm{w} / \mathrm{v}$ ) in the gelling medium, whereas beads treated with polyethyleneimine in presence of acetic acid did not disintegrate within the first 2 h. (Table 4).

Table 4 shows also that (Ca) alginate/ polyethyleneimine gel microcapsules did not disintegrate in S.I.F., $\mathrm{pH} 7.4$ within $>72 \mathrm{~h}$. of testing. This may be attributed to an extracrosslinking in presence of polyethyleneimine alone and formation of water-insoluble polyelectrolyte complex (PEC) film resulting in tighter packing of the alginate gel matrix..$^{34}$

Figures 4-6 show the effect of different gelling agents on the weight changes (rate of gelation) of microcapsules, beads or treated beads. Generally, the results of weight changes indicated that, during the initial several hours, the interior water is rapidly squeezed out and the curing gradually reaches its fully stage in about $48 \mathrm{~h}$. in acetic acid or chitosan and/or polyethyleneimine-treated beads or (Ca) alginate/polyethyleneimine gel microcapsules. The chitosan/polyethyleneimine or acetic acid/ polyethyleneimine-treated beads exhibited faster gelation and much water reduction (average weight of beads $=0.584,0.329 \mathrm{gm}$, respectively after 72 h.) than other beads or microcapsules (average weights $=0.771 \mathrm{gm}$ after $72 \mathrm{~h}$.). This may be attributed to discharge of associated calcium ions from the beads which may be interpreted in a way that the carboxyl groups shifted to an unionized form in the acid environment resulting in water discahrge, decreased solubility of beads and formation of porous gel structure. ${ }^{42}$

The release characteristics of $\mathrm{Ca}$-alginate gel beads as a function of gelation time, core/coat ratio, $\mathrm{pH}$ and ionic strength of release medium are displayed in Figs 7-9. Longer exposure (up to $48 \mathrm{~h}$.) of the beads to the counter ions solution probably increased the degree of ionic crosslinking between $\mathrm{Ca}^{2+}$ ions and carboxyl groups of alginate molecules resulting in increasing the disintegration time and, in turn, decreasing the rate of melatonin release (Fig. 7). The same trend was observed with increasing the coating ratio. Similar results were obtained with Bodmeier et al. ${ }^{43}$ working on calcium alginate beads containing propranololloaded ethylcellulose microspheres.

The release of melatonin from beads is markedly faster in S.I.F., pH 7.4 (release was almost complete at $60 \mathrm{~min}$.) than in S.G.F., pH 1.2 (about $75 \%$ of melatonin released after 60 min.) and increases with increasing $\mathrm{pH}$ of phosphate buffers of constant ionic strenghts (0.154 $\mathrm{M} \mathrm{Na}^{+}$ions) (Fig. 8).

Figure 9 shows that the release rate increased significantly with an increase in ionic strength of phosphate buffers (pH 7.4). An effect which may be attributable to the increase in $\mathrm{Na}^{+}$ions concentration in media with high pH or ionic strength resulting in disruption of the coating and formation of water soluble polysaccharides. ${ }^{14,23}$

In-vitro release of melatonin from $(\mathrm{Ca})$ alginate/polyethyleneimine (PEI) gel microcapsules containing melatonin resinates was influenced by many variables viz, polyethyleneimine concentration, gelation time, melatonin/ resin ratio, and core/coat ratio, in addition to the $\mathrm{pH}$ and ionic strength of the release medium (Figs. 10-15).

The release behaviour of melatonin from alginate microcapsules (melatonin/resin ratio of $1: 6$ and core/coat ratio of 1:2) was not greatly affected by variations in polyethyleneimine 
Table 4: Effect of various treatment conditions on disintegration properties of Ca-alginate gel beads and $\mathrm{Ca}$-alginate gel microcapsules in simulated intestinal fluid (pH 7.4)

\begin{tabular}{|c|c|c|c|}
\hline Treatment agent & $\begin{array}{c}\text { Preparation } \\
\text { type }\end{array}$ & $\begin{array}{c}\mathrm{pH} \text { of gelling } \\
\text { solution }\end{array}$ & $\begin{array}{l}\text { Disintegration in } \\
\text { S.I.F. (pH 7.4) }\end{array}$ \\
\hline Control & beads $^{c}$ & 5.8 & $+++(1 \sim 2 \mathrm{hrs})^{\mathrm{b}}$ \\
\hline $\begin{array}{l}\text { Polyethyleneimine (PEI) conc. \% } \\
\text { w/v } \\
0.5 \\
2 \\
4 \\
1 \\
2 \\
2.5 \\
\end{array}$ & $\begin{array}{c}\text { beads } \\
\text { beads } \\
\text { beads } \\
\text { microcapsules } \\
\text { microcapsules } \\
\text { microcapsules }\end{array}$ & $\begin{array}{l}10.1 \\
10.3 \\
10.6 \\
10.2 \\
10.3 \\
10.4 \\
\end{array}$ & $\begin{array}{l}+++(3 \mathrm{hrs}) \\
-(>48 \mathrm{hrs}) \\
+(3-5 \mathrm{hrs}) \\
-(>72 \mathrm{hrs}) \\
-(>72 \mathrm{hrs}) \\
-(>72 \mathrm{hrs}) \\
\end{array}$ \\
\hline $\begin{array}{c}\text { Chitosan conc. \%(w/v) } \\
0.05 \\
0.10 \\
0.15 \\
\end{array}$ & $\begin{array}{l}\text { beads } \\
\text { beads } \\
\text { beads } \\
\end{array}$ & $\begin{array}{l}4.5 \\
4.2 \\
4.2 \\
\end{array}$ & $\begin{array}{c}-\mathrm{d} \\
+++(1 \mathrm{hr}) \\
+++(1-3 \mathrm{hrs}) \\
\end{array}$ \\
\hline $\begin{array}{c}\text { Acctic acid conc. \% (v/v) } \\
1.96 \\
4.76 \\
9.0 \\
\end{array}$ & $\begin{array}{l}\text { beads } \\
\text { beads } \\
\text { beads }\end{array}$ & $\begin{array}{l}3.0 \\
2.9 \\
2.7 \\
\end{array}$ & $\begin{array}{l}+++(1-2 \mathrm{hrs}) \\
+++(1-2 \mathrm{hrs}) \\
+++(1-2 \mathrm{hrs}) \\
\end{array}$ \\
\hline $\begin{array}{c}\text { Chitosan : PEI } \\
(\% \mathrm{w} / \mathrm{v}):(\% \mathrm{w} / \mathrm{v}) \\
0.1: 0.5 \\
0.1: 0.8 \\
0.1: 1.0 \\
0.1: 2.0 \\
0.15: 2.0 \\
\end{array}$ & $\begin{array}{l}\text { beads } \\
\text { beads } \\
\text { beads } \\
\text { beads } \\
\text { beads }\end{array}$ & $\begin{array}{l}5.8 \\
6.5 \\
7.3 \\
8.9 \\
8.4 \\
\end{array}$ & $\begin{array}{c}+++(2-3 \mathrm{hrs}) \\
+++(5-6 \mathrm{hrs}) \\
++(5 \mathrm{hrs}) \\
-(72 \mathrm{hrs}) \\
-(>24 \mathrm{hrs}) \\
\end{array}$ \\
\hline $\begin{array}{c}\text { Acetic acid : PEI } \\
\begin{array}{r}(\% \mathrm{v} / \mathrm{v}) \quad:(\% \mathrm{w} / \mathrm{v}) \\
1.96: 2 \\
4.76: 2 \\
1.96: 2\end{array} \\
\end{array}$ & $\begin{array}{c}\text { beads } \\
\text { beads } \\
\text { microcapsules } \\
\end{array}$ & $\begin{array}{l}3.8 \\
4.0 \\
3.8 \\
\end{array}$ & $\begin{array}{l}-(1-2 \mathrm{hrs}) \\
-(1-2 \mathrm{hrs}) \\
+++(2 \mathrm{hrs}) \\
\end{array}$ \\
\hline
\end{tabular}

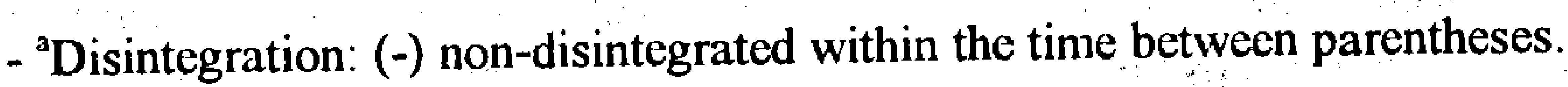

$(+)$ very slight disintegration. $(++)$ incomplete disintegration.

$(+++)$ complete disintegration.

- bata between parentheses refer to disintegration time (hours) (S.I.F. pH 7.4).

Beads and microcapsules did not disintegrate in S.G.F. (pH 1.2) in 24 hours.

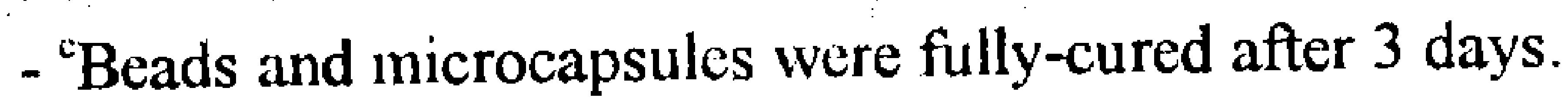

$-{ }^{\mathrm{d}}$ Run for which data could not be collected. 

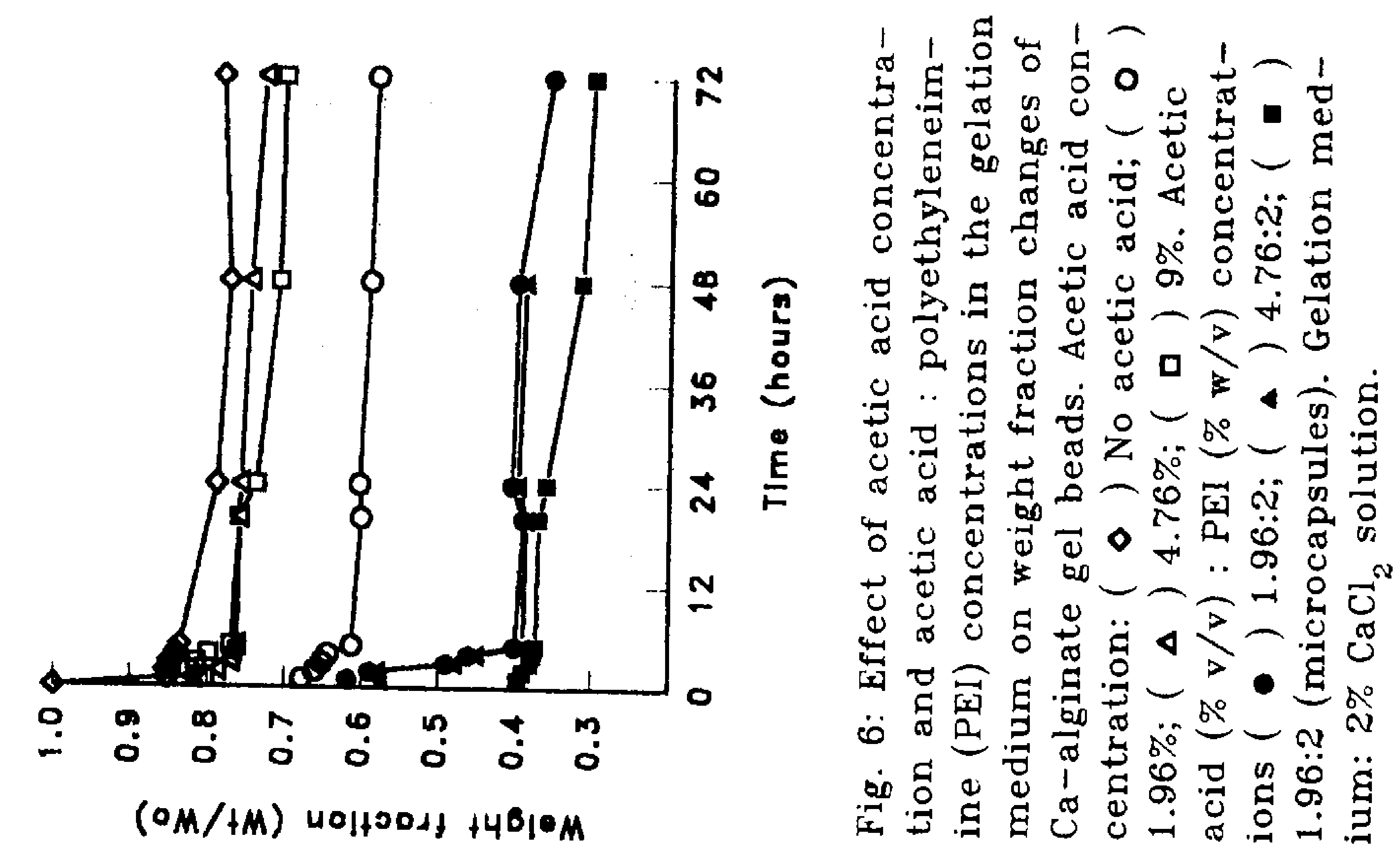

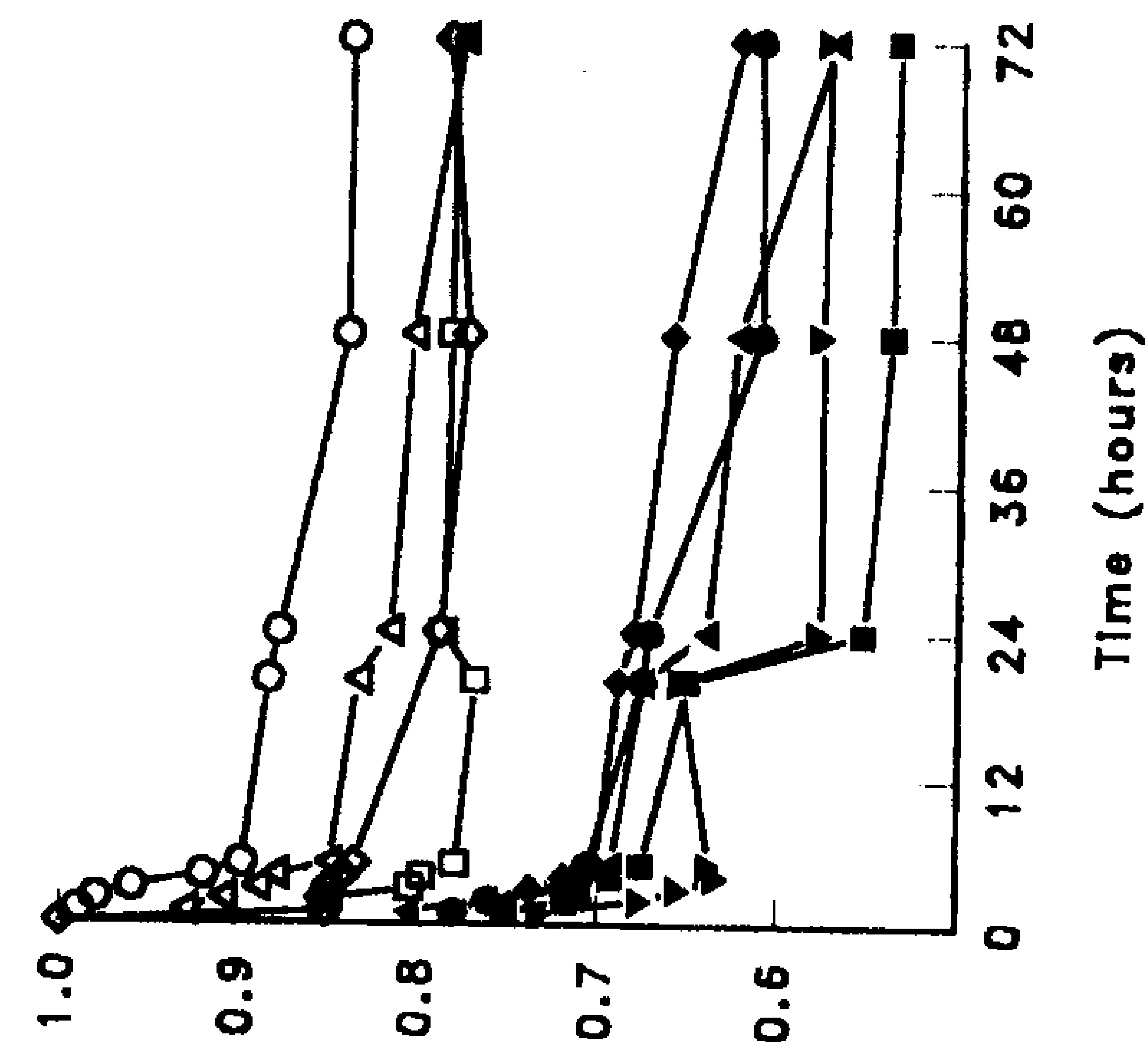

$(O M /+M) 4011001 /+4 B_{10 M}$

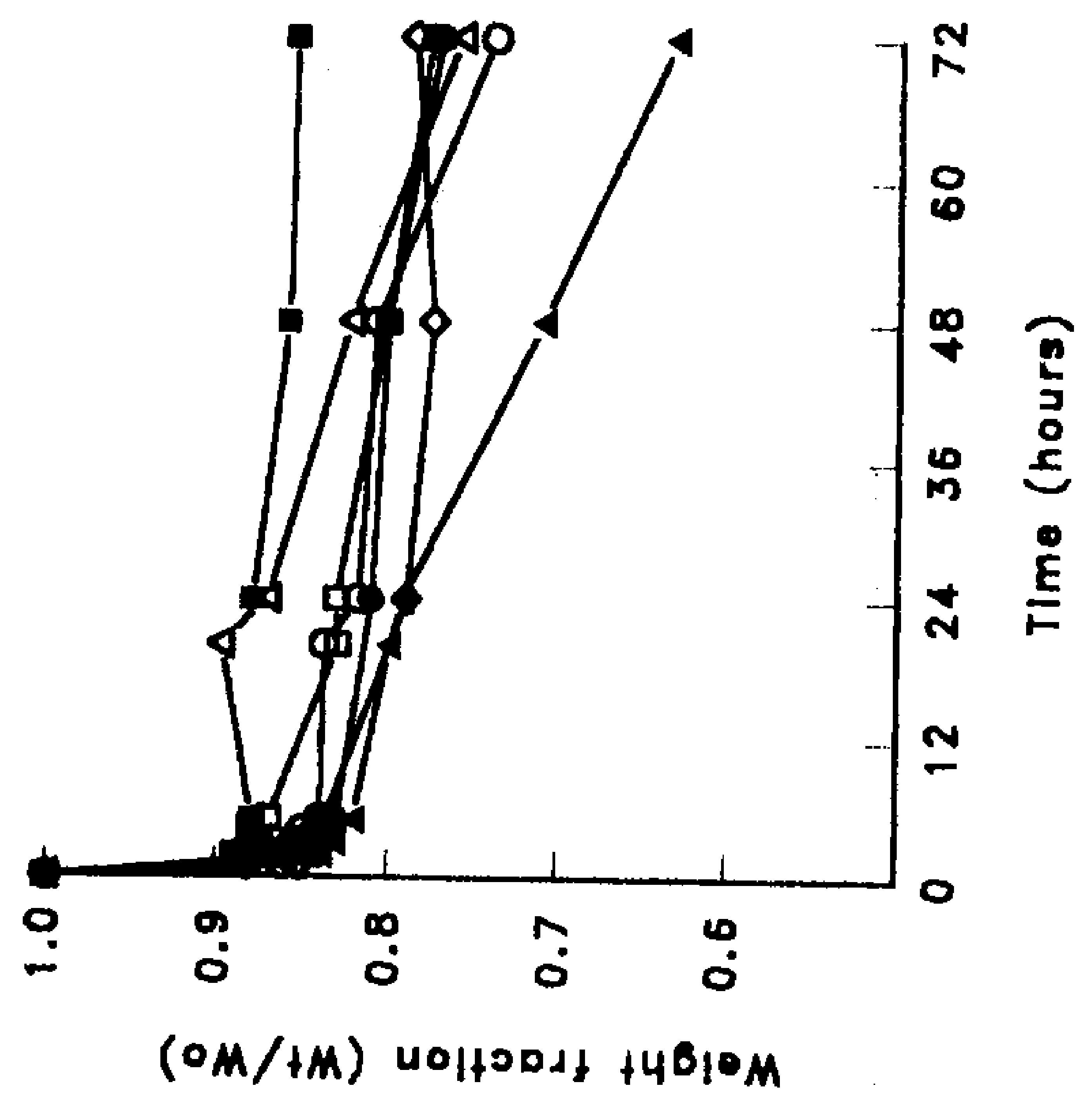

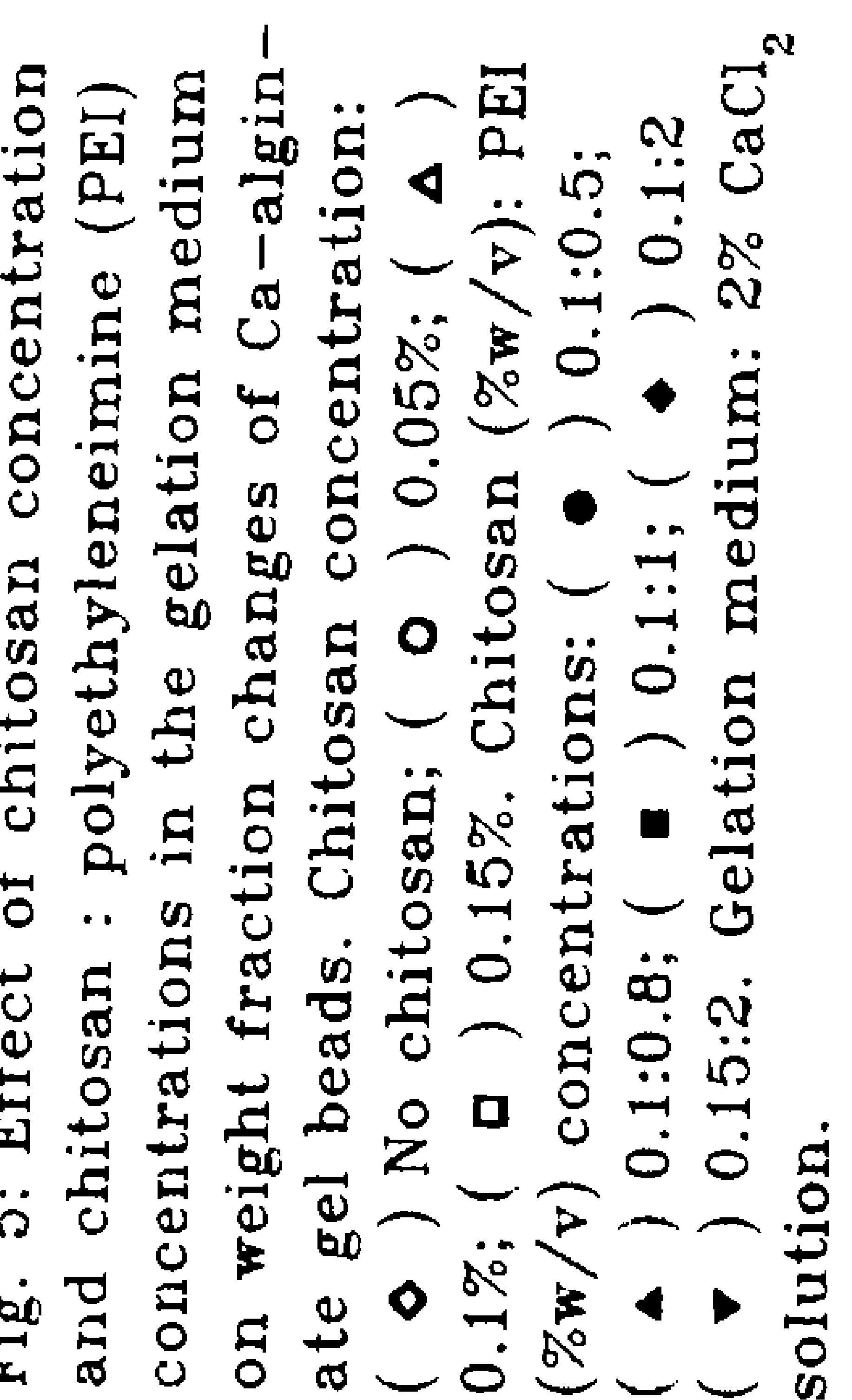

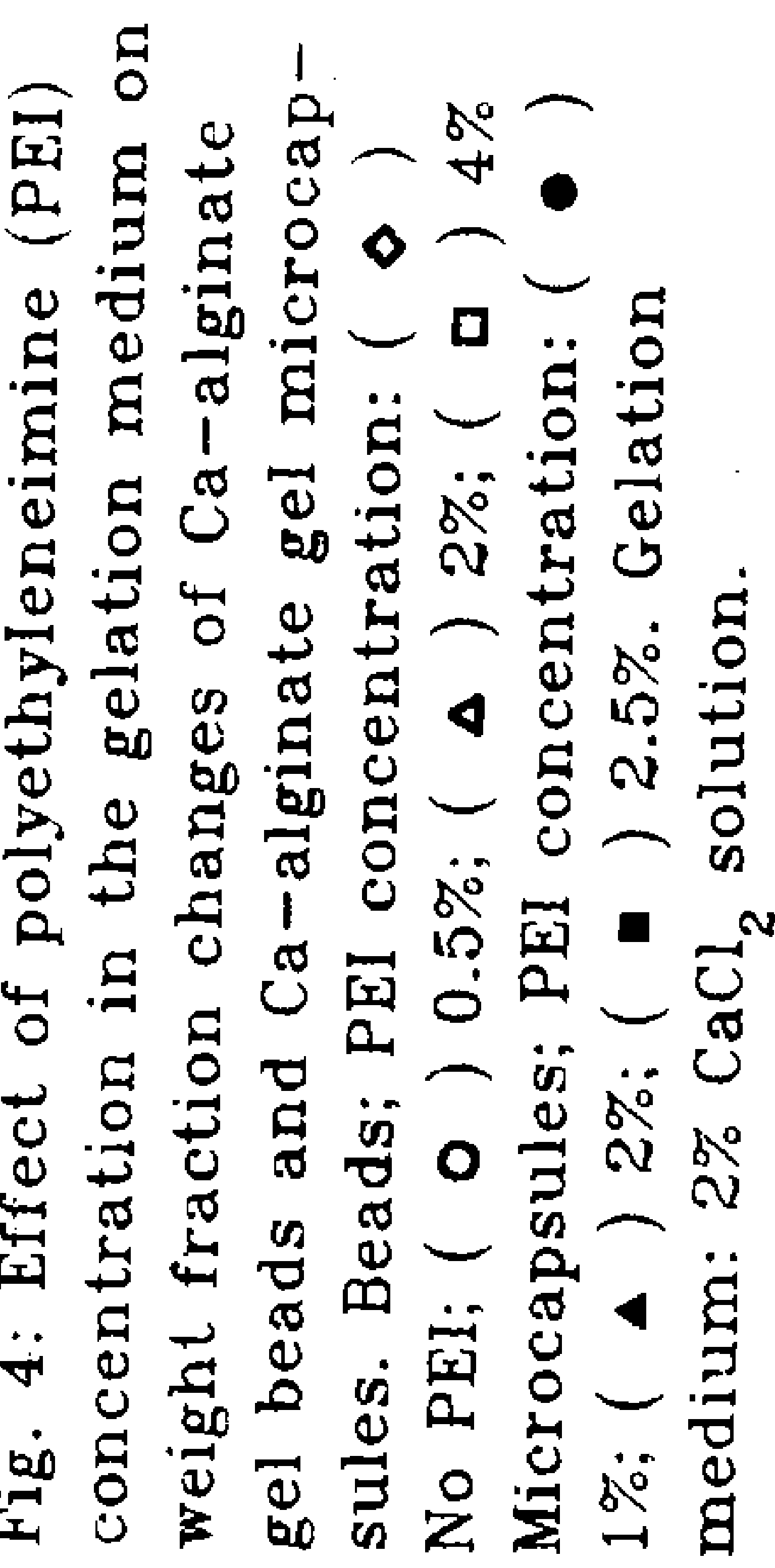




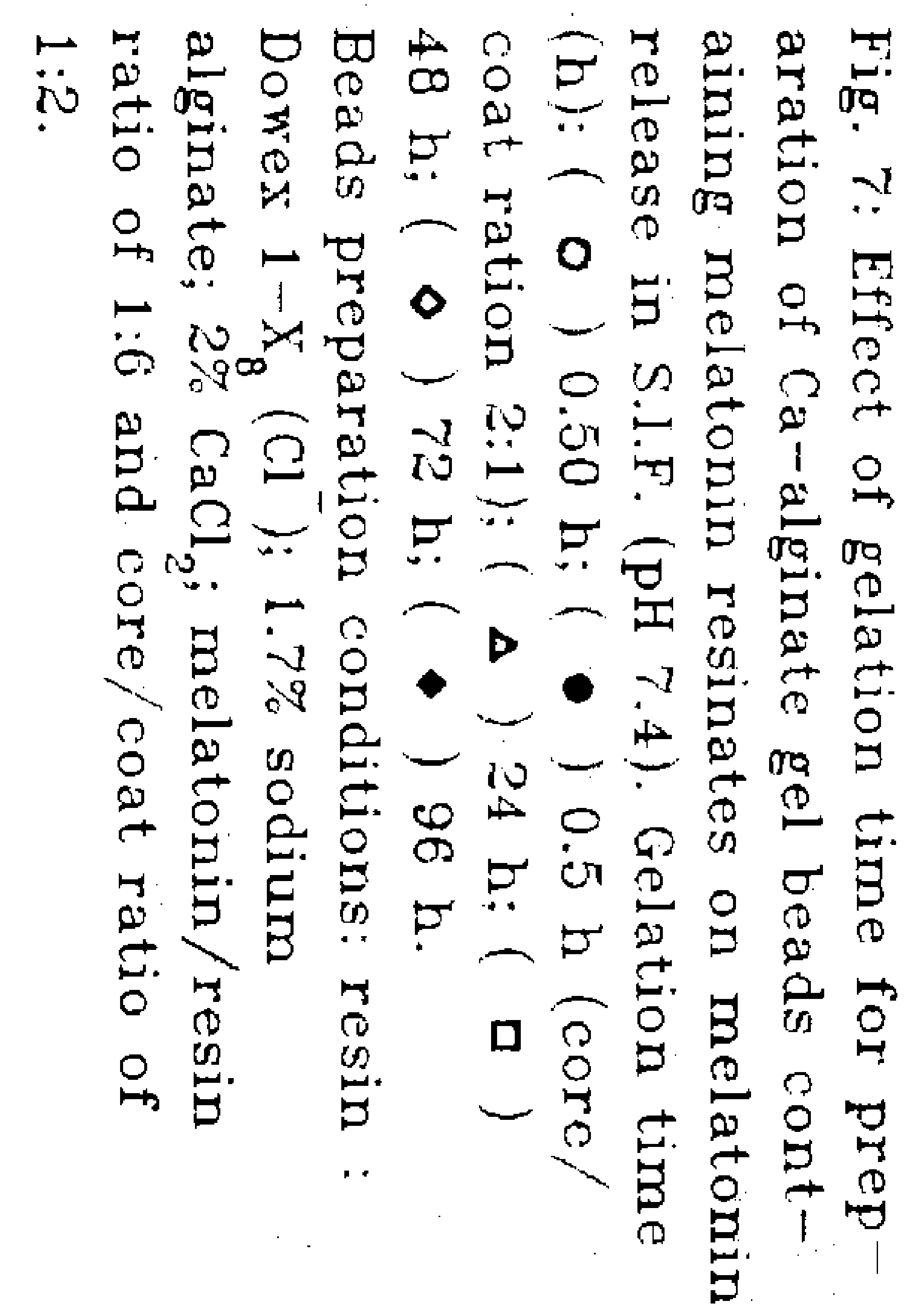

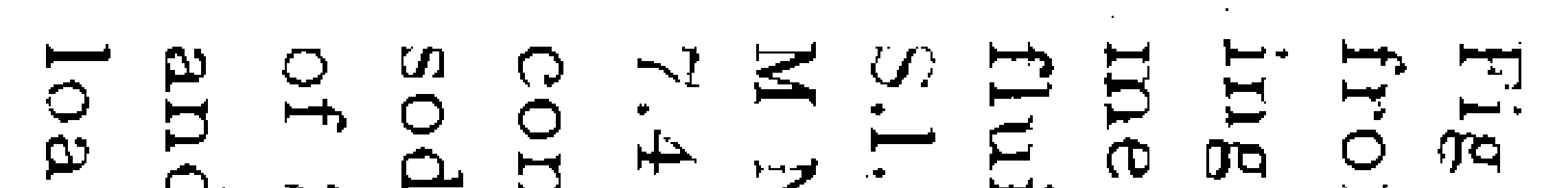

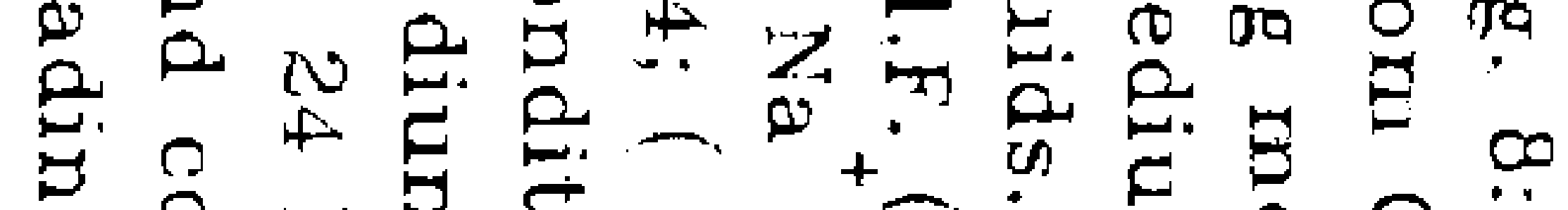

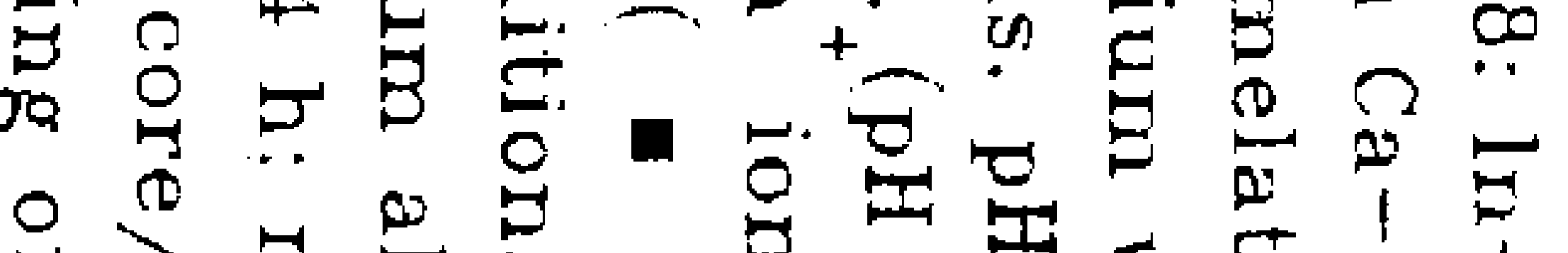

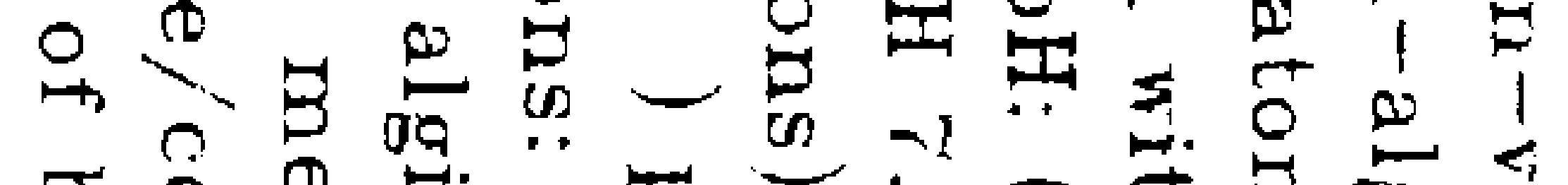

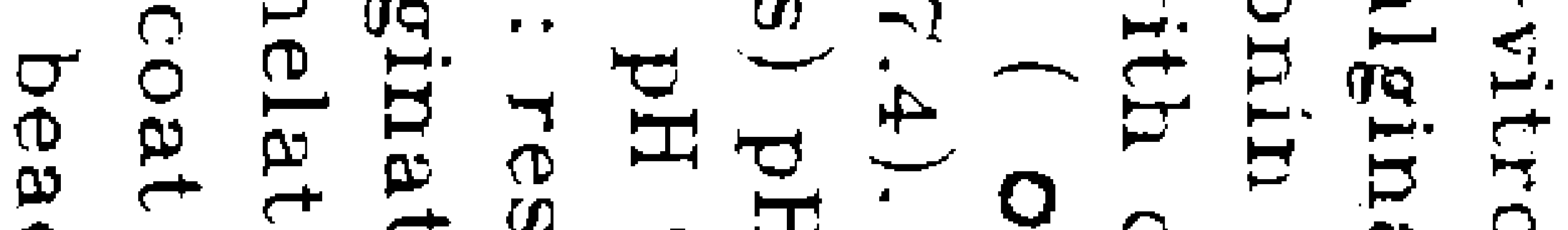
क

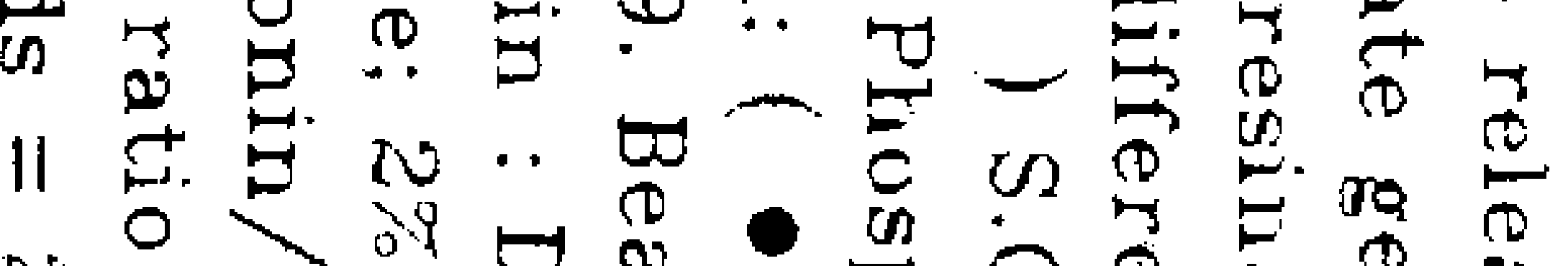

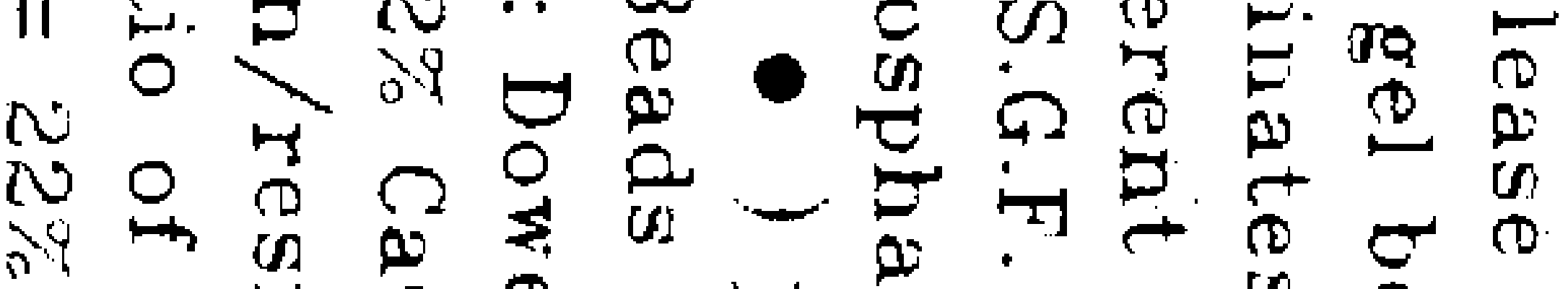

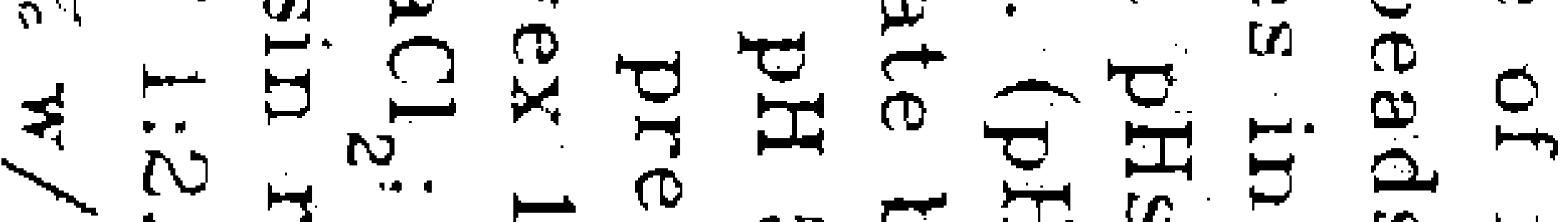
\%

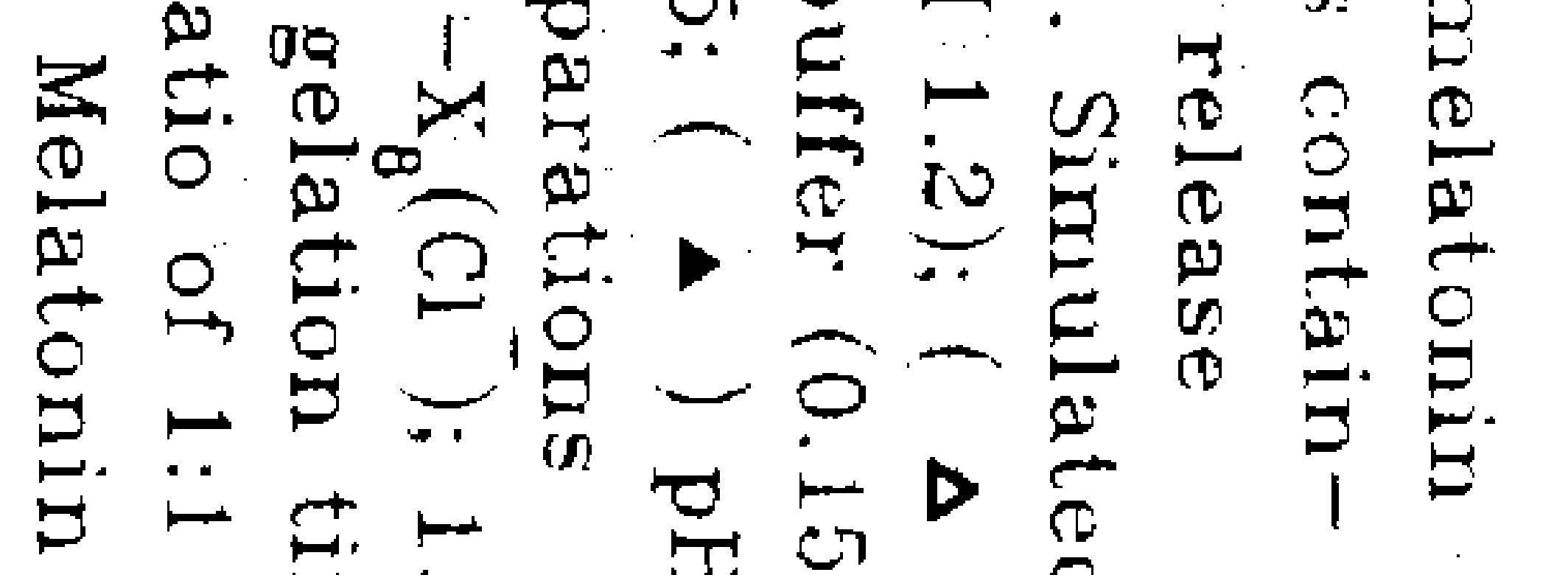

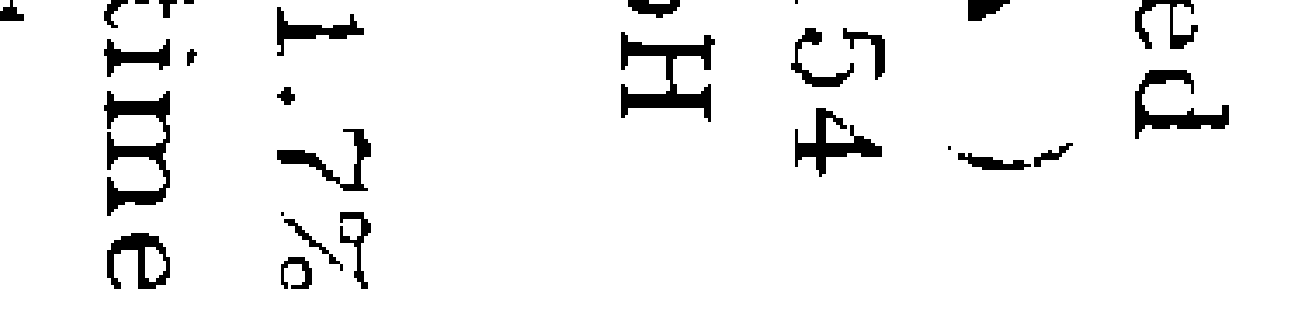

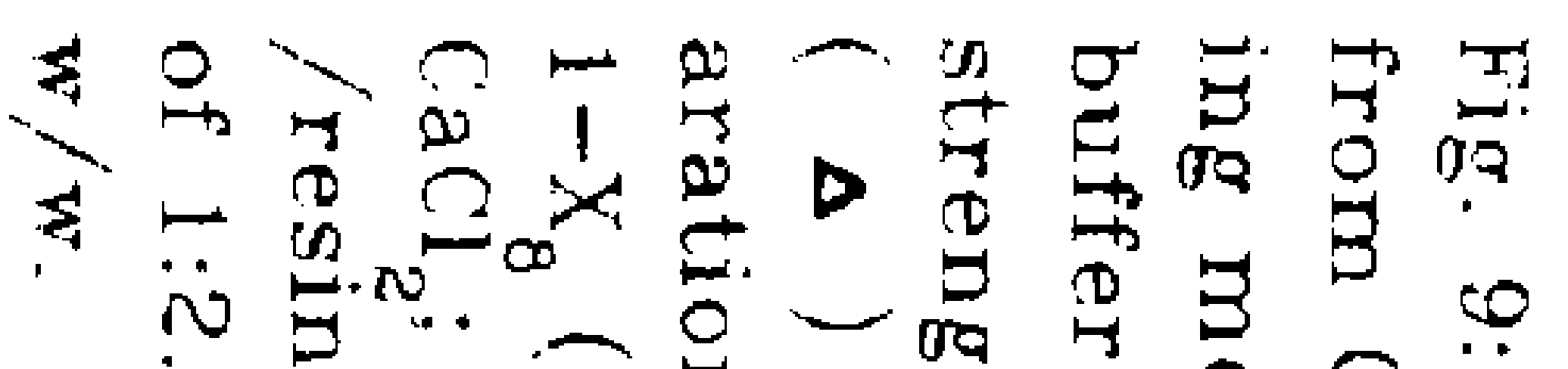
द

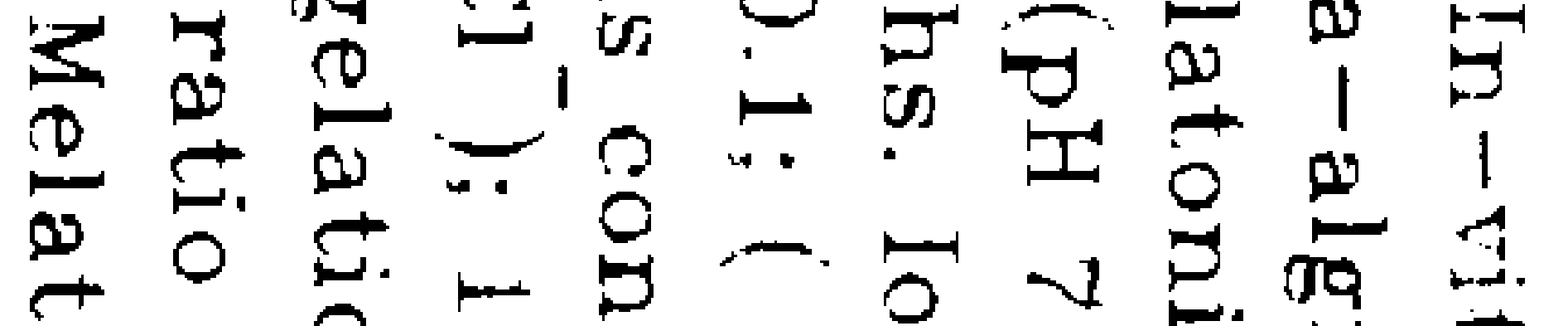

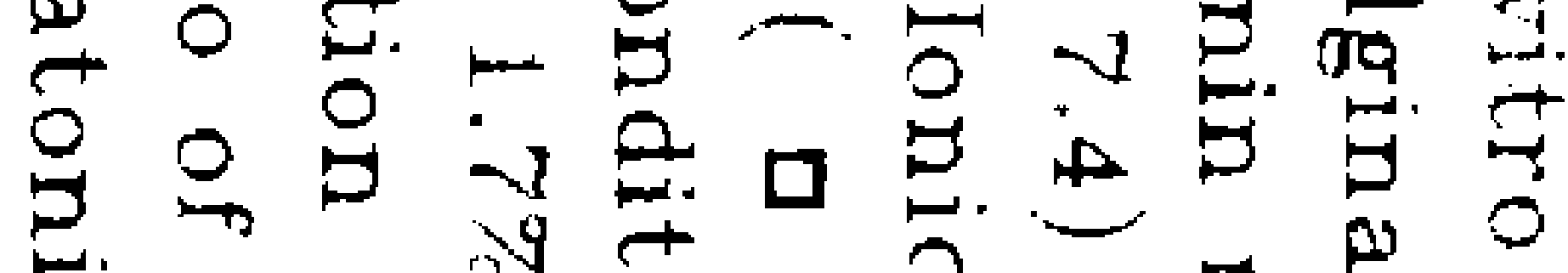

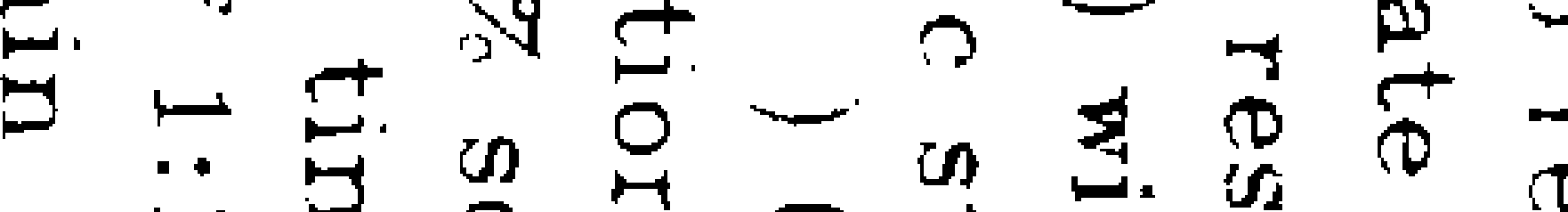

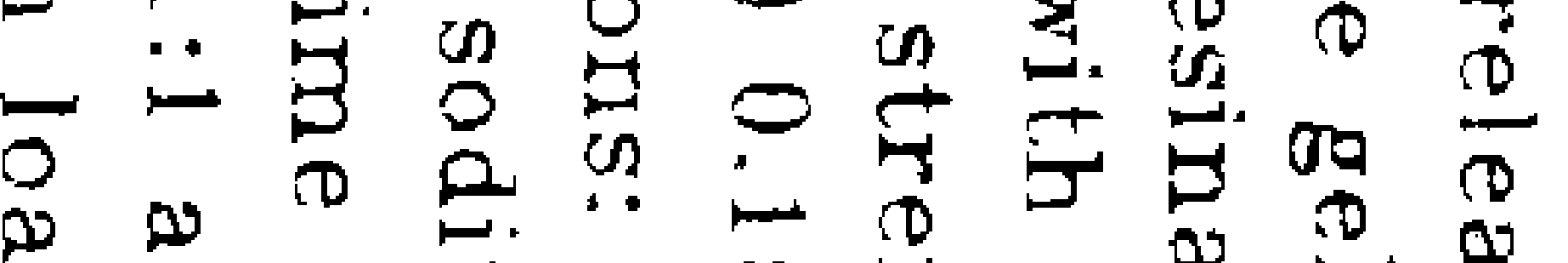

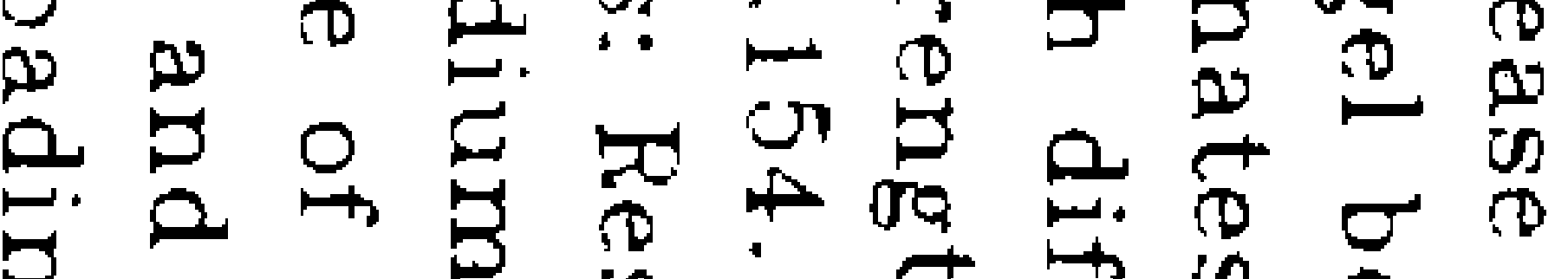

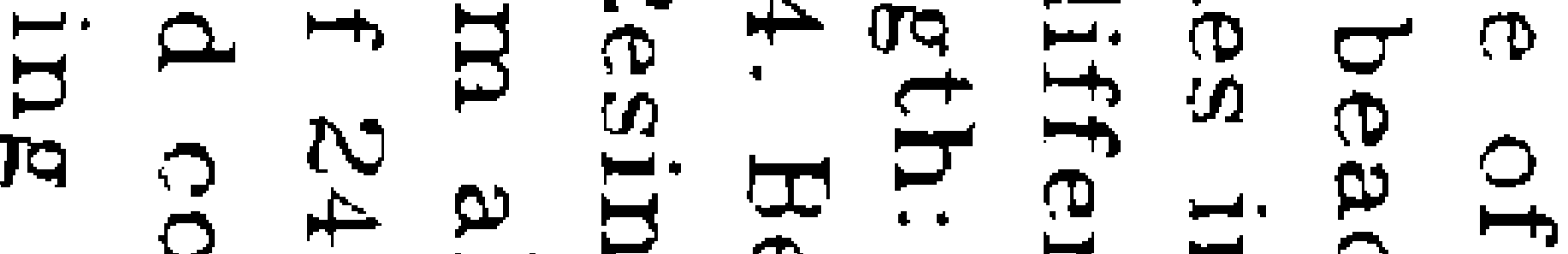

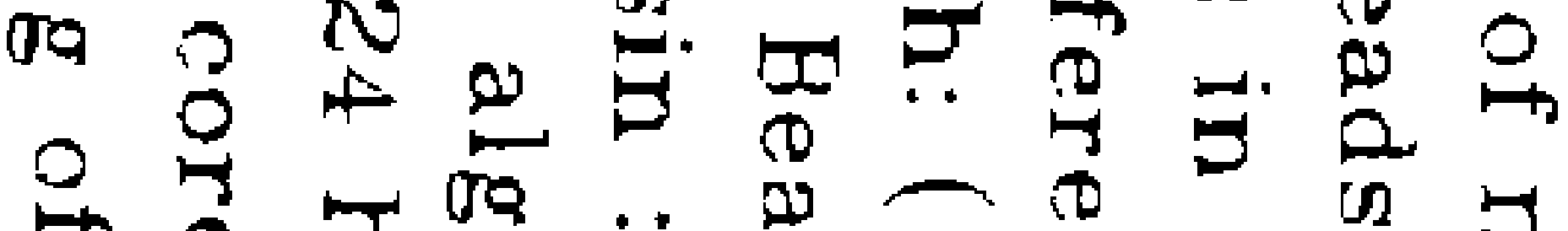

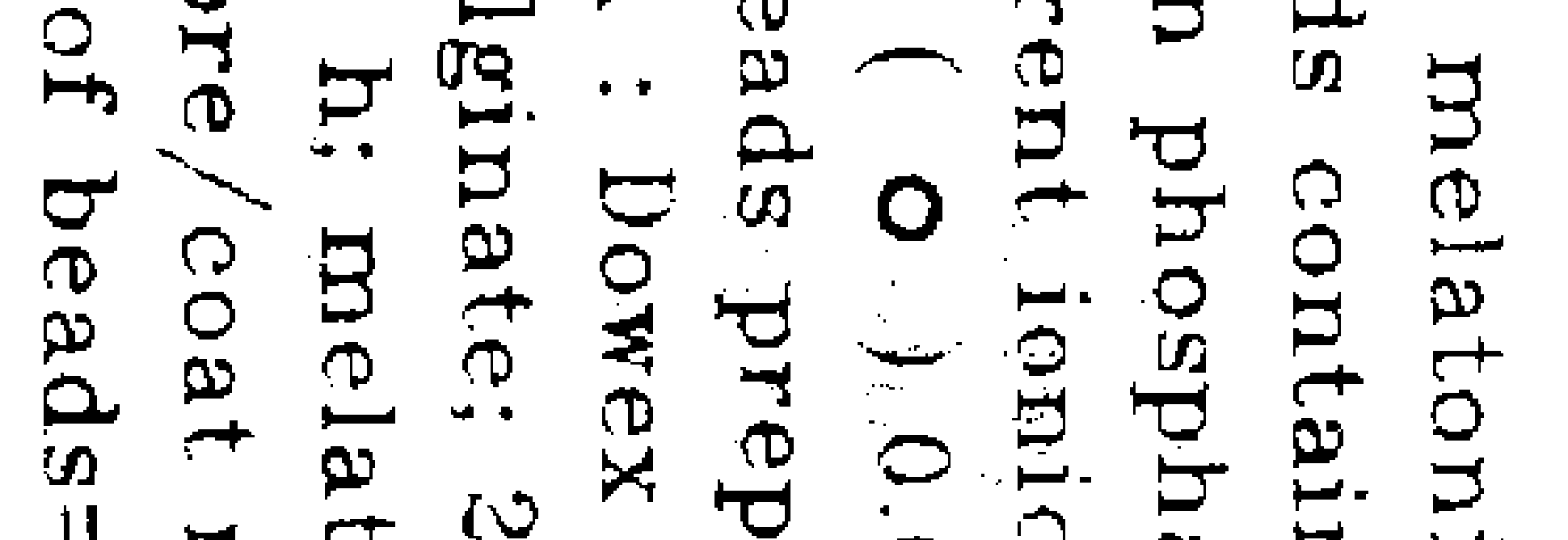

Amount released, \%

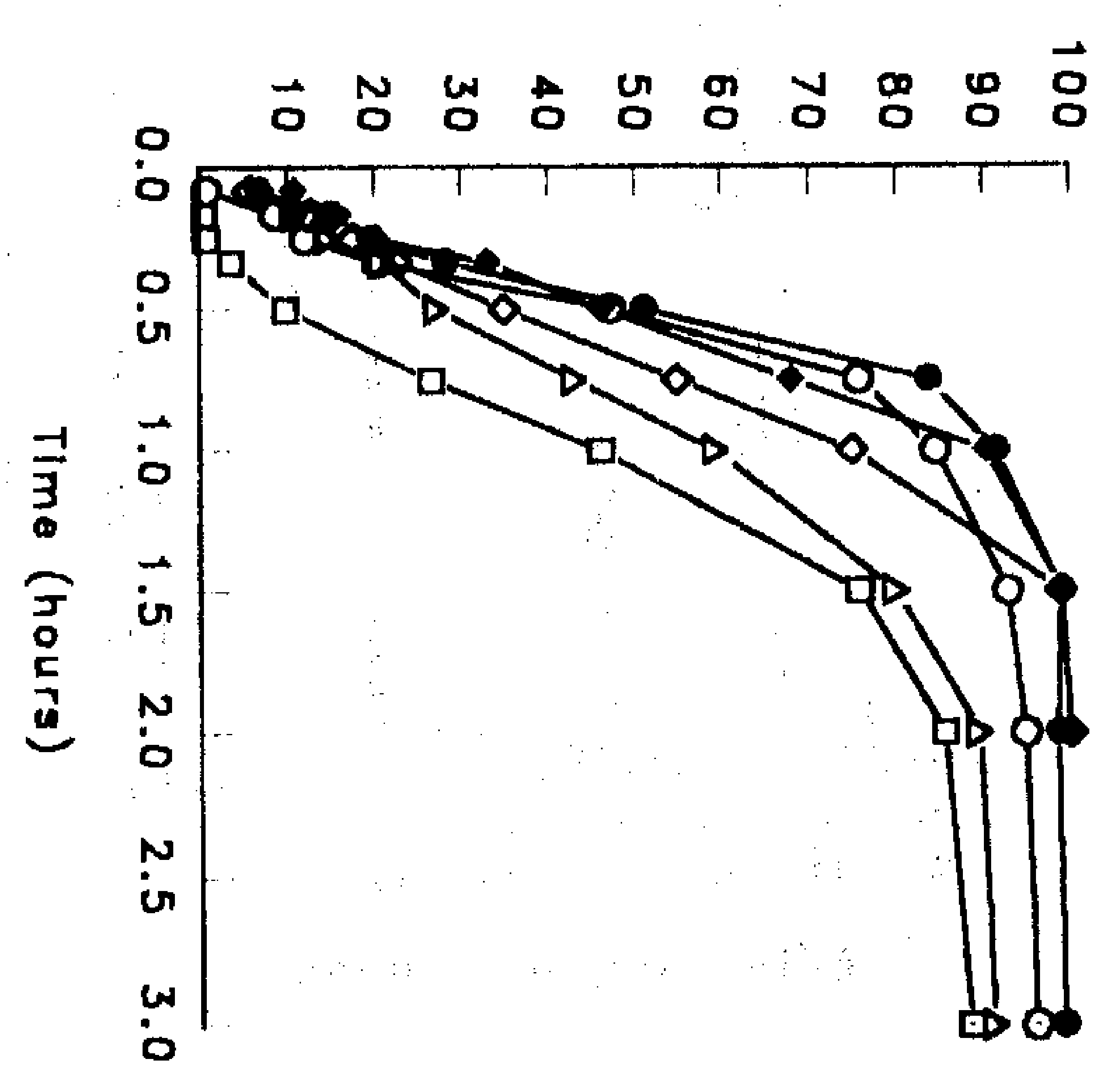

Amount reloosed, \%

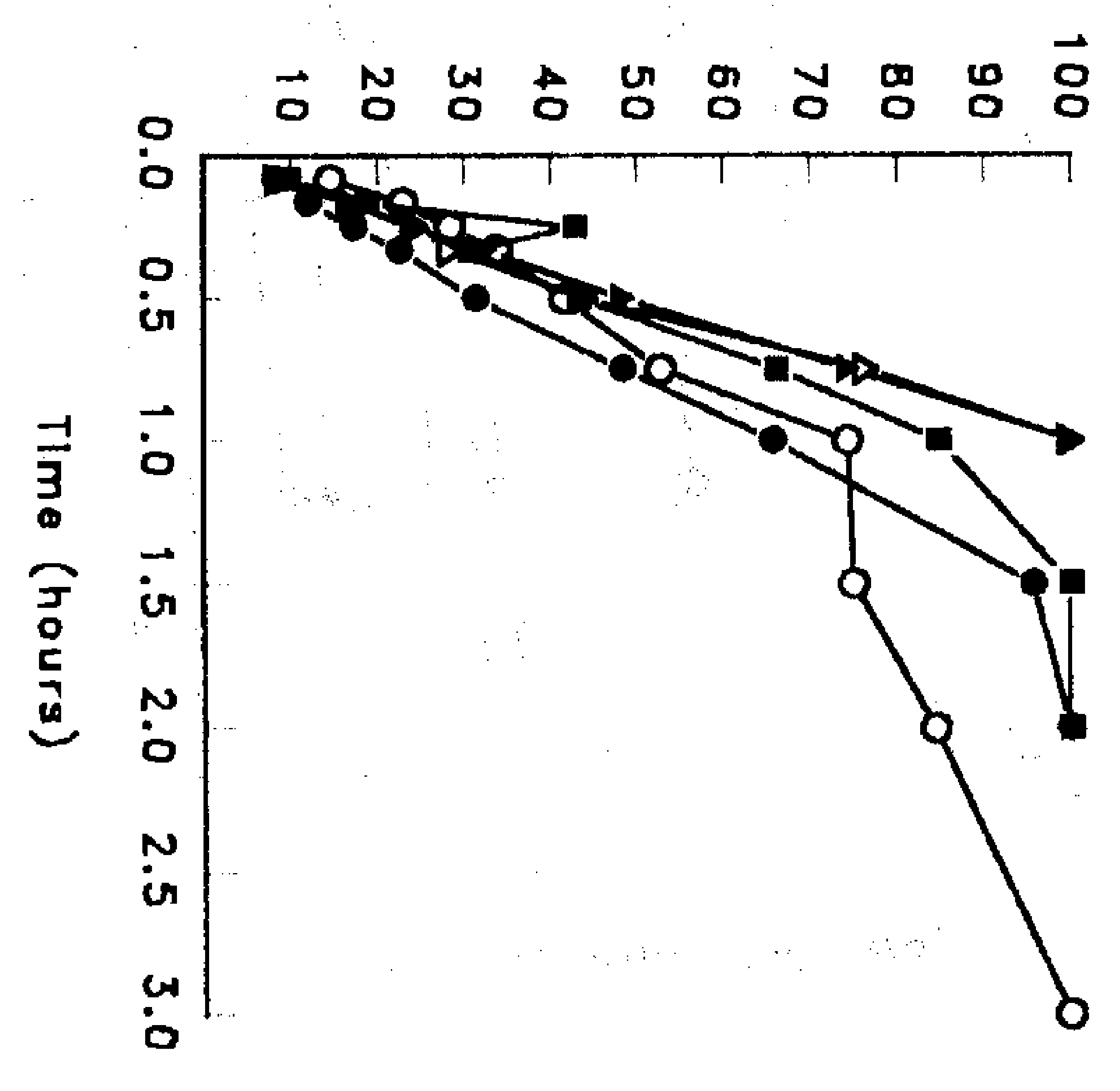

Amount reloosed, $\%$

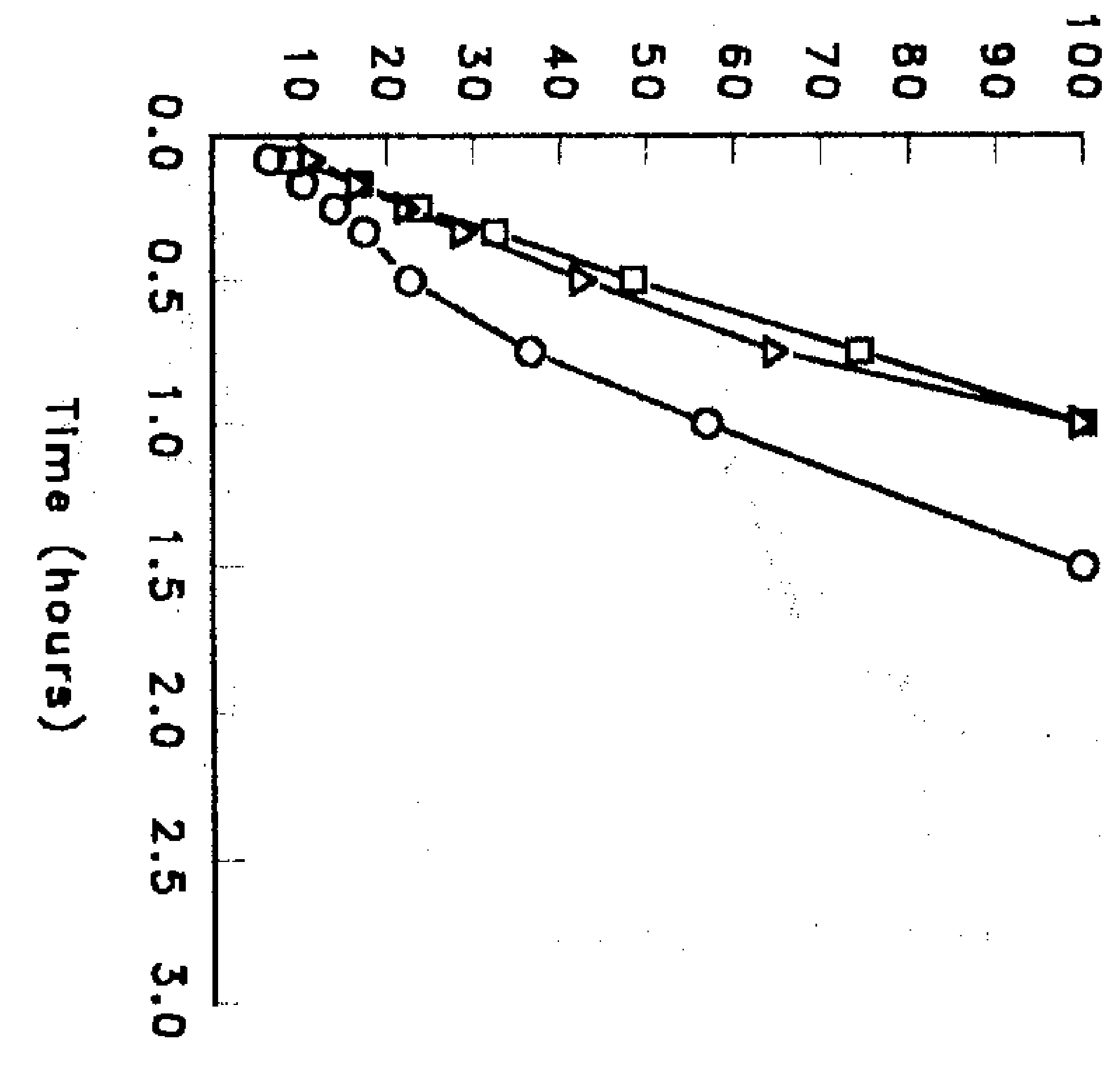




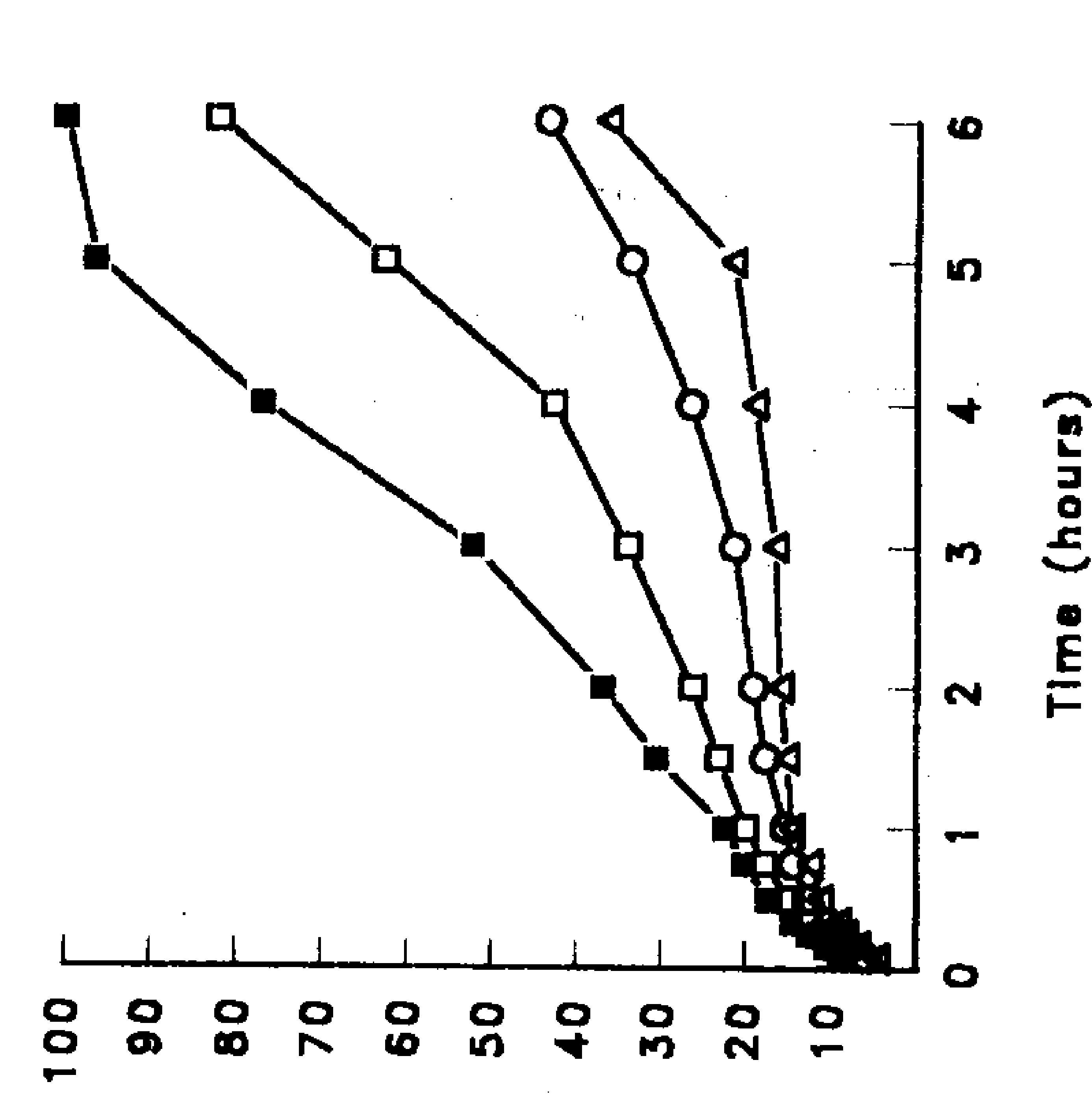

\% 'posooped funowy

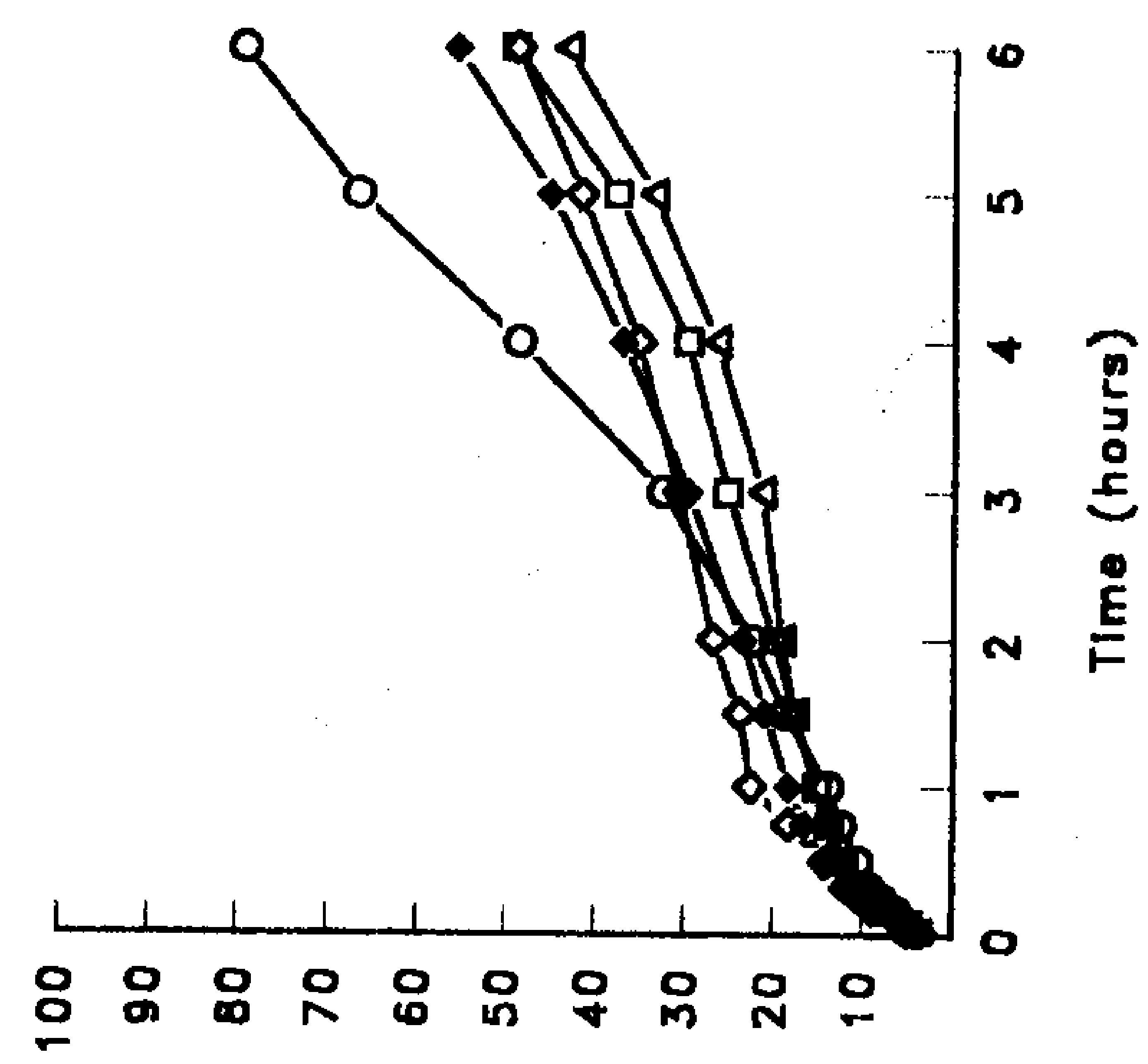

\% "posdoped funowy

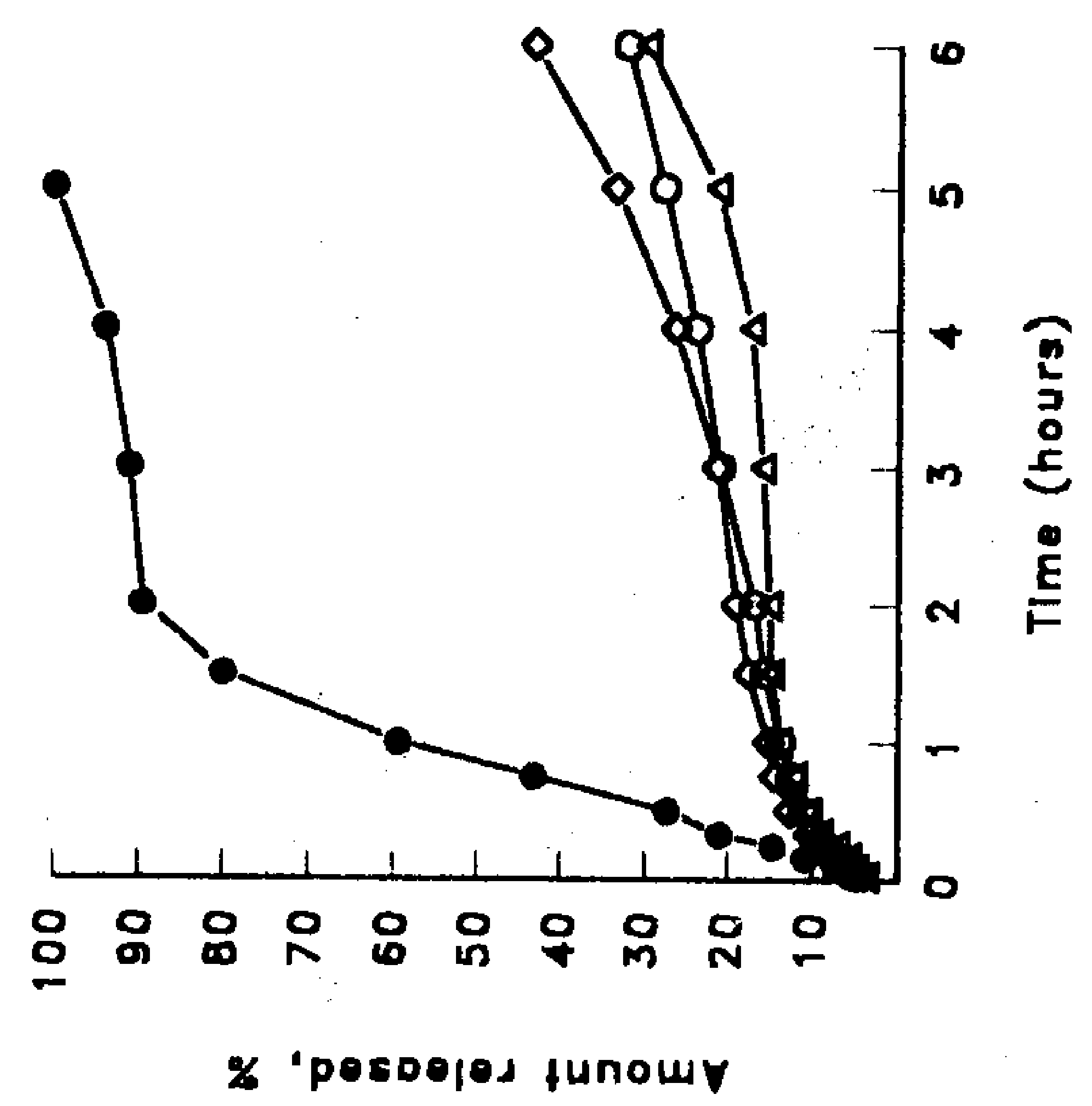

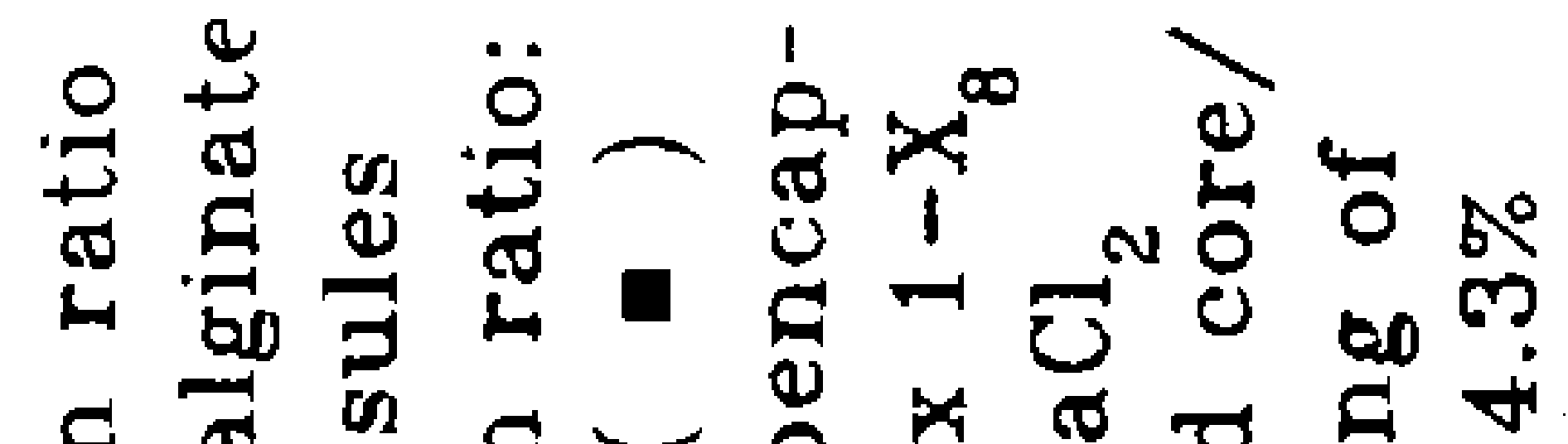

舫

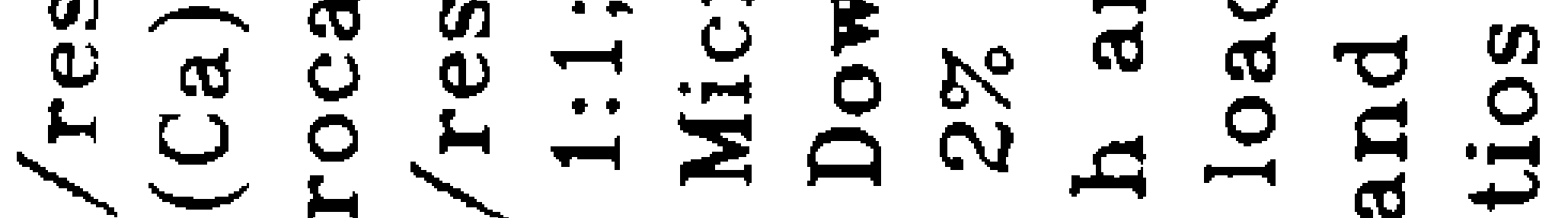

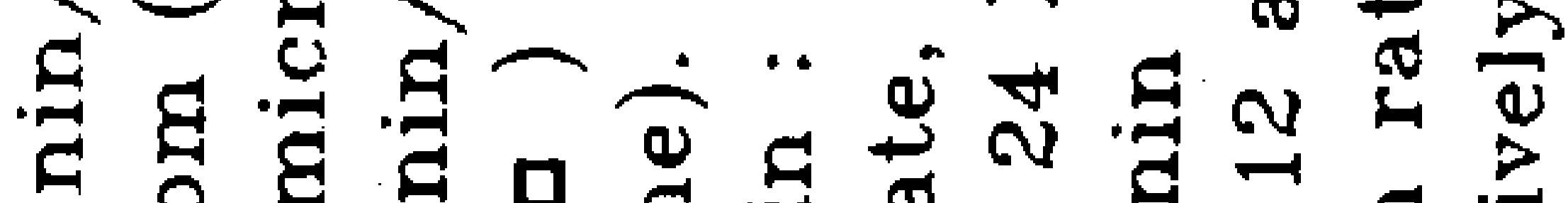

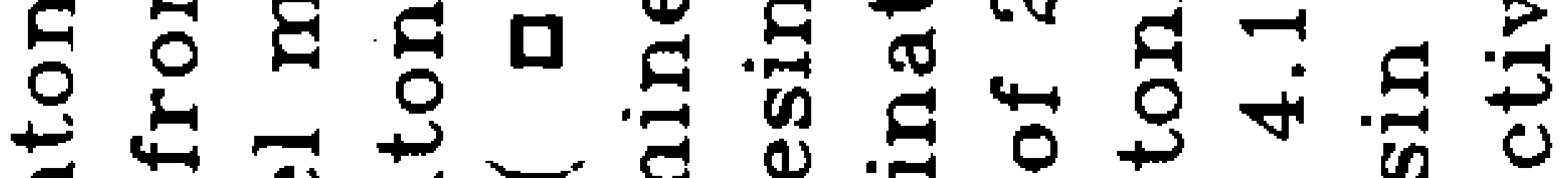

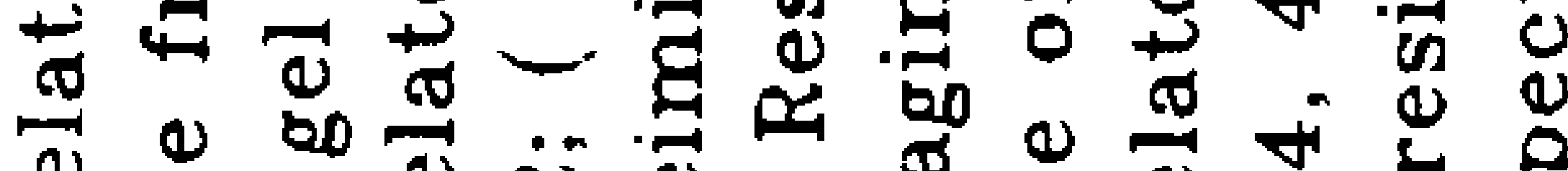
G

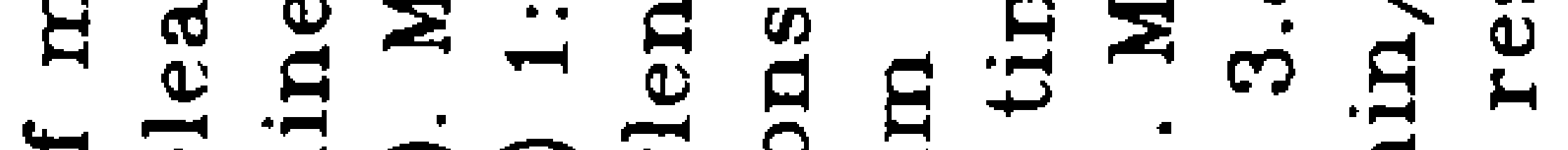

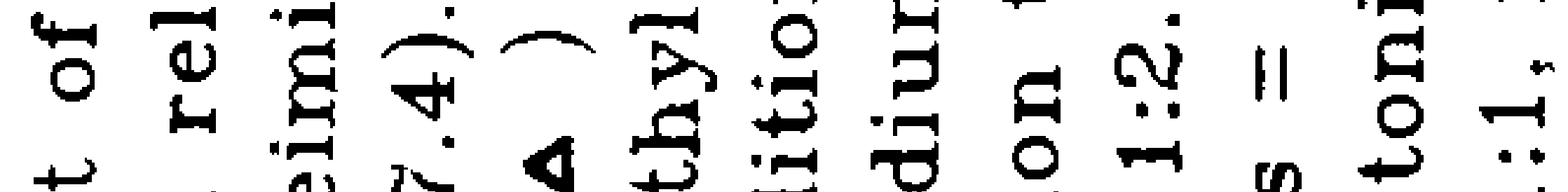

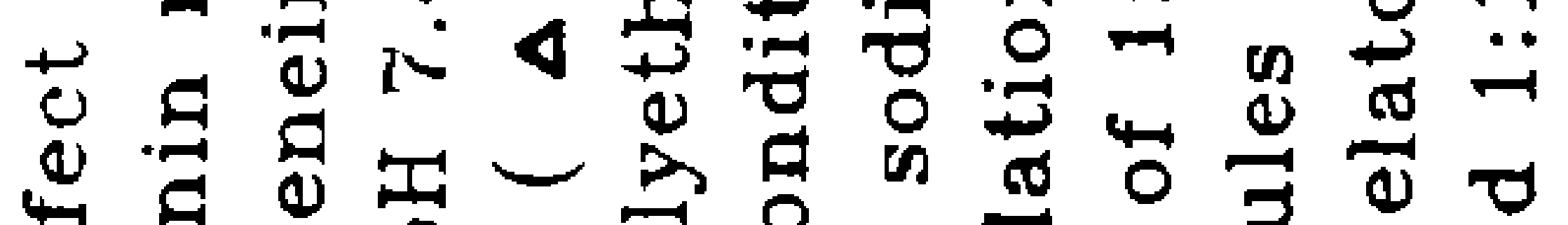
嵌

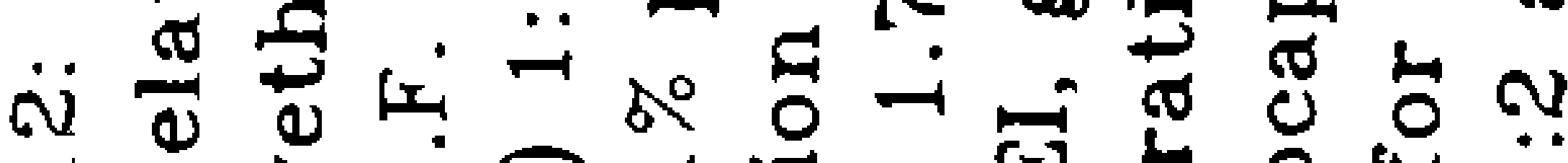

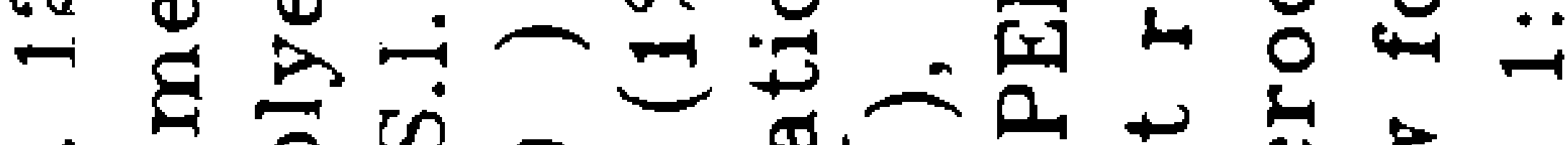

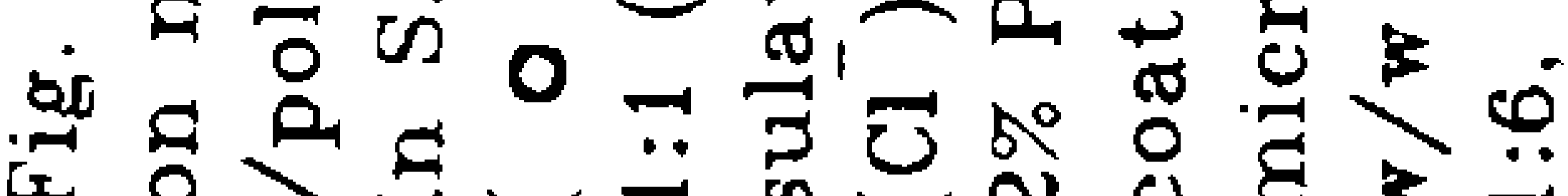
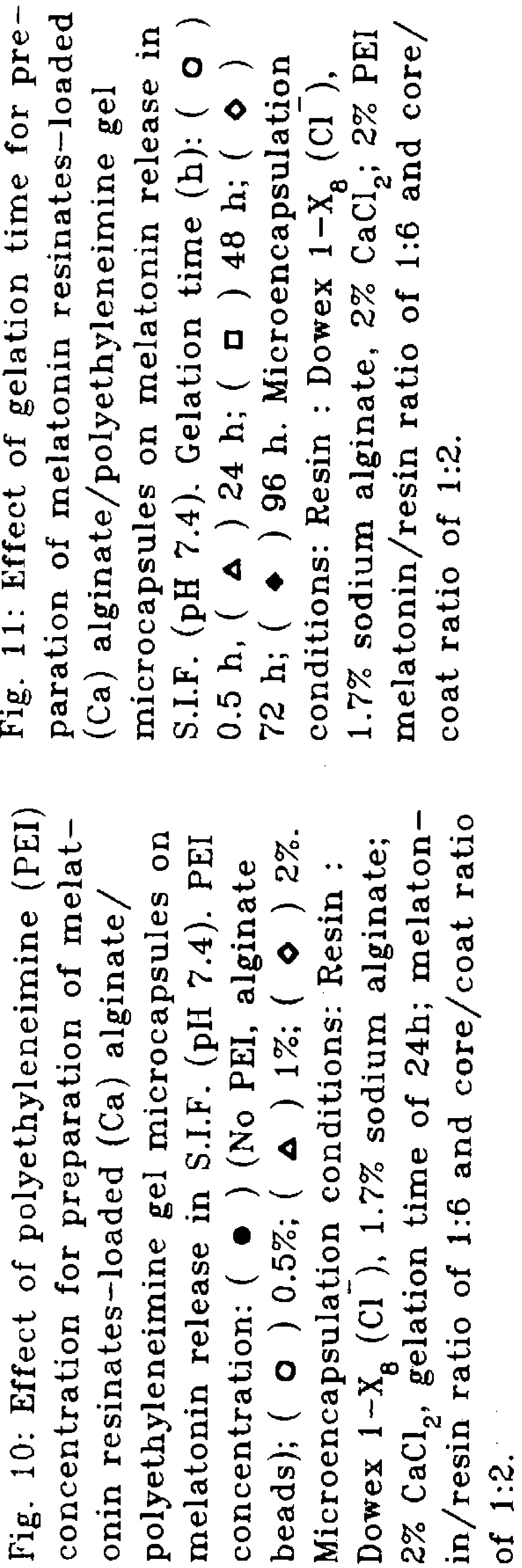

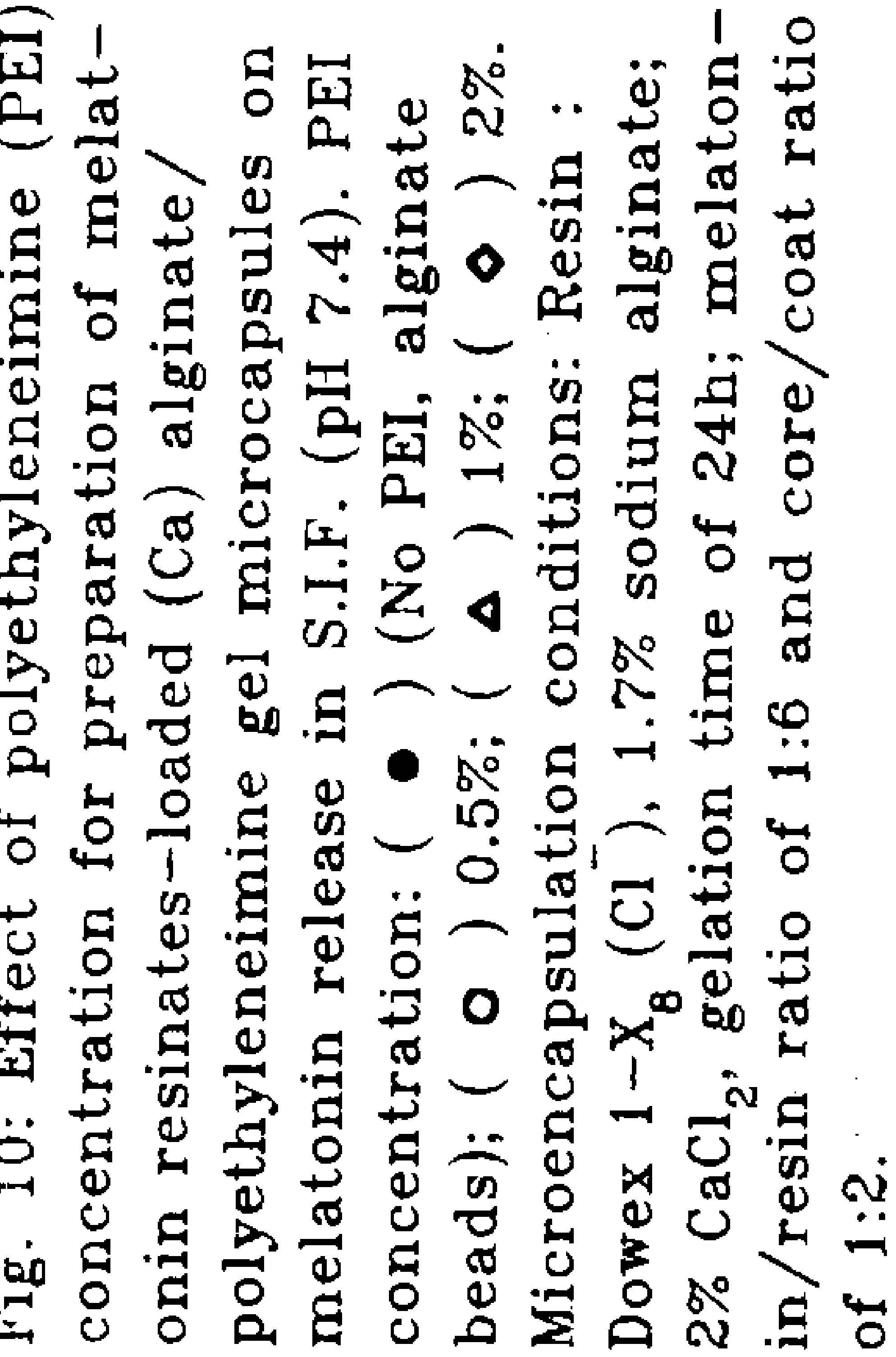



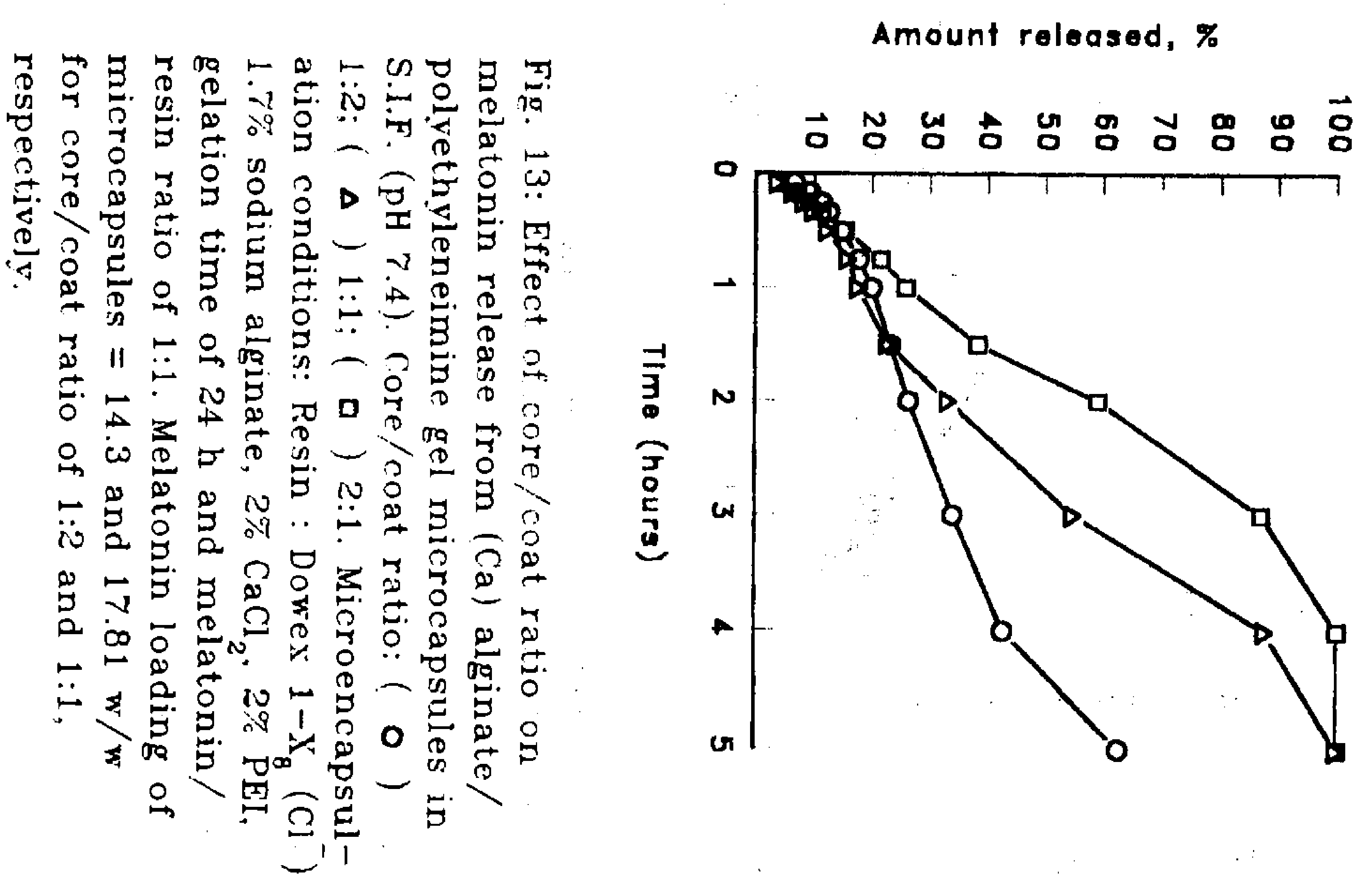

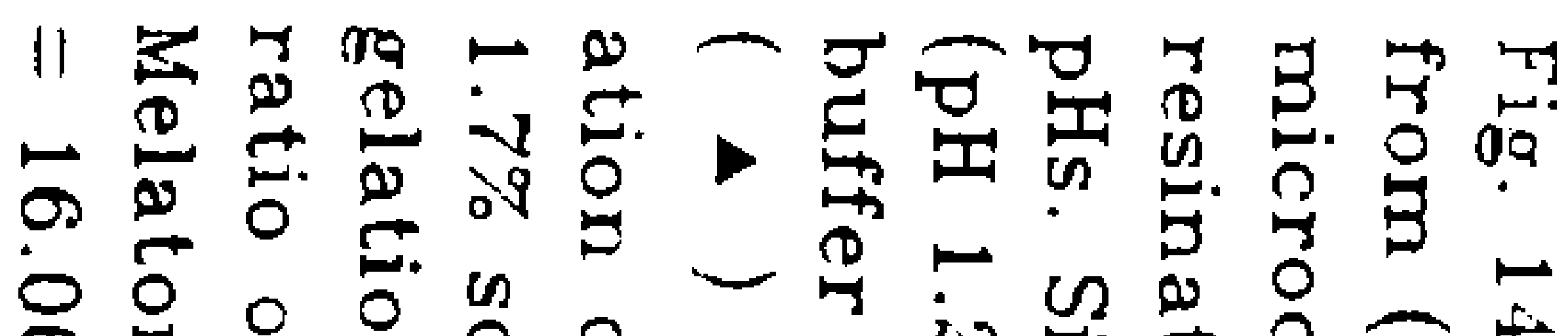

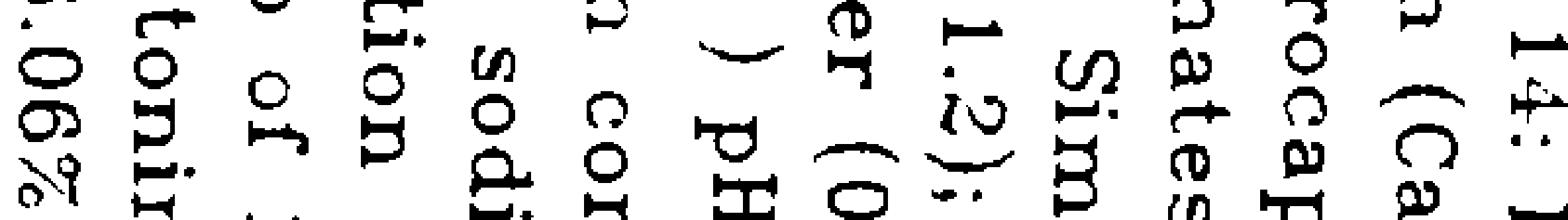

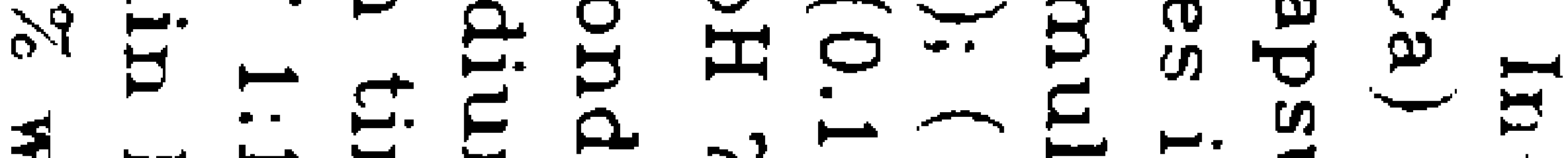

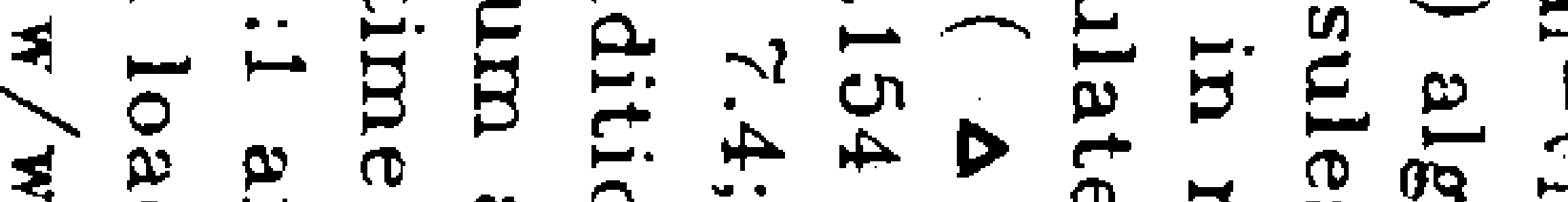

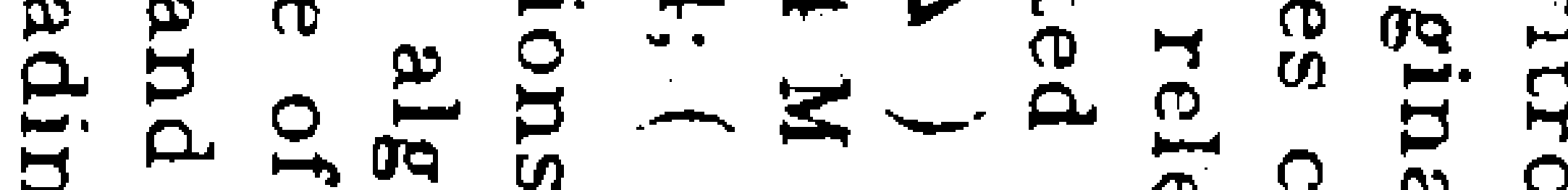

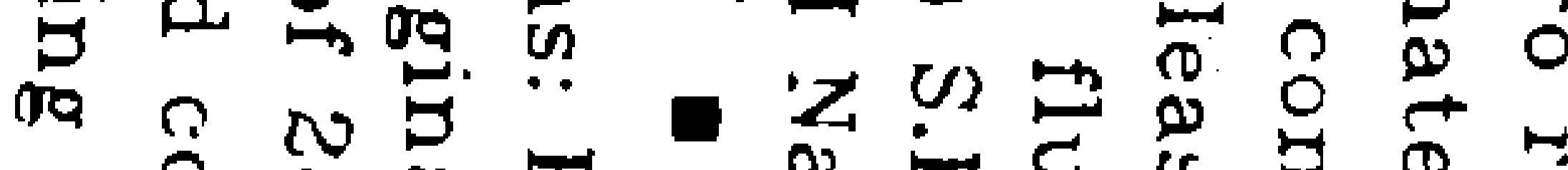

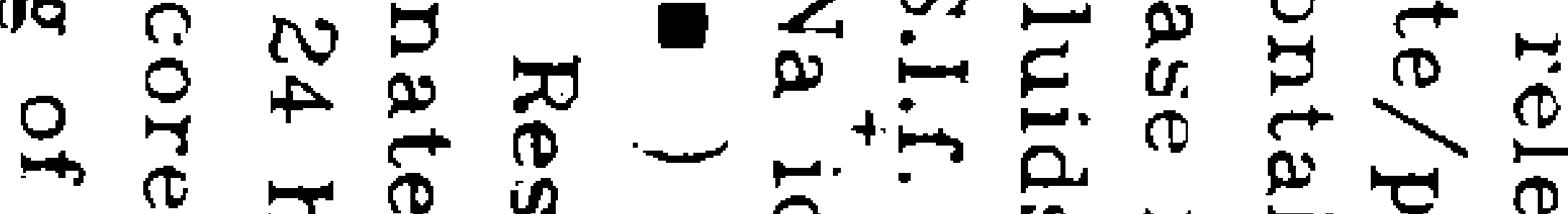

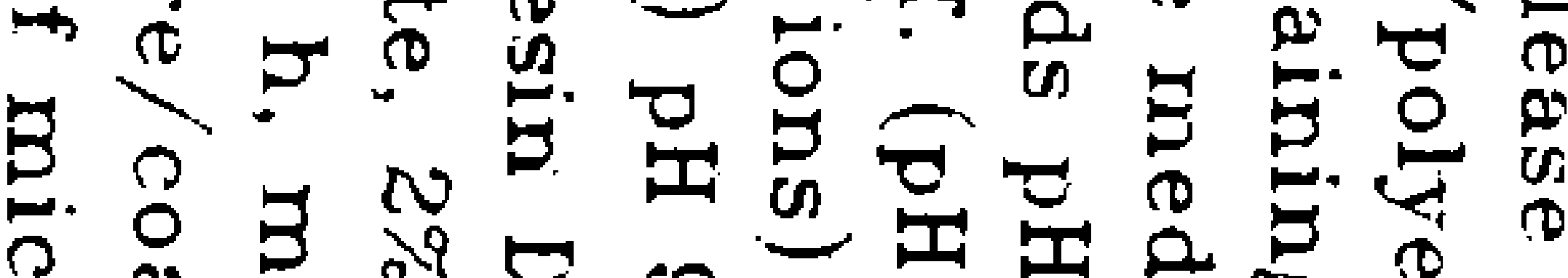

今

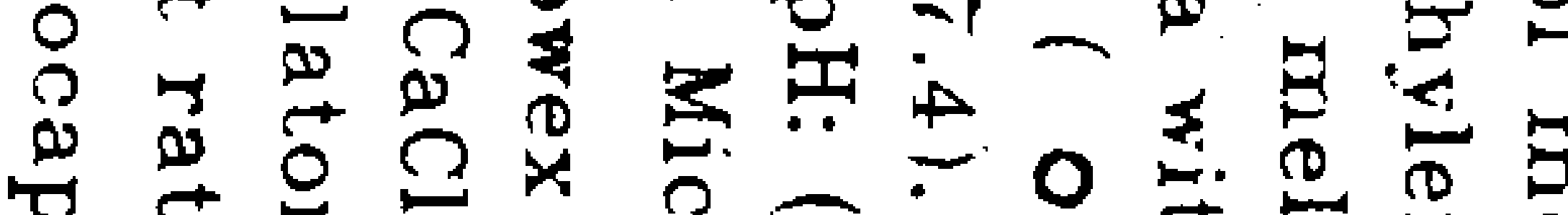

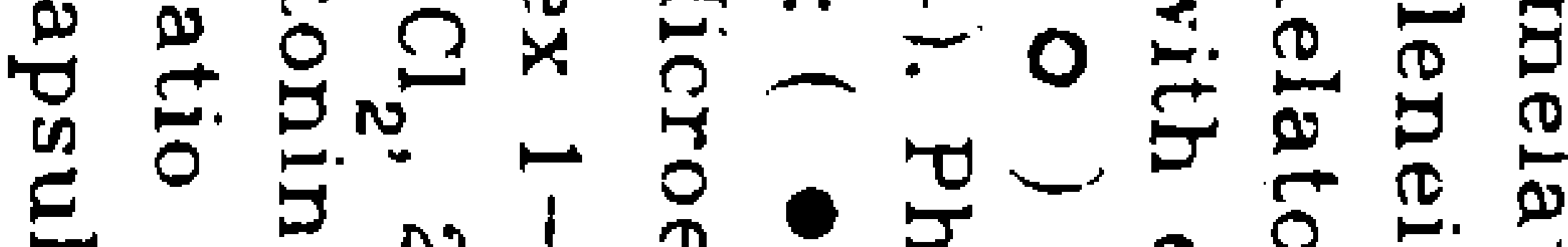

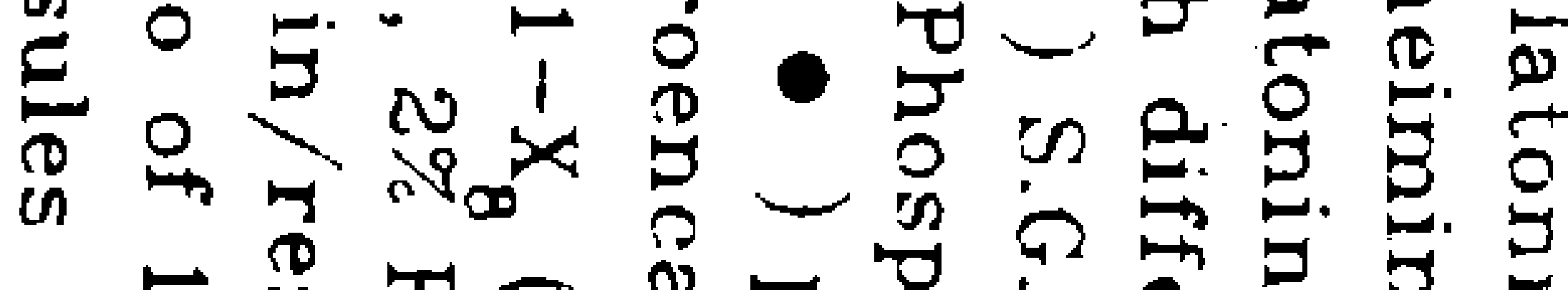

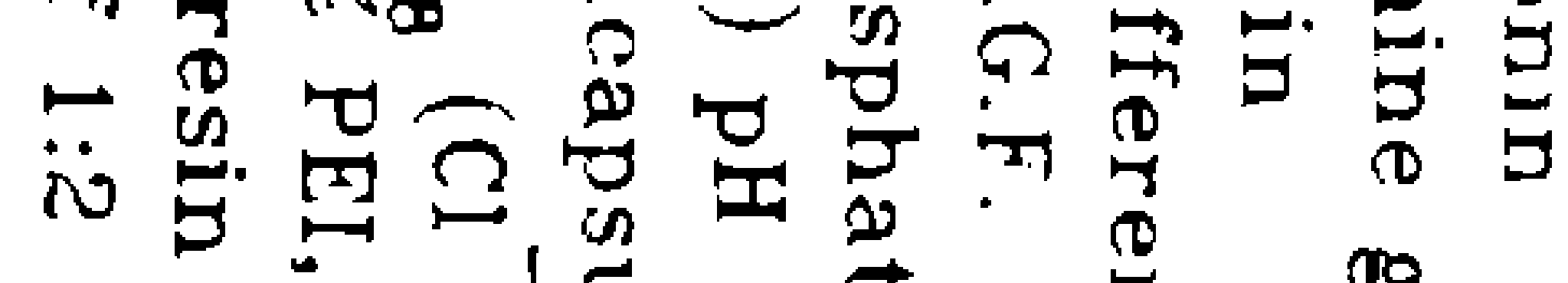

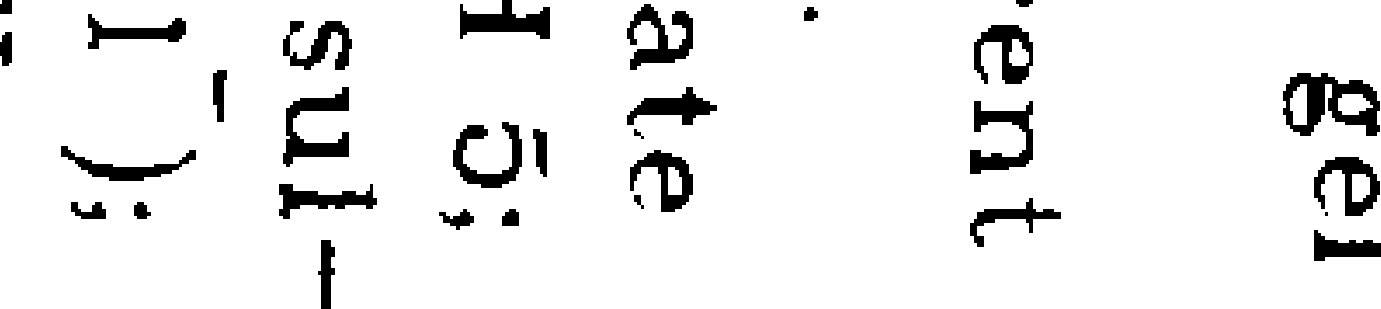

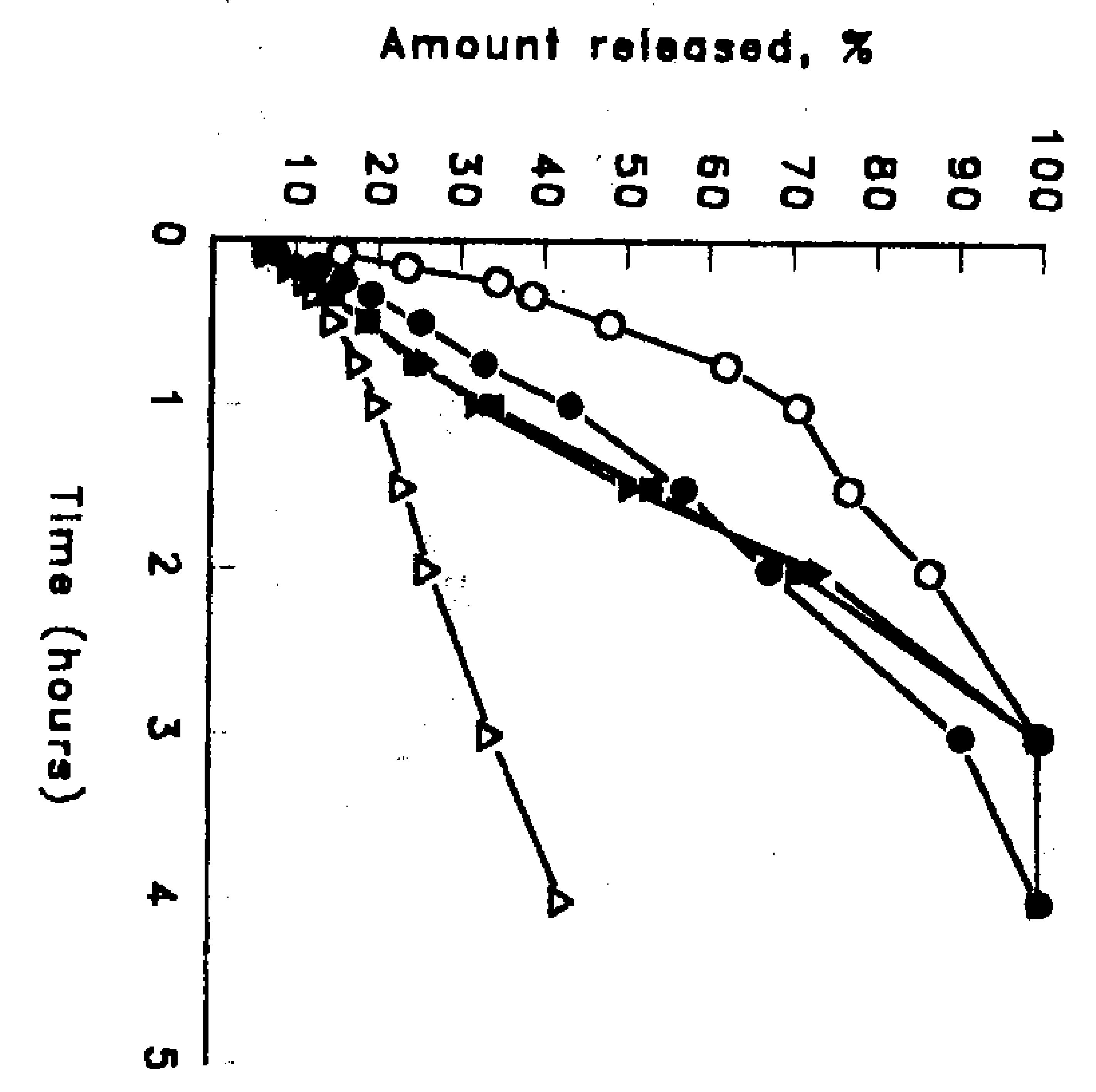

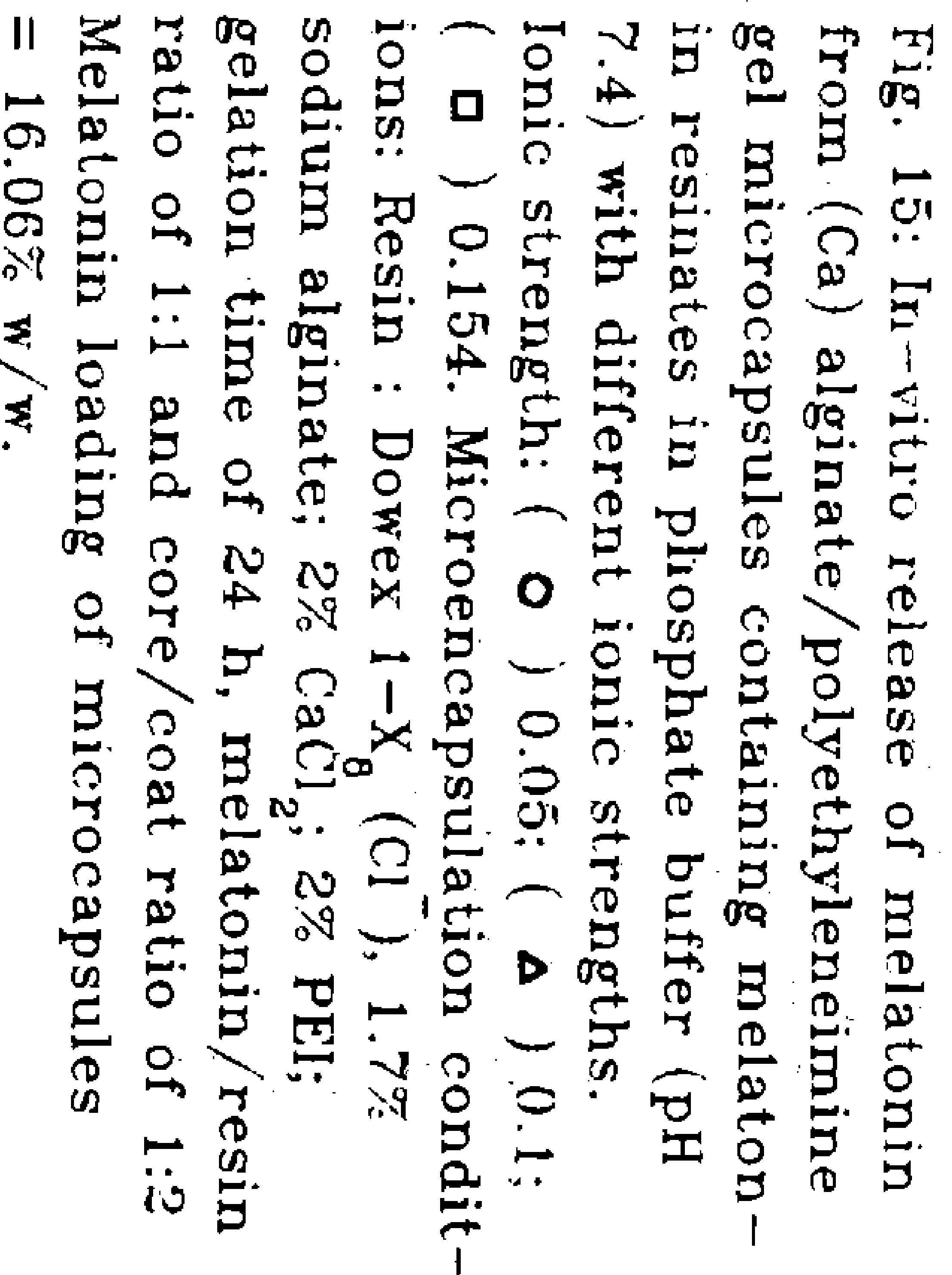

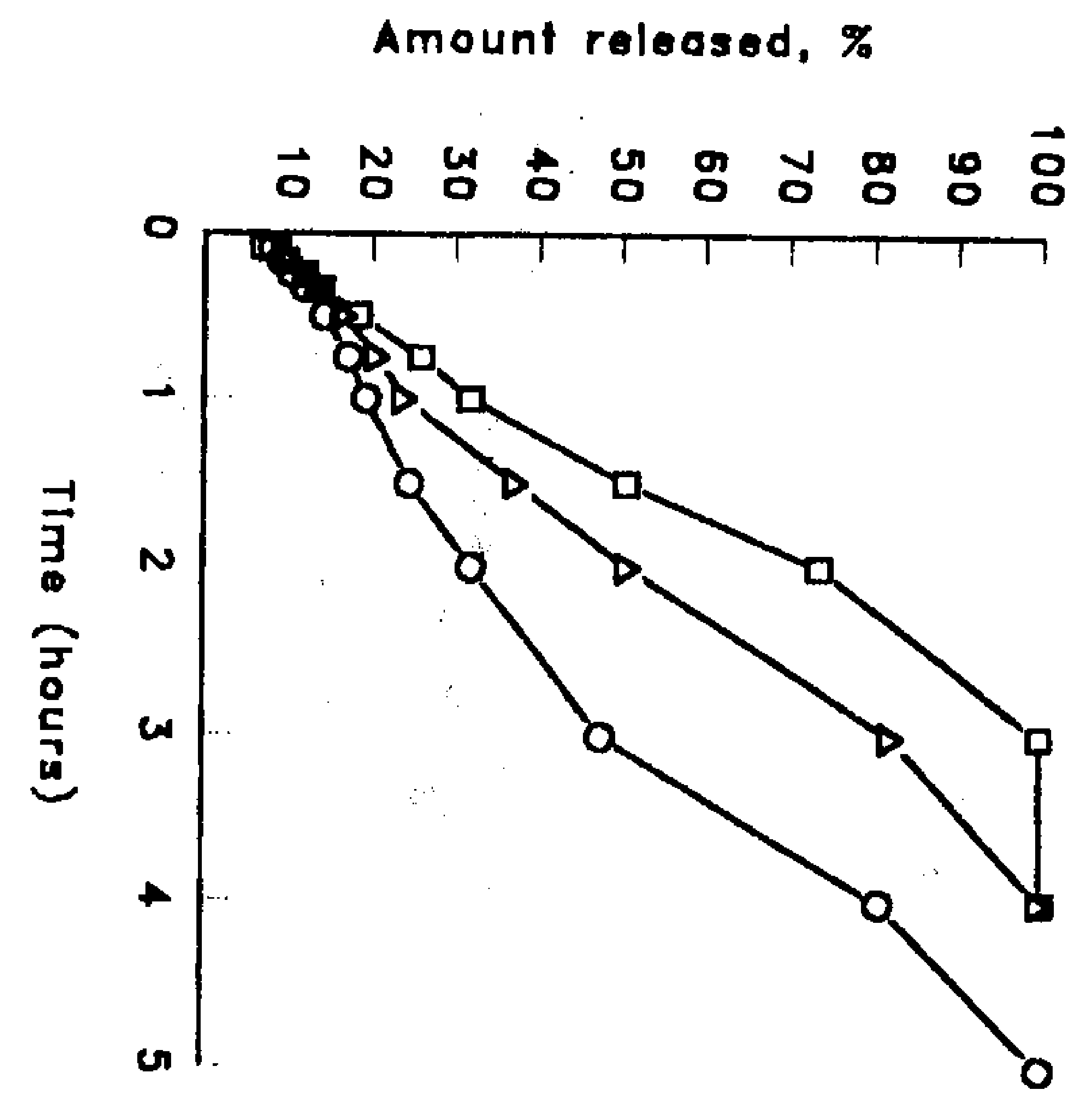


concentration from 0.5 to $2 \%$ in the gelation medium and only $15-19 \%$ of melatonin was released in the first $2 \mathrm{~h}$. of testing (Fig. 10). The optimum polyethyleneimine concentration appeared to be $2 \%$ at which a release rate of $\mathrm{K}_{1}=0.724 \times 10^{-1} \mathrm{hr}^{-1} \quad\left(\mathrm{t}_{0.5}=9.57 \mathrm{~h}.\right)$ was estimated and no expansion or disintegration of microcapsules in S.I.F. (pH 7.4) was observed even after $72 \mathrm{~h}$. of testing. On the other hand, alginate beads (melatonin/resin ratio of $1: 6$, core/coat ratio of $1: 2$ and no polyethyleneimine) exhibited a dramatic increase in the release rate of melatonin (about $60 \%$ was released in the first hour of testing) and a release rate of $\mathrm{K}_{1}=$ $7.861 \times 10^{-1} \mathrm{hr}^{-1}\left(\mathrm{t}_{0.5}=0.8816 \mathrm{~h}\right.$.) was estimated in S.I.F. (pH 7.4) (Fig. 10). The results can be explained on the basis of the crosslinking of ionic functional groups of alginate with polyethyleneimine and thus forms a polyelectrolyte complex membrane and an enhanced interpenetrating polymer network which acts as a physical barrier to retard melatonin release from microcapsules. ${ }^{34}$

It is clearly indicated in Fig. 11 that gelation time of $24 \mathrm{~h}$. was sufficient $\left(K_{1}=\right.$ $0.724 \times 10^{-1} \mathrm{hr}^{-1}\left(\mathrm{t}_{0.5}=9.57 \mathrm{~h}\right.$.) and that longer gelation time resulted gradually in enhancing melatonin release. A 30-min reaction time (the shortest time tested reaction) had the highest release rate $\left(\mathrm{K}_{1}=2.22 \times 10^{-1} \mathrm{hr}^{-1}\left(\mathrm{t}_{0.5}=3.122 \mathrm{~h}\right.\right.$. $)$ and showed a marked microcapsules swelling and burst after $24 \mathrm{~h}$. in S.I.F. (pH 7.4). The results indicate that an extracrosslinking and/or surface build-up occurred, which could have caused the swelling to decrease with an increase in gelation time from $30 \mathrm{~min}$. to $24 \mathrm{~h}$. This is probably due to polycations diffusing into the gel core of the microcapsules and either crosslinking to form stronger bonds or simply reducing the repulsion forces by the presence of the positively charged amine groups resulting in reducing membrane permeability. ${ }^{30}$

Figure 12 depicts that the release of melatonin from alginate microcapsules increased as melatonin/resin ratio (melatonin loading) varied from 1:6 $\left(\mathrm{K}_{1}=0.711 \times 10^{-1} \mathrm{hr}^{-1}\right.$, S.I.F. $(\mathrm{pH} 7.4)$, melatonin loading $=3.84 \% \mathrm{w} / \mathrm{w})$ to $1: 1\left(\mathrm{~K}_{1}=2.174 \times 10^{-1} \mathrm{hr}^{-1}\right.$, melatonin loading $=$ $14.3 \% \mathrm{w} / \mathrm{w})$, with a melatonin/resin ratio of $1: 2$ being the most efficient $\left(\mathrm{K}_{1}=0.476 \times 10^{-1} \mathrm{hr}^{-1}\right)$.
The release profiles of alginate microcapsules prepared with varying core/coat ratios are shown in Fig. 13. The results revealed that microcapsules prepared at core/coat ratio of $1: 2$ exhibited the slowest release rate $K_{1}=$ $1.144 \times 10^{-1} \mathrm{hr}^{-1}$ (up to 4 h., S.I.F. (pH 7.4)). This finding might be interpreted in light of the fact that the higher coating ratio increased the coat thickness. ${ }^{22}$

A marked retardation in the release rate of melatonin in S.I.F. (pH 7.4) was also achieved, being 8-times lower than the dissolution rate of the microcapsules in S.G.F. (pH 1.2) (Fig. 14). This may be attributed to the fact that melatonin cations of the resintates were probably replaced by $\mathrm{H}^{+}$ions in the acidic release medium and quickly diffused out of microcapsules. Moreover, melatonin solubility in S.G.F., pH $1.2(1.89 \mathrm{mg} / \mathrm{ml})$ was found to be higher than in S.I.F., pH $7.4(1.647 \mathrm{mg} / \mathrm{ml})$. Tomida et $a .^{23}$ found that a more rapid release of cationic drug, imipramine from alginate beads was observed in a more acidic solution ( $\mathrm{pH}$ 1.2).

It is of interest to note that ionic character of the polyelectrolyte complex membranes (alginate/polyethyleneimine) might result in $\mathrm{pH}$ independent release of melatonin over a period of $2 \mathrm{~h}$. from microcapsules in phosphate buffer of constant ionic strength $\left(0.154 \mathrm{M} \mathrm{Na}^{+}\right.$ions). The estimated release rates were found to be $\mathrm{K}_{1}=5.42 \times 10^{-1}, 5.995 \times 10^{-1}$, and $5.78 \times 10^{-1} \mathrm{hr}^{-1}$ for $\mathrm{pH}^{\prime}$ 's of $5.5,7.4$ and 9 , respectively (Fig. 14). Similar results were reported with a polyelectrolyte complex membranes of $\mathrm{K}$ carrageenan and chitosan. ${ }^{31}$

Figure 15 demonstrates that increasing ionic strength of the release medium (phosphate buffer, $\mathrm{pH}$ 7.4) was accompanied by an increase in melatonin release rate from the alginate microcapsules.

In an attempt to reduce the release rate of melatonin in S.G.F. (pH 1.2) further, the alginate/PEI gel microcapsules were coated with cross-linked protein membranes or polyamide/ polyethyleneimine (PEI) - graft co-polymer membranes through a modified interfacial polymerization process. Bovine serum albumin on the microcapsule surface was cross-linked by the diacid halide, terephthaloyl chloride as a cross-linking agent, ${ }^{35}$ whereas, synthesis of 
polyamide/PEI-graft co-polymer membranes on microcapsule surface was obtained by an improved interfacial polymerization reaction between an aqueous mixture of tetraethylenepentamine (TEP, aqueous monomer) and polyethyleneimine (PEI, aqueous polymer) and the organic monomer, terephthaloyl chloride (TPC). The resulting membrane might be of a complex structure consisting of a polyamide component (terephthalamide) with chainterminating carboxy-functions and a PEI incorporated throughout the membrane having residual amine functions. The polyamide membranes can be obtained by the following reaction:

$$
\begin{aligned}
& \mathrm{Cl}-\stackrel{O}{\mathrm{C}} \stackrel{\mathrm{O}}{\|} \stackrel{\mathrm{C}}{\mathrm{C}}-\mathrm{Cl}+ \\
& \mathrm{NH}_{2}-\left(\mathrm{CH}_{2} \mathrm{CH}_{2} \mathrm{NH}\right)_{3} \mathrm{CH}_{2} \mathrm{CH}_{2}-\mathrm{NH}_{2} \underset{\mathrm{pH}}{\stackrel{\text { alkaline }}{\longrightarrow}}
\end{aligned}
$$

(TEP)

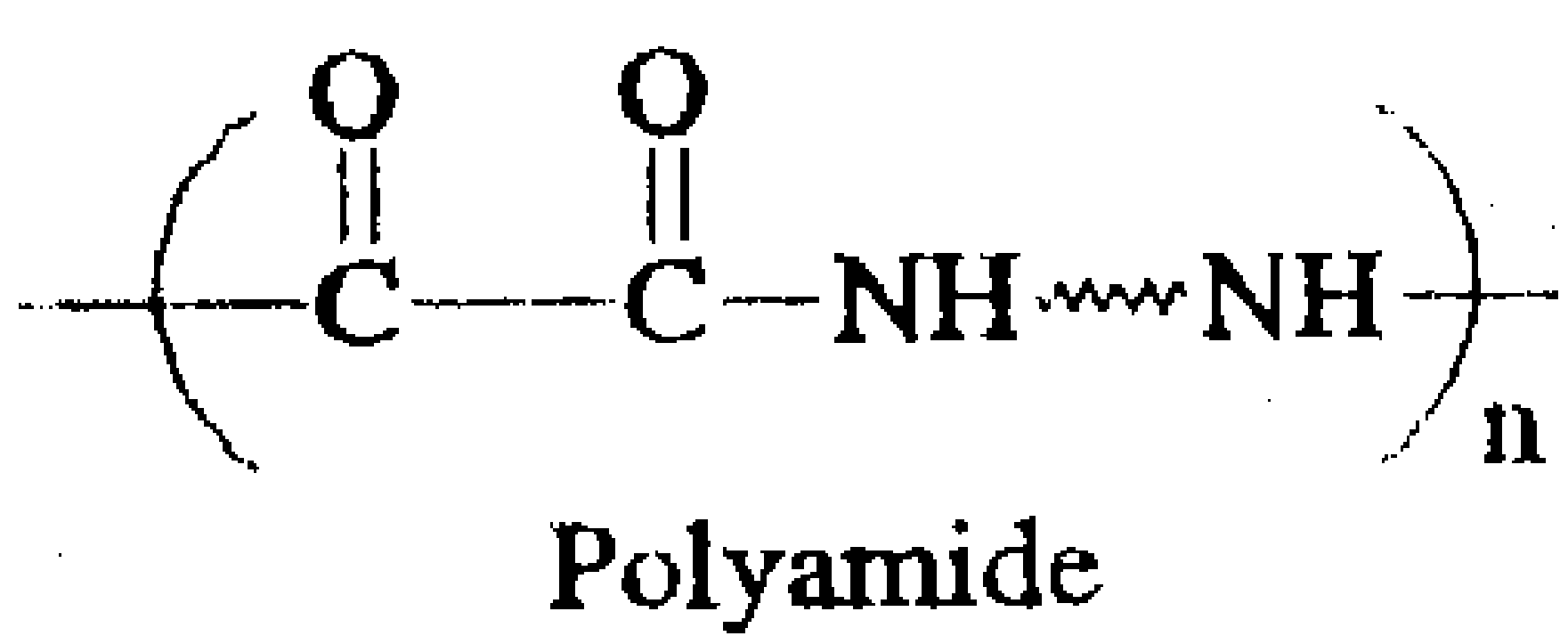

Composite microcapsule membranes of nylon, poly(hexamethylene diaminoterephthalamide) with a cross-linked polyethyleneimine were reported for encapsulating haemoglolin and nucleophilic targets. ${ }^{44}$

Figure 16 shows clearly that alginate microcapsules coated with the synthetic polyamide/PEI-graft co-polymer membranes exhibited the slowest release rate in S.G.F (pH 1.2) $\left(\mathrm{K}_{1}=6.290 \times 10^{-1} \mathrm{hr}^{-1}\right)$ in comparison with those of crosslinked protein membranes-coated microcapsules, uncoated microcapsules and beads $\left(\mathrm{K}_{1}=8.08 \times 10^{-1}, 9.336 \times 10^{-1}\right.$ and $9.01 \times 10^{-1}$ $\mathrm{hr}^{-1}$, respectively). Crosslinking between PEI and the polyamide chains thus had yielded an extended network for which Zwitterionic polarization between the amine and carboxylate components could have substantial effects on the functional properties of this semipermeable membranes. ${ }^{45}$
The release rates of uncoated microcapsules, cross-linked protein membranescoated microcapsules and polyamide/PEI-graft co-polymer membranes-coated microcapsules in S.I.F. ( $\mathrm{pH} 7.4)\left(\mathrm{K}_{1}=1.144 \times 10^{-1}, 2.734 \times 10^{-1}\right.$ and $1.622 \times 10^{-1} \mathrm{hr}^{-1}$, respectively) were greatly reduced when compared to that of the beads $\left(K_{1}=19.59 \times 10^{-1} \mathrm{hr}^{-1}\right)$ (Fig. 16).

\section{In-vivo performance of enzymes activity}

Glutathione S-transferases (GSTs) are one of the most important enzymatic systems in body tissues, particularly liver GSTs which were believed to help in protection of cellular macromolecules from attact by reactive electrophiles. Besides, GSTs via their glutathione (GSH) dependent peroxidase activity may participate in protecting tissues from organic hydroperoxides or endoperoxide produced during oxidative stress. ${ }^{46}$ In addition, the GSTs function as an intracellular detoxificating system of mutagens, carcinogens and other toxic compounds and non-carcinogens such as bilirubin, drugs and hormones. ${ }^{8,47}$

Scaiano $^{48}$ and Poeggeler et al..$^{49}$ have reported that melatonin directly neutralizes toxic tree radicals as being an effective scavenger. However, the rapid elimination of melatonin from blood (half-life of a maximum of 24 minutes)" necessitates the development of a sustained release product for melatonin. Thus, melatonin resinates-loaded (Ca) alginate/ polyethyleneimine gel microcapsules prepared using melatonin/resin ratio of $1: 6$, core/coat ratio of $1: 2,2 \%$ polyethyleneimine and gelation time of $24 \mathrm{~h}$. are good candidate for controlled delivery of melatonin $\left(T_{0.5}=9.57\right.$ h. in S.I.F., $\mathrm{pH}$ 7.4).

Table (5) shows the activities of glutathione S-transfirases (GSTs) and glutathione peroxidase (GSH-Px), as well as, glutathione (GSH) content in the total protein of liver homogenate in control (non-treated group), phenobarbitone (which has the ability to induce formation of microsomal enzymes and of cytochrome p-450), melatonin and melatonin resinates-loaded (Ca) alginate/PEI gel microcapsules treated rats. It is of interest to note that melatonin resinates-loaded 


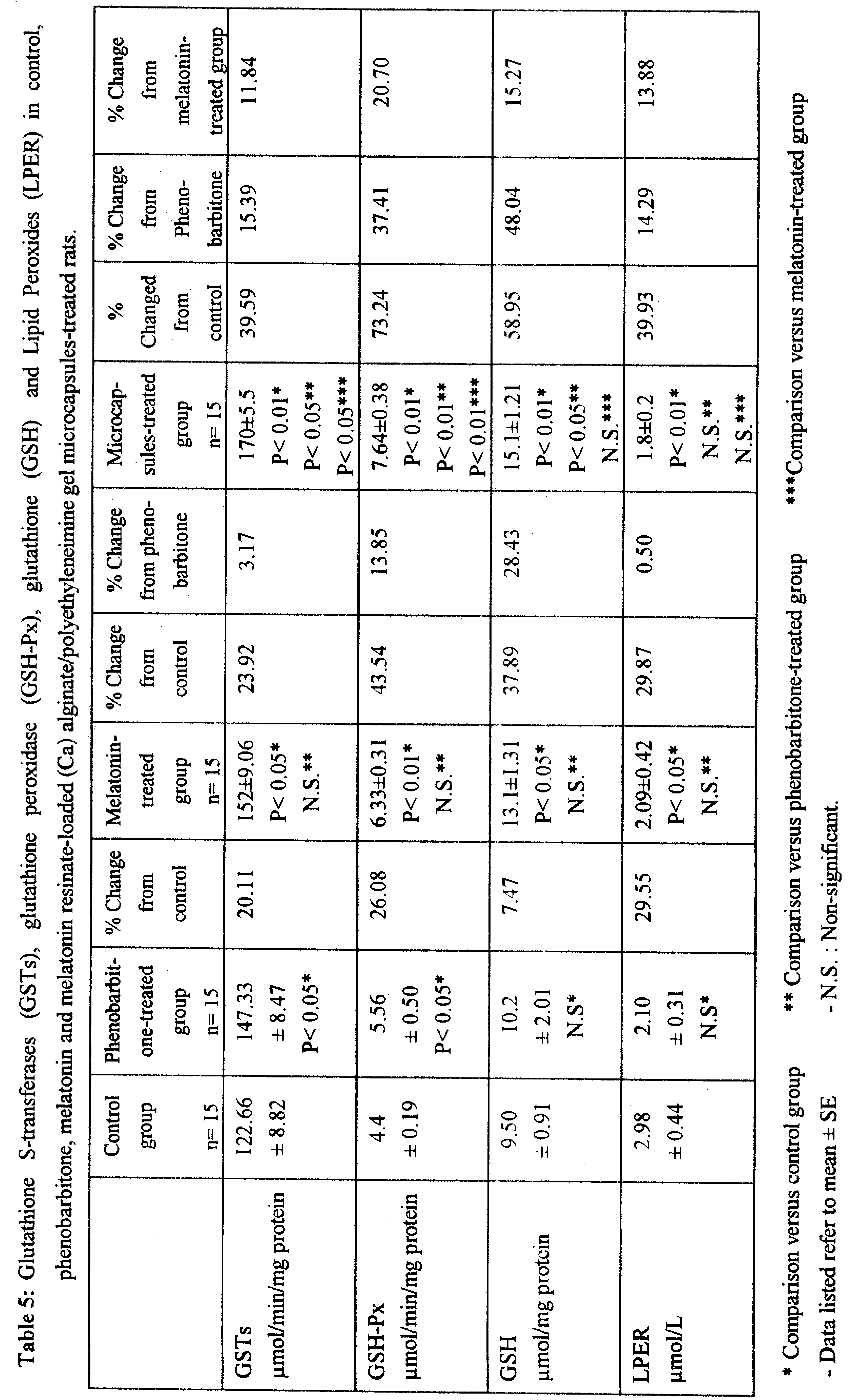



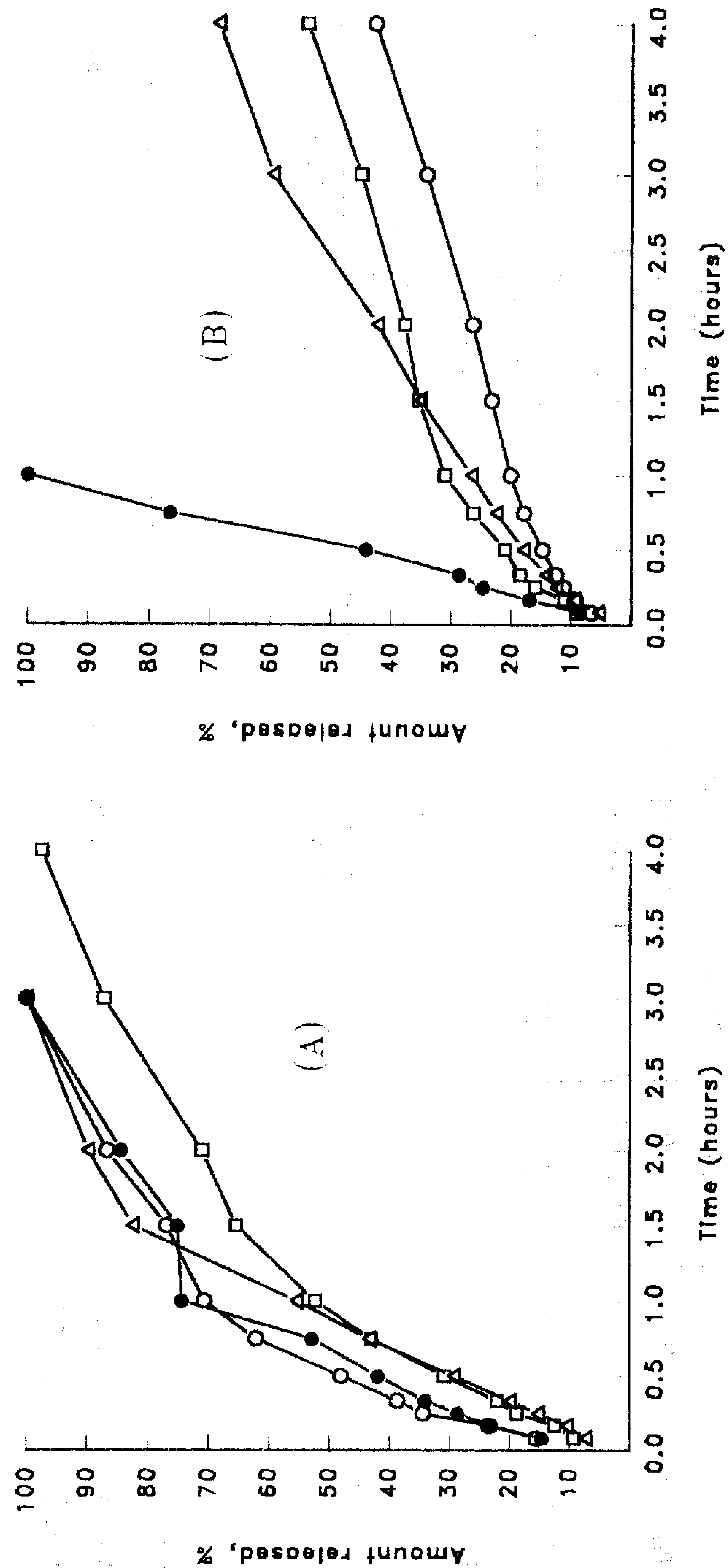

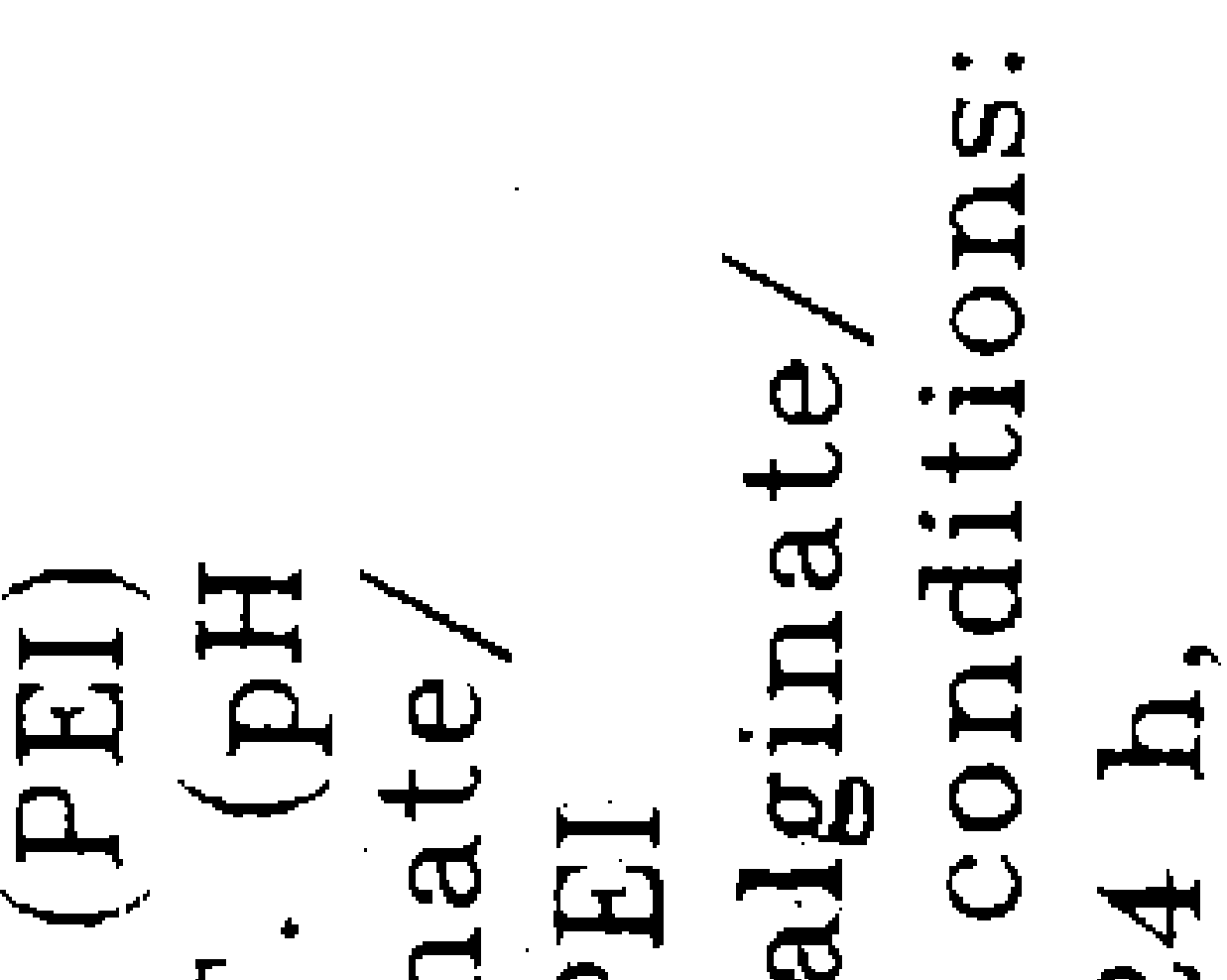

स.

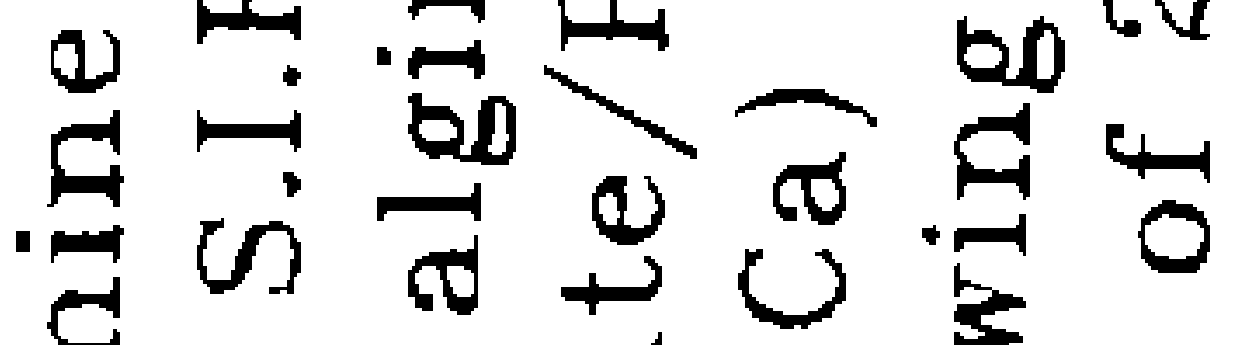

है $\pi$

..

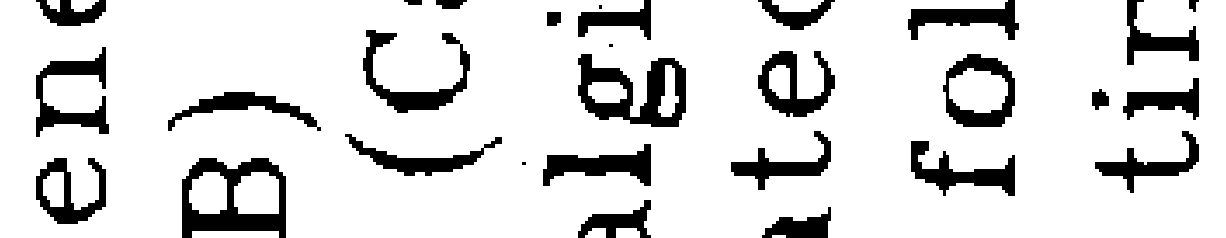

s 000

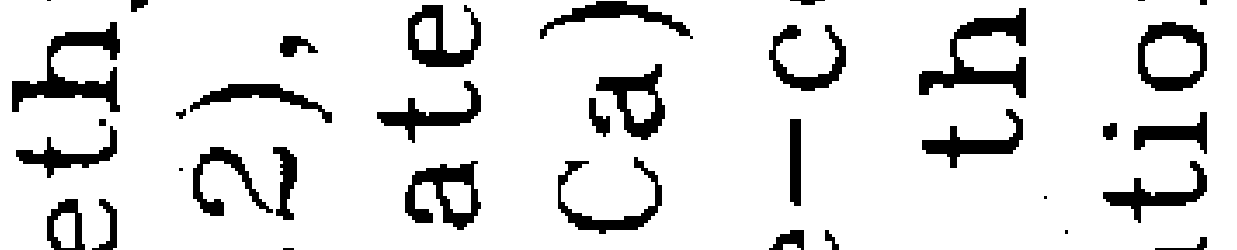

겅요

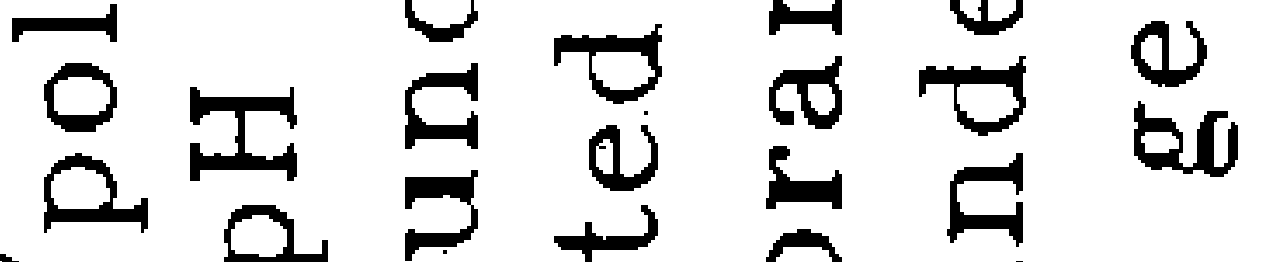

今

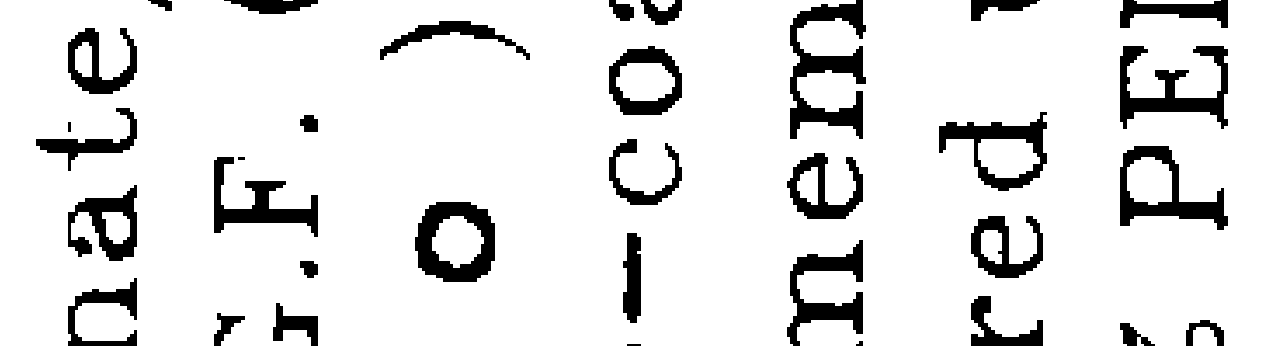

घن व द वे

av vi . ⿷匚

क $\approx$ is

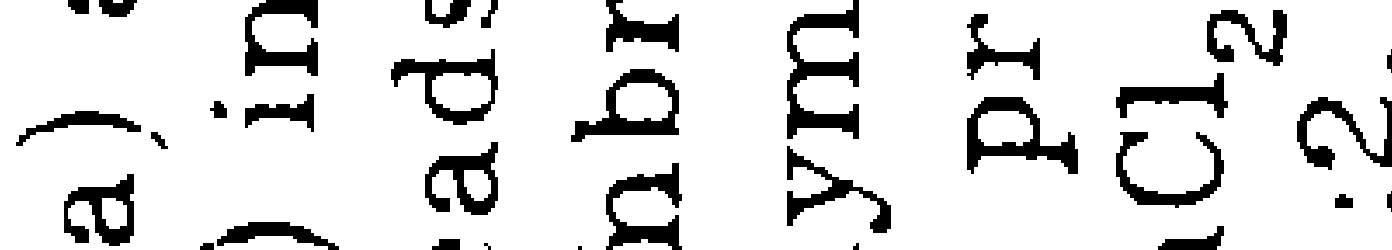

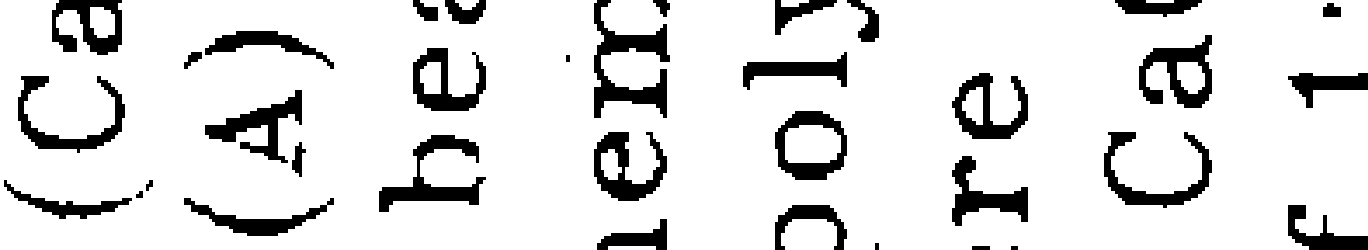

- का दी 1

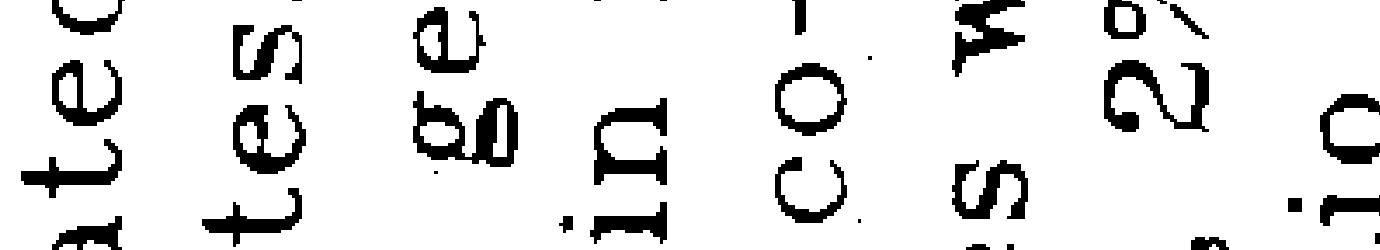

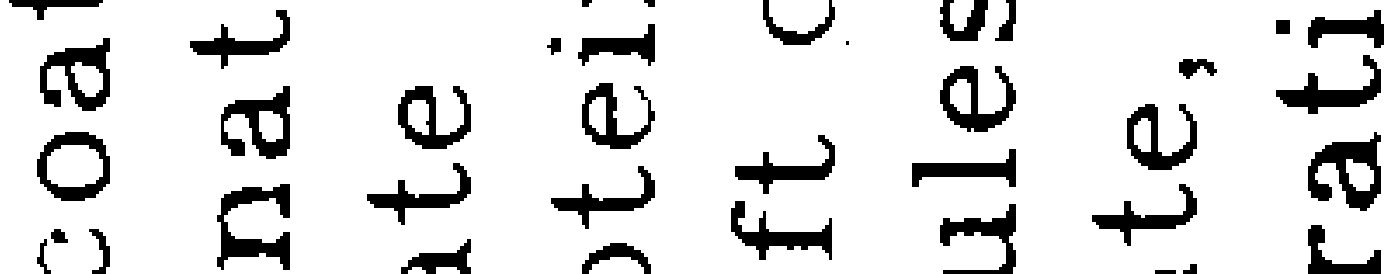

.

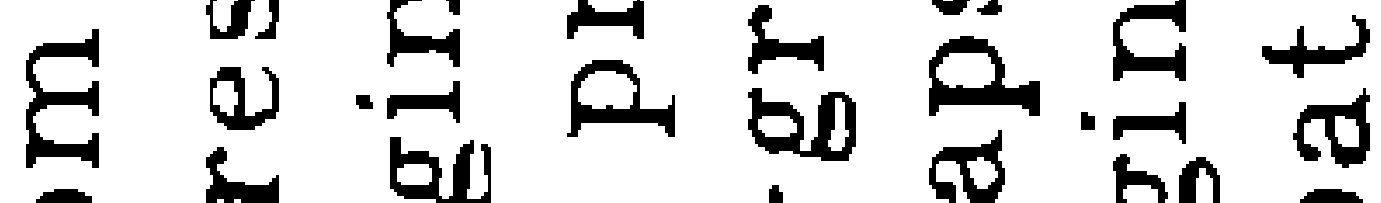

- 1000

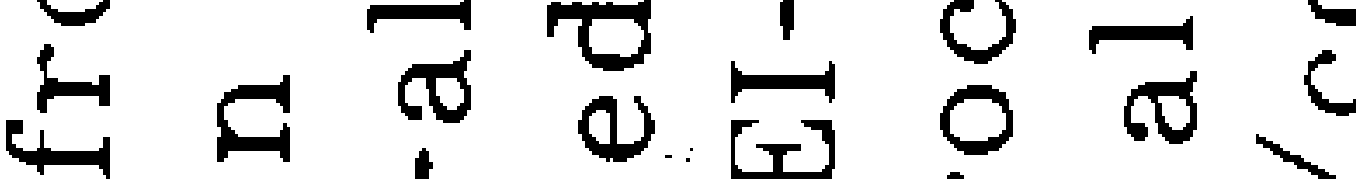

द वี

ส

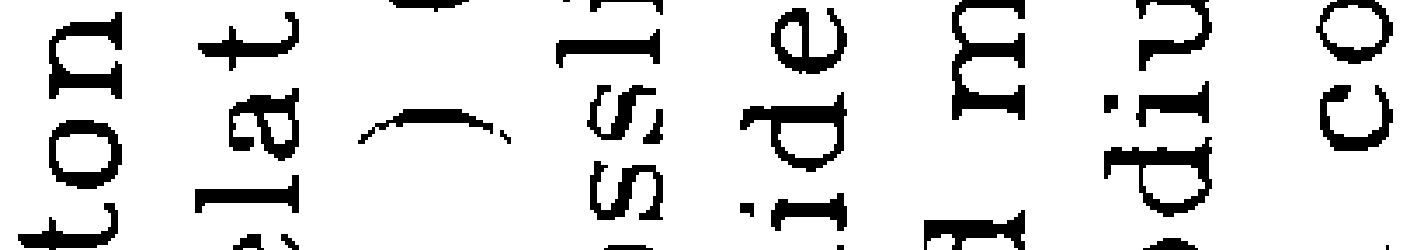

崩

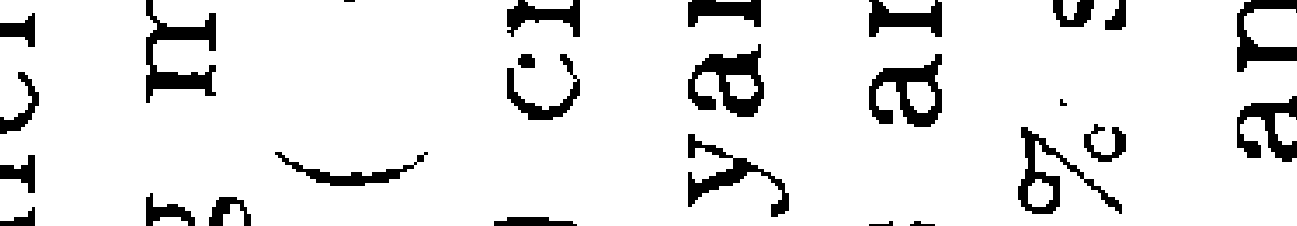

a

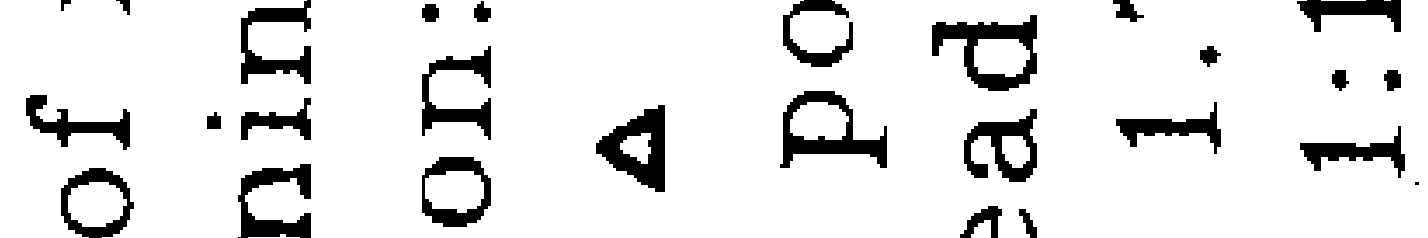

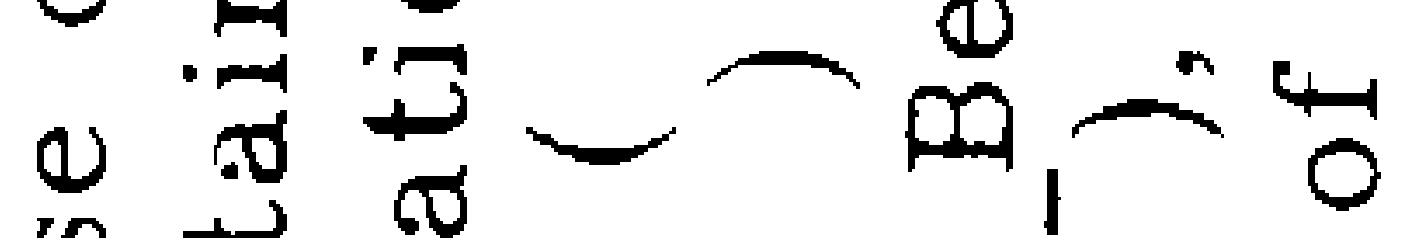

के in प मे

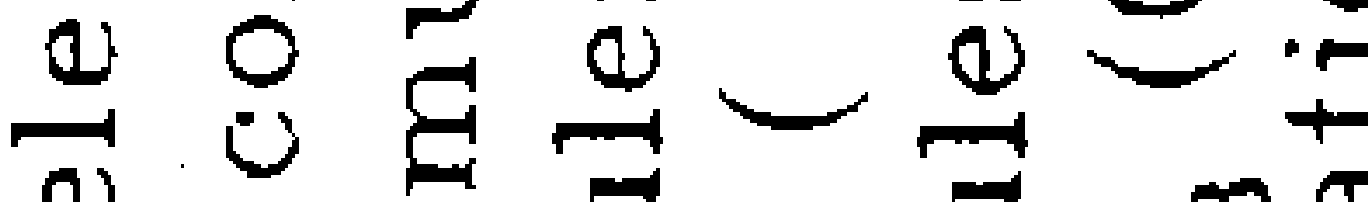

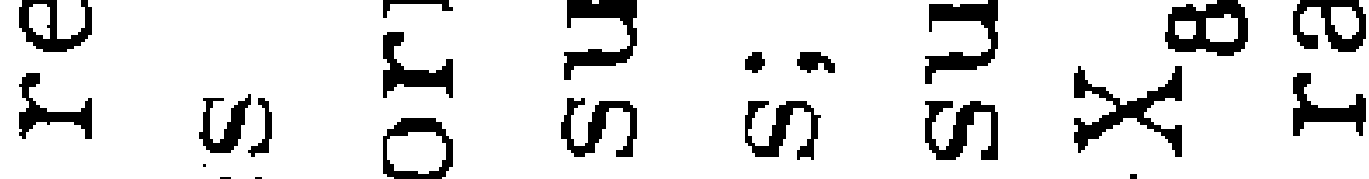

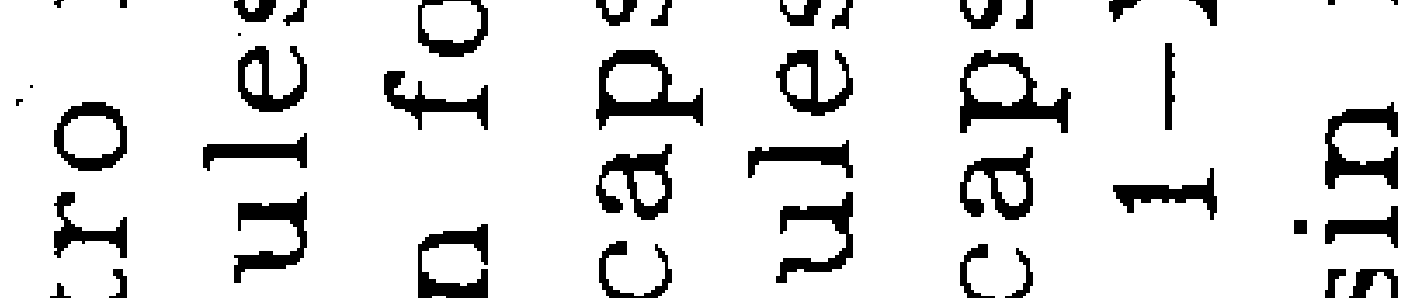

in 5 in 0

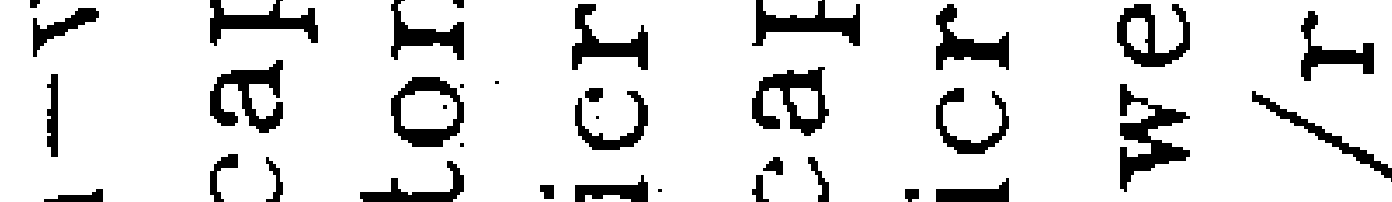

g 용

$\ddot{0} .0$

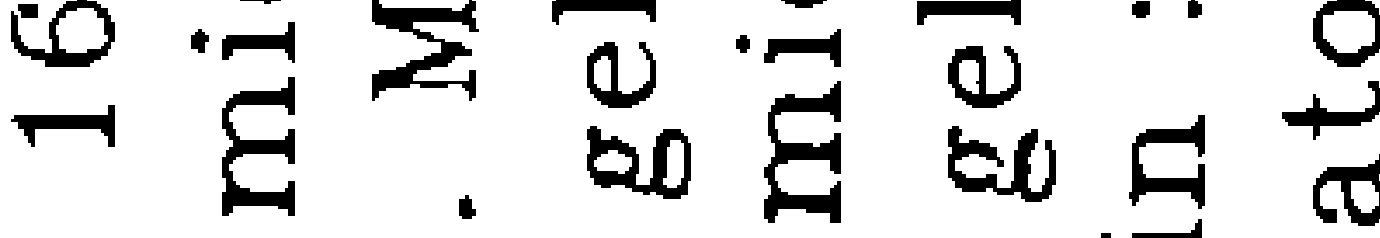

म0

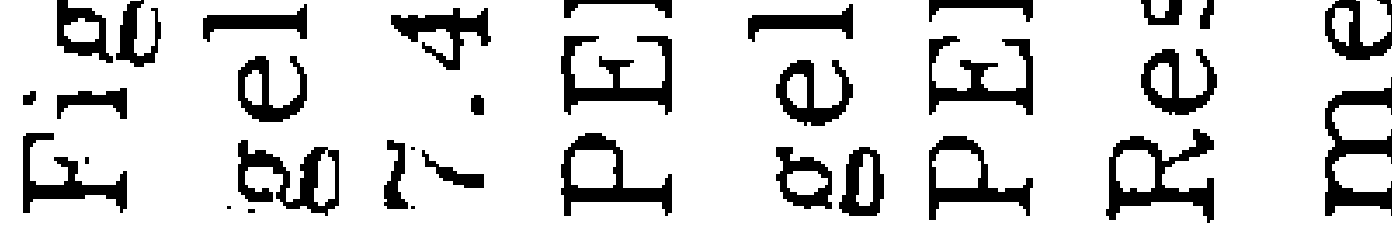


microcapsules had delayed melatonin release rate. An effect which might result in the highest increase in GSTs $(\mathrm{P}<0.05)$ and GSH-Px $(\mathrm{P}<$ $0.01)$ activities as well as an increase in GSH content in hepatic tissues, when compared with rats treated with pure melatonin or phenobarbitone. Obviously, GSTs activity was significantly increased $(\mathrm{P}<0.01$ and $\mathrm{P}<0.05)$ in liver of rats treated with microcapsules and pure melatonin or phenobarbitone, respectively, when compared with the control (non-treated group). On the other hand, GSH-Px activity was increased significantly $(P<0.01)$ in rats treated with melatonin and those treated with microcapsules, while it only increased significantly $(\mathrm{P}<0.05)$ in rats treated with phenobarbitone when compared with the control. Also, Table (5) represents that glutathione (GSH) content was increased significantly ( $P<$ 0.01 and $P<0.05$ ) in rats treated with melatonin resinates-loaded microcapsules and pure melatonin, respectively when compared with the control (non-treated group), whereas it increased significantly $(\mathrm{P}<0.05)$ in rats treated with microcapsules in comparison with phenobarbitone-treated rats.

Table (6) shows the correlation among all parameters. GSTs was significantly $(\mathrm{P}<0.01$ and $P<0.05$ ) positive correlated with GSH-Px and GSH, respectively, whereas GSH-Px has significant $(\mathrm{P}<0.05)$ positive correlation with the level of GSH.
Thus, the maximum induction of GSTs, phase II (GSH-Px) and GSH content in rats liver after different treatments could be arranged in the following order: melatonin resinates-loaded (Ca) alginate/PEI gel microcapsules $>$ pure melatonin $>$ phenobarbitone $>$ control (nontreated group).

The induction of higher GSTs levels on using melatonin resinates-loaded microcapsules may therefore be more useful than pure melatonin for excretion of bilirubin, ${ }^{50}$ protection against xenobiotics (such as drugs, food additives and environmental pollution which were metabolised in 2 phases, the first by cytochrome p-450 and the second by GSTs, GSH-Px and $\mathrm{GSH}^{51}$ ) and replacing phenobarbitone in treatment of neonate physiological jaundice. $^{\text {so }}$ In addition, GSH detoxifies the bacterial promutagen, aflatoxin $B_{1}$ $\left(A F \beta_{1}\right)$ (which is a potent hepatocarcinogen) to $\mathrm{AF}_{1}$-GSH by GSTs. ${ }^{52}$

The oxidative stress represented by lipid peroxides (LPER) was decreased significantly $(P<0.01$ and $P<0.05)$ in rats treated with microcapsules and pure melatonin, respectively, while it was not changed in rats treated with phenobarbitone when compared with the control (non-treated group) (Table 5). Lipid peroxidation results in-vivo in the destruction of polyunsaturated fatty acids in membrane lipids. ${ }^{47}$ The reduction of lipid peroxides may be due to

Table 6: Correlation coefficient (r) between GSTs, GSH-Px, GSH and LPER in control, phenobarbitone, melatonin and melatonin resinate-loaded (Ca) alginate/polyethyleneimine gel microcapsules-treated rats.

\begin{tabular}{|c|c|c|c|c|}
\hline & GSTs & GSH-Px & GSH & LPER \\
\hline GSTs & 1 & $+0.982^{* *}$ & $+0.901^{*}$ & $-0.967^{*}$ \\
\hline GSH-Px & & 1 & $+0.965^{*}$ & $-0.907^{*}$ \\
\hline GSH & & & 1 & -0.785 N.S \\
\hline LPER & & & & 1 \\
\hline
\end{tabular}

N.S.: Non significant; *: Significant at $\mathrm{P}<0.05$; **: Significant at $\mathrm{p}<0.01$ 
induction of GSTs. ${ }^{8}$ The significant $(\mathrm{P}<0.05)$ negative correlation between GSTs, GSH-Px and lipid peroxides (Table 6) may indicate their role on lipid peroxidation by reduction of hydroxyl free radicals, thereby protecting body from their harmful effects. Glutathione peroxidase (GSH$P x)$ was considered an important antioxidative enzyme, especially in liver and brain. It catalyzes the destruction of $\mathrm{H}_{2} \mathrm{O}_{2}$ by reduced glutathione (GSH) as follows,

$$
2 \mathrm{GSH}+\mathrm{H}_{2} \mathrm{O}_{2} \stackrel{\text { peroxidase }}{\longrightarrow} \mathrm{G}-\mathrm{S}-\mathrm{S}-\mathrm{G}+2 \mathrm{H}_{2} \mathrm{O}
$$

thus protecting membrane lipids and haemoglobin from oxidation by $\mathrm{H}_{2} \mathrm{O}_{2}{ }^{5,47}$ Moreover, Reiter et al. ${ }^{4}$ reported also that, the reduction of lipid peroxides may be due to direct effect of melatonin as a potent antioxidant and as a direct free radical scavenger both in-vivo and in-vitro.

In conclusion, ( $\mathrm{Ca}$ ) alginate/polyethyleneimine gel microcapsules can be categorized as a reservoir-type drug delivery system with a $\mathrm{pH}$ independent dissolution pattern and a ratecontrolling polyelectrolyte complex (PEC) polymer membranes which did not disintegrate or dissolve in S.I.F. (pH 7.4) (Table 4) and resulted in a greatly reduced release rates in S.I.F. (pH 7.4). Unlike the gel microcapsules, (Ca) alginate beads are a matrix-type gel system which swelled and then rapidly disintegrated and dissolved in S.I.F. ( $\mathrm{pH} 7.4$ ), thereby resulting in the fastest release rates. The study revealed that melatonin in its new form had a potent antioxidant effects through induction of the most potent antioxidant systems, glutathione-Stransferases (GSTs) and glutathione-peroxidase (GSH-Px). The reduction of lipid peroxides and elevation of GSH content in this study may support strongly the hypothesis that melatonin reduced lipid peroxidation through its direct antioxidant effects.

Considering the final dosage form, the melatonin resinates-loaded (Ca) alginate/PEI gel microcapsules could be administered as prepared, compressed into tablets or be filled into capsules. Melaonin resinates also could be compressed into tablets.

\section{REFERENCES}

1- Martindale, The extra Pharmacopoeia, Thirtieth Edition, J. E. F. Reynolds (ed.), The Pharmaceutical Press, London, p. 1385 (1993).

2- A. Miles, D. R. S. Philbrick and C. Thompson, Melatonin, clinical perspectives, Oxford University Press, New York (1988).

3- B. J. Lee, K. A. Parrott, J. W. Ayres and R. L. Sack, Drug. Deve. Ind. Pharm., 22, 269 (1996).

4- J. R. Reiter, C. S. Oh and D. Fujimori, Trands Endocrinol. Metab., 7, 22 (1996).

5- B. Ketterer, Mutation Res., 202, 343 (1988).

6- D. Melchiorri, R. J. Reiter, A. M. Attia, M. Hara, A. Burgos and G. Nistico, Life Sci., 56, 83 (1994).

7- D. Steinhilber, M. Brungs and O. Werz, J. Biol. Chem., 270: 7037 (1995).

8- V. Daniel, Crit. Rev. Bioch. Mol. Biol., 28: 173 (1993).

9- F. P. Gibbs and J. Veriend, Endocrinol., 109: 1790 (1981).

10- W.J. Irwin, R. Machale and P.J. Watts, Drug Deve. Ind. Pharm., 16: 883 (1990).

11- G. Garcia-Encina, D. Torres, B. seijo and J. L. Vila Jato, J. Control. Rel., 23: 201 (1993).

12- W. J. Irwin, K. A. Belaid and H. O. Alpar, Drug Dev. Ind. Pharm., 14: 1307 (1988).

13- Y. Chen, M. A. Burton, J. P. Codde, S. Napoli, I. J. Martins and B. N. Gray, J. Pharm. Pharmacol., 44: 211 (1992).

14- W. H. McNeely and D. J. Pettitt, In Industrial gums-polysaccharides and their derivatives, R.L. Whistler, J.N. Be Miller (Eds). Academic Press: New York, pp. 49-81 (1973).

15- A. Katchalsky, R. E. Cooper, J. Upadhyay and A. Wassermann, J. Chem. Soc., 5198 (1961).

16- M. Kierstan, G. Darcy and J. Reilly, Biotechnol. Bioeng., 24: 1507 (1982). 
17- P. Bajpai and A. Margaritis, Enzyme Microb. Technol., 7: 34 (1985).

18- R. J. Mumper, A. S. Hoffman, P. A. Puolakkainen, L. S. Bouchard, W. R. Gombotz, J. Control. Rel., 30: 241 (1994).

19- M. F. A. Goosen, G. M. O'Shea, H. M. Gharapetion, S. Choiu and A. M. Sun, Biotechnol. Bioeng., 27: 146 (1985).

20- T. Yotsuyanagi, T. Ohkubo, T. Ohashi and K. Ikeda, Chem. Pharm. Bull., 35: 1555 (1987).

21- N. Segi, T. Yotsuyanagi and K. Ikeda, Chem. Pharm. Bull., 37: 3092 (1989).

22- I. Tomida, C. Nakamura, H. Yoshitomi and S. Kiryu, Chem. Pharm. Bull., 41: 2161 (1993).

23- H. Tomida, C. Mizuo, C. Nakamura and S. Kiryu, Chem. Pharm. Bull., 41: 1475 (1993).

24- K. Tateshita, S. Sugawara, T. Imai and M. Otagiri, Biol. Pharm. Bull., 16: 420 (1993).

25- G. Pfister, M. Bahadir and F. Korte, J. Control. Rel., 3: 229 (1986).

26- W. Argüeles-Monal and C. Peniche-covas, Makromol. Chem., Rapid Commu., 9: 693 (1988).

27- T. Takahashi, K. Takayama, Y. Machida and T. Nagai, Int. J. Pharm, 61: 35 (1990).

28- S. Shiraishi, T. Imai and M. Otagiri, J. Control. Rel., 25: 217 (1993).

29- L. Lin-Shu, L. Shu-Qin, N. Y. Steven, F. Michael, O. Tadao and H. Jorge, J. Control. Rel., 43: 65 (1997).

30- A. Polk, B. Amsden, K. De Yao, T. Peng and M. F. A. Goosen, J. Pharm. Sci., 83: 178 (1994).

31- H. Tomida, C. Nakamura and S. Kiryu, Chem. Pharm. Bull., 42: 979 (1994).

32- F. Lim, Microencapsulation of living cells and tissues-Theory and practice. In Biomedical applications of microencapsulation. F. Lim (ed.), CRC Press, Boca Raton, Florida pp. 138-154 (1984).

33- K. H. Lee, P. M. Lee and Y. S. Siaw, J. Chem. Tech. Biotechnol., 57: 27 (1993).

34- K. H. Lee, P. M. Lee and Y. S. Siaw, J. Chem. Tech. Biotechnol., 54: 375 (1992).

35- M. C. Lévy, P. Rambourg, J. Lévy and G. Potron, J. Pharm. Sci., 71: 759 (1982).
36- P. Rambourg, J. Lévy and M.C. Lévy, J. Pharm. Sci., 7: 753 (1982).

37- T. Yotsuyanagi, I. Yoshioka, N. Segi and K. Ikeda, Chem. Pharm. Bull., 39: 1072 (1991).

38- W. H. Habig, M. J. Pabst and W. B. Jekoby, J. Biol. Chem., 249: 7130 (1974).

39- W. J. Goodwin, J. R. Helen, M. Bracpord, A. C. Grippin, H. Geoppert and R. Jesse, Cancer, 51: 110 (1983).

40- G. L. Ellman, Arch. Biochem. Biophys., 82: 70 (1959).

41 - J. A. Beuge and S. D. Aust, Cancer Res., 41: 1502 (1978).

42- T. Yotsuyanagi, I. Yoshioka, N. Segi and K. Ideda, Chem. Pharm. Bull., 38, 3124 (1990).

43- R. Bodmeier, H. Chen and O. Paeratakul, Pharm. Res., 6, 413 (1989).

44- A. C. Povey, H. Bartsch, J. R. Nixon and I. K. O'Neill, J. Pharm. Sci., 75, 831 (1986).

45- T. Seki, T. Okahata, J. Poly. Sci., Polymer Chemistry, 24, 61 (1986).

46- B. Coles and B. Ketterer, CRC Crit. Rev. Bioch. Mol. Biol., 25, 47 (1990).

47- I. Listowsky, Glutathione S-transferases: Intra-cellular binding, detoxification and adaptive responses in hepatic and bile secretion transport: Physiology and pathophysiology, N. Tavoloni and P. D. Berk eds., Raven Press, New York, pp. 397 (1993).

48- J. C. Scaiano, J. Pineal. Res., 19: 109 (1995).

49- B. Poeggeler, R. J. Reitter, E. HardelandSewerynek, D. Melchiorri and L. R. Barlow-Walden, Neuroendocrinol Lett., 17: 87 (1995).

50- W. B. Jakoby and D. M. Ziegler, J. Biol. Chem., 265, 20715 (1990).

51 - R. K. Murray, Metabolism of xenobiotics. In: Harper's biochemistry, R. K. Murray, Granner, P. A. Mayes and V. W. Rodwell (eds.)., 23 edition, Appleton and Lange, London, pp. 704-709 (1993).

52- T. W. Kensler, P. A. Egner, N. E. Davidson, B. D. Roebuck, A. Pikul and J. D. Groopman, Cancer Res., 46, 3924 (1986). 